San Jose State University

SJSU ScholarWorks

Master's Theses

Master's Theses and Graduate Research

Spring 2013

\title{
The SJSU Ecological Footprint Challenge and Its Impacts on Pro- Environmental Behavior
}

Matthew Eugene Lambert

San Jose State University

Follow this and additional works at: https://scholarworks.sjsu.edu/etd_theses

\section{Recommended Citation}

Lambert, Matthew Eugene, "The SJSU Ecological Footprint Challenge and Its Impacts on Pro-

Environmental Behavior" (2013). Master's Theses. 4286.

DOI: https://doi.org/10.31979/etd.cy2q-7spt

https://scholarworks.sjsu.edu/etd_theses/4286

This Thesis is brought to you for free and open access by the Master's Theses and Graduate Research at SJSU ScholarWorks. It has been accepted for inclusion in Master's Theses by an authorized administrator of SJSU ScholarWorks. For more information, please contact scholarworks@sjsu.edu. 


\title{
THE SJSU ECOLOGICAL FOOTPRINT CHALLENGE AND ITS IMPACTS ON PRO-ENVIRONMENTAL BEHAVIOR
}

\author{
A Thesis \\ Presented to \\ The Faculty of the Department of Environmental Studies \\ San Jose State University \\ In Partial Fulfillment \\ of the Requirements for the Degree \\ Master of Science
}

By

Matthew Eugene Lambert

May 2013 
(C) 2013

Matthew Eugene Lambert

ALL RIGHTS RESERVED 
The Designated Thesis Committee Approves the Thesis Titled

THE SJSU ECOLOGICAL FOOTPRINT CHALLENGE AND ITS

IMPACTS ON PRO-ENVIRONMENTAL BEHAVIOR

by

Matthew Eugene Lambert

APPROVED FOR THE DEPARTMENT OF ENVIRONMENTAL STUDIES

SAN JOSÉ STATE UNIVERSITY

May 2013

Dr. Katherine Cushing Department of Environmental Studies

Dr. Eugene Cordero Department of Meteorology and Climate Science

Linden Skjeie, M.S. $\quad$ City of San José Environmental Services

Department 


\title{
ABSTRACT \\ THE SJSU ECOLOGICAL FOOTPRINT CHALLANGE AND ITS IMPACTS ON PRO-ENVIRONMENTAL BEHAVIOR
}

\author{
By Matthew Eugene Lambert
}

Estimates suggest that humanity requires one-and-a-half Earths to sustainably

provide the resources demanded. Observed consequences of this are rising atmospheric carbon, loss of arable land, fishery collapse, drinking water scarcity, and irreparable degradation to the Earth's ecosystems. The ecological footprint is a tool that calculates the amount of land needed to support a population or an individual's level of resource use. The action of calculating an individual's footprint has been shown to improve knowledge about environmental issues, change attitudes about natural resources, and increase understanding about the connection between one's actions and the environment.

This research examined the impacts of a sustainability campaign on the proenvironmental behaviors of students, faculty, and staff at San José State University (SJSU) using an online ecological footprint quiz. It involved promotion of the campaign, administering the ecological footprint via an online survey, educational outreach on reducing one's footprint, and measuring reported behavioral change over a seven-month period. An ecological footprint study of this scale using the pre-test and post-test method had not been attempted before. Data collection also included focus groups for investigating why people changed their lifestyles during the study period. On average, participants in the footprint challenge decreased their ecological footprint by $10.3 \%$. By comparison, individuals who attended one of the monthly sustainability lectures reported a $17 \%$ decrease in footprint. 


\section{ACKNOWLEDGEMENTS}

First I would like to thank my wonderful wife, Zuhayl Lambert, for supporting me throughout this process, reviewing my thesis, and motivating me to persevere. I would sincerely like to thank my committee Katherine Cushing, Eugene Cordero, and Linden Skjeie for sharing their feedback, expertise, and support throughout this project. I would also like to thank the SJSU President's Office for making a commitment to sustainability and funding the Ecological Footprint Challenge. Without the hard work of the "sustainability initiative team" and the help of the students in the SJSU Environmental Resource Center this project would not have succeeded. My heartfelt thanks go out to Lisa Benham, Jennifer Gorospe, Loren Lewis, and all the other students who volunteered their time to create a physical presence on campus for the Ecological Footprint Challenge. Last I want to thank the challenge participants, especially those who volunteered to take part in the focus groups, for without them this project would not have been possible. 


\section{TABLE OF CONTENTS}

List of Tables viii

List of Figures. ix

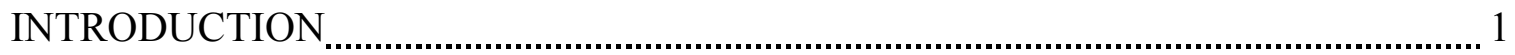

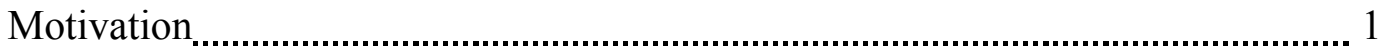

Background

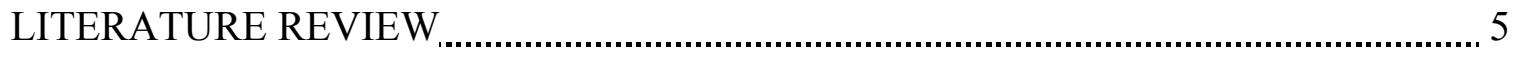

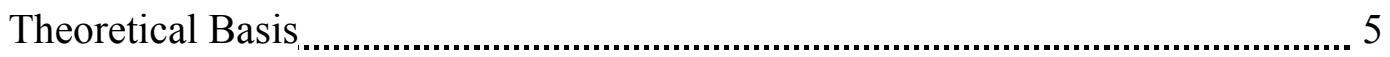

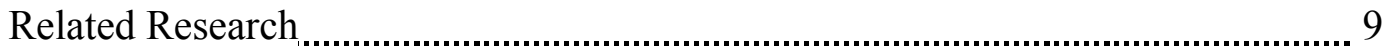

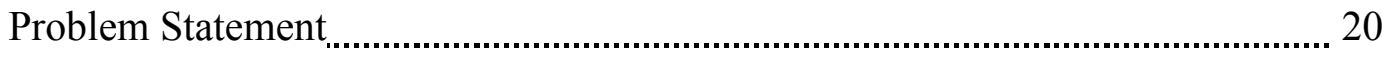

Objectives

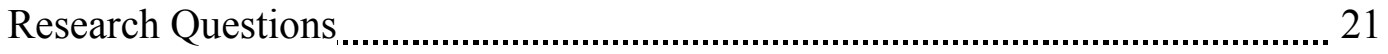

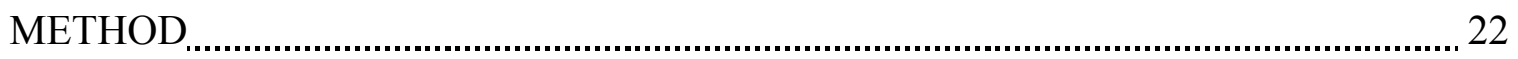

Study Site and Sampling Frame

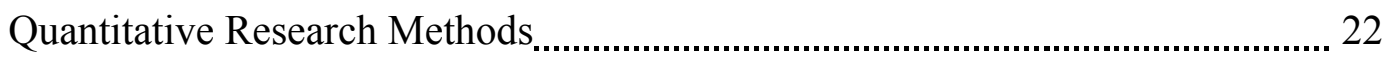

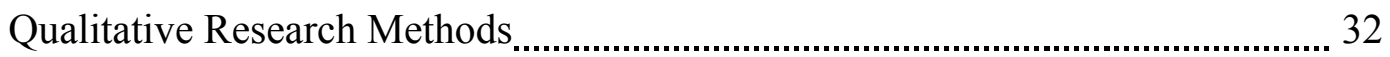

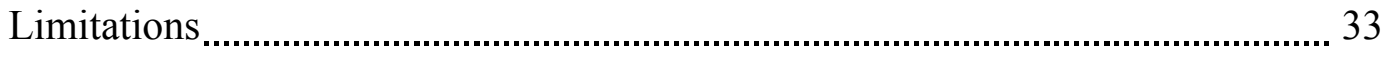

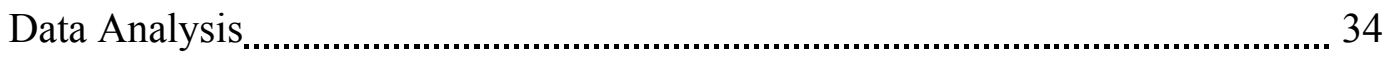

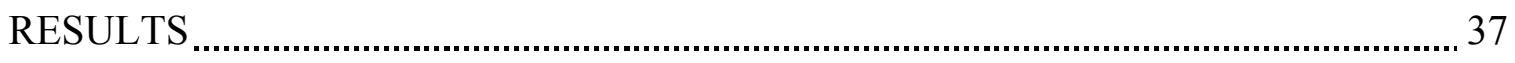

The Baseline Ecological Footprints of Students, Faculty, and Staff at SJSU....... 37

Change in Ecological Footprint During the Ecological Footprint Challenge........ 42 
The Effect of Concurrent Educational Outreach on the Ecological Footprint ...... 56

Reasons Participants Did or Did Not Change Behaviors....................................... 60

Long-Term Ecological Footprint Trends of Focus Group Participants .................. 69

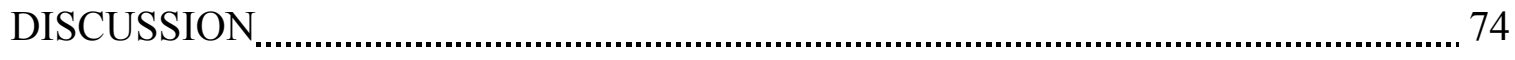

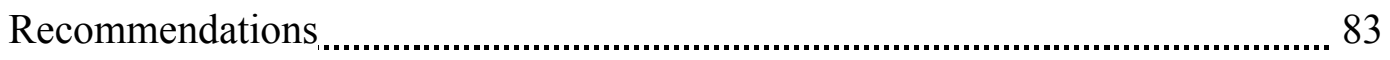

CONCLUSION

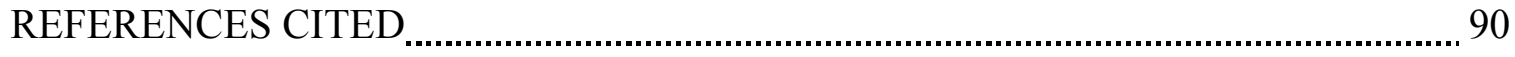

APPENDIX A: Baseline Ecological Footprint Quiz ...................................................... 94

APPENDIX B: Getting to Your 10\% Footprint Reduction Form................................... 109

APPENDIX C: Focus Group Informed Consent Form and Semi-Structured Guides .... 110

APPENDIX D: Baseline Ecological Footprint Quiz Answers - All 2,739 Participants..117

APPENDIX E: Change in Ecological Footprint Quiz Answers - All 738 Participants.. 121

APPENDIX F: Change in Ecological Footprint Quiz Answers - Students..................... 125

APPENDIX G: Change in Ecological Footprint Quiz Answers - Faculty ....................... 129

APPENDIX H: Change in Ecological Footprint Quiz Answers - Staff........................... 133 


\section{LIST OF TABLES}

Page

1. Studies on Sustainability Projects and Pro-Environmental Behavior at Universities

2. Studies Using the Ecological Footprint to Measure Behavior Change at Universities

3. Sustainability Matters Lecture Series Topics and Attendance ............................ 28

4. Ecological Footprint Challenge Participants ....................................................... 38

5. Ecological Footprint Baseline Results .......................................................... 38

6. Change in Ecological Footprints for Returning Participants ................................ 48

7. Change in Ecological Footprint by Category …………………........................ 49

8. Multiple Linear Regression Ecological Footprint Answers and Demographics -

All Participants ............................................................................................ 56

9. Mann-Whitney Test Statistics for Electronic Mailing List .................................... 58

10. Mann-Whitney Test Statistics for Workshop Attendees....................................... 59

11. Common Themes from Focus Groups................................................................. 69

12. Descriptive Statistics - Average Unchanged Footprint Group ............................ 70

13. Mauchly's Test of Sphericity - Average Unchanged Footprint Group ................. 70

14. Tests of Within-Subjects Effects - Average Unchanged Footprint Group ........... 71

15. Descriptive Statistics - Greatest Reduction, Lowest Footprint Group.................. 72

16. Tests of Normality - Greatest Reduction, Lowest Footprint Group ..................... 72

17. Paired Samples $T$-Test - Greatest Reduction, Lowest Footprint Group ................ 73 


\section{LIST OF FIGURES}

Page

1. Pro-Environmental Behavior Conceptual Framework .................................. 6

2. Ecological Footprint Challenge Tabling, October 2009 …............................... 23

3. Ecological Footprint Challenge Pizza Party, November 2009 .......................... 24

4. Baseline Ecological Footprint Results Page .................................................. 26

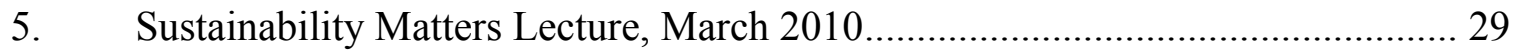

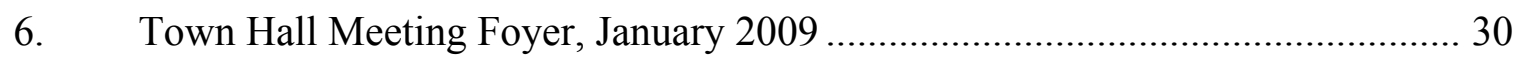

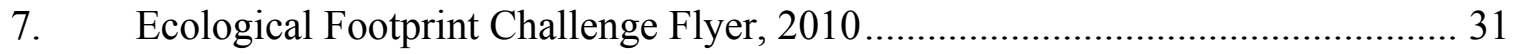

8. Ecological Footprint Baseline Distribution - All Participants ........................... 40

9. Ecological Footprint Baseline Distribution - Students .................................... 40

10. Ecological Footprint Baseline Distribution - Faculty .................................. 41

11. Ecological Footprint Baseline Distribution - Staff ....................................... 41

12. Change in Average Ecological Footprint for All Returning Participants ............ 43

13. EF Distribution - All Participants: Fall 2009 versus Spring 2010 ..................... 44

14. EF Distribution - Students: Fall 2009 versus Spring 2010 .............................. 45

15. EF Distribution - Faculty: Fall 2009 versus Spring 2010 ................................ 46

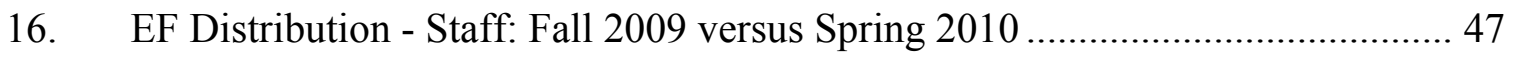

17. Footprint Distributions for Electronic Mailing List Members........................... 58

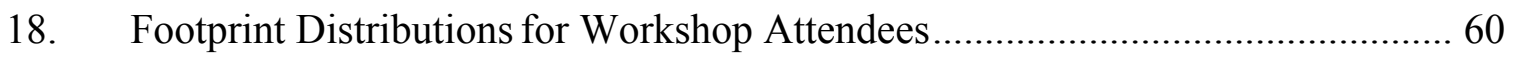




\section{Introduction}

\section{Motivation}

Estimates suggest that humanity's ecological footprint is currently $50 \%$ higher than the earth can sustainably provide, which can result in an ecological overshoot. Ecological overshoot occurs when the demands of a population outpace the capacity of their ecosystem to regenerate the resources being consumed and absorb the wastes being released (Bagliani, Galli, Niccolucci, \& Marchettini, 2008; Rees \& Wackernagel, 1996). Consequences of overshoot are increased carbon emissions, forest loss, fishery collapse, drinking water scarcity, and ultimately, climate change (Rosenburg, Vedlitz, Cowman, \& Zahran, 2010). Americans have a big impact on this number as their estimated ecological footprint is 6.35 times higher than the sustainable rate while only making up $5 \%$ of the global population (Center for Sustainable Economy, www.myfootprint.org). To avoid ecological overshoot, humanity must establish initiatives emphasizing increased proenvironmental behaviors and reduced ecological footprints in individuals, corporations, and governments. Actions considered pro-environmental behaviors protect or benefit the environment; at a minimum they are behaviors that do not harm the environment (Krajhanzl, 2010). However, establishing pro-environmental initiatives is only the first step; each initiative should be tracked and evaluated using results-based tools to determine the effectiveness of the initiative. A sustainable society is one that meets its needs while preserving biodiversity and natural ecosystems for future generations.

One tool to track environmental impacts is the ecological footprint (EF or footprint), which was developed in 1996 by Wackernagel and Rees and has continually 
been improved since then (Wackernagel, 2009). At the individual level, an ecological footprint is defined as the total area of land and sea, often expressed in global hectares or acres, necessary to sustainably supply all required resources and absorb all emissions produced by one person (Wackernagel \& Rees, 1996). All the decisions a person makes throughout the day, from driving one's car to work versus taking public transportation, to eating a steak dinner versus eating a vegan entrée, affect the size of their footprint. An individual's ecological footprint is calculated by answering a series of questions about one's income, living arrangements, energy use, diet, technology, and purchasing practices (Wackernagel et al., 2004). The footprint is also used to calculate the number of Earths needed if everyone on the planet had the same ecological footprint as a particular individual (Wackernagel \& Rees, 1996). By calculating an individual's footprint at multiple points in time, change in behavior and demand on natural resources can be measured.

\section{Background}

The Global Footprint Network estimates, in its annual National Footprint Accounts, that in 2009 the United States accounted for $16 \%$ of the global ecological footprint. The average per capita U.S. ecological footprint was about four times higher than the rest of the world (Global Footprint Network, 2009). The ecological footprints of people in the U.S. are among the highest and must be reduced to achieve sustainable use of resources globally.

Along with the goal of better educating students about sustainable systems, university campuses are recognizing the need to practice sustainability on campus 
(Wright, 2003). San José State University (SJSU) has recently signed the Talloires Declaration, joining over 420 universities around the globe. This declaration is a 10point action plan for incorporating sustainability and environmental literacy in teaching, research, operations, and outreach at colleges and universities (Conway, Dalton, Loo, \& Benakoun, 2008; Roorda, 2000). Educators have a growing responsibility to engage students in sustainability issues through action-oriented learning and tools like the ecological footprint (Cordero, Todd, \& Abellera, 2008).

However, as Roorda (2000) states, in many cases sustainability initiatives are vague about specific goals and the actions needed to reach them. In addition, many times the effectiveness of the campaign is not measured systematically. The literature review from Corcoran, Walker, and Wals (2004), of 54 journal articles on sustainability in higher education institutions, concluded that case studies were the predominant research method. However, these case studies "rarely included any information on the theoretical approach to the methodology or on the methods used to gather the data. Instead, stories of successes were reported and the data supporting these successes are not readily available for public critique" (Corcoran, et al., 2004, p. 14). Studies using an appropriate assessment tool to characterize the current situation, such as the ecological footprint, are needed to determine how to focus future sustainability efforts (Conway, et al., 2008). As a vehicle for this process, SJSU used the online ecological footprint analysis to challenge students, faculty, and staff to calculate their own footprints and reduce them by $10 \%$ over the course of the academic year. The SJSU Ecological Footprint Challenge did not 
calculate the sustainability of the university as an institution. Instead, the study measured the sustainability of the lifestyles of the SJSU students, faculty, and staff.

The ecological footprint tool uses pro-environmental behavior as the centerpiece of its calculations. The first time a person calculates his or her ecological footprint, required resources and carbon emission absorption are summarized in the easily visualized concept of land area. By doing this, the ecological footprint can educate people from all walks of life about their impact on the world's natural resources. When the same person returns to calculate his or her footprint again, changes in behavior are captured by the tool, resulting in an observed change in footprint. This unique study employed the ecological footprint quiz as a pre-test and post-test instrument, in a university-wide outreach effort on sustainability. The researcher also investigated how participants reacted to the footprint survey, concurrent educational outreach, and why they changed their behaviors during the course of the study. 


\section{Literature Review}

\section{Theoretical Basis}

\section{Environmental Knowledge, Locus of Control, and Pro-Environmental}

Behavior. Educators have assumed that environmental knowledge will encourage proenvironmental behavior. However, this is not always the case (Darner, 2009; Frick, Kaiser, \& Wilson, 2004; Olli, Grendstad, \& Wollebaek, 2001; Pooley \& O’Connor, 2000). Frick et al. (2004) have identified system-knowledge (understanding natural processes and ecosystems), action-related knowledge (knowing what can be done about environmental problems), and effectiveness-knowledge (knowledge about the relative benefit of the action) as important aspects of promoting pro-environmental behavior. They found that system knowledge does not have a direct effect on pro-environmental behavior (Figure 1). However, system knowledge does explain 29\% of the variance of

action knowledge. System knowledge and action knowledge together explain $6 \%$ of the pro-environmental behavior variance. Action-related and system knowledge jointly predicted $18 \%$ of the variance of effectiveness knowledge. This result was very close to comparable studies. Frick et al. concluded, "with regard to environmental decisions, behavioral costs often are obvious, but the environmental benefits generally are unknown to the public" (2004, p. 1610). The online ecological footprint tool directly addresses action-related knowledge and effectiveness knowledge by providing pro-environmental actions and showing, in real time, the benefit to the environment.

Once a person has considered the action-knowledge and effectiveness-knowledge, the next step is deciding to engage in pro-environmental behaviors. This decision is an 
intention to act. Intentions to act have been significantly correlated to long-lasting proenvironmental behaviors (Staats, Harland, \& Wilke, 2004). In addition, a technique has been developed called the commitment technique, in which a pledge is made to act in a pro-environmental manner in the future. In their review of 10 studies, Staats et al. (2004) found that this technique has produced behavior changes that are relatively long lasting when applied to pro-environmental behavior. Furthermore, when combined with providing information, feedback, and social support, such a campaign may be especially successful in fostering pro-environmental behavior change.

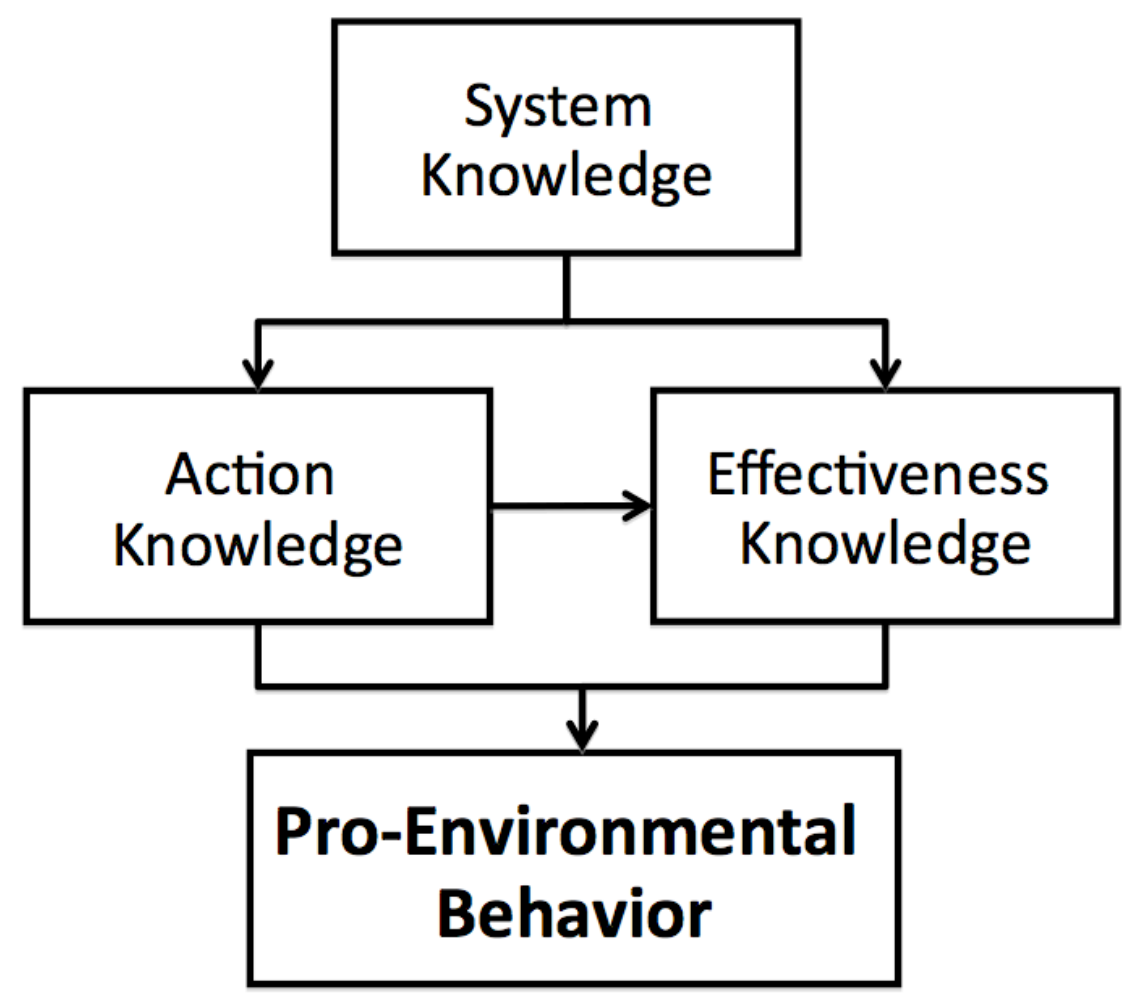

Figure 1. Pro-Environmental Behavior Conceptual Framework.

The hypothesis of the Locus of Control, developed by Lefcourt (1982), may help to explain why participants chose to change their behavior. This hypothesis states that 
the degree to which individuals take action in certain situations depends on their perceived control of the outcome. This psychological framework states that people who have a high external locus of control believe that their actions do not make a difference and that outcomes are determined by external forces. Individuals with a high internal locus of control believe that they do have control over outcomes and that their actions make a difference. Therefore, Lefcourt suggests that when faced with evidence of environmental devastation and the reality of human induced climate change, those who have a high internal locus of control are more apt to take action, believing that their individual actions make a difference. These same individuals do not blame external forces for their inability to act more sustainably.

In addition people choosing to make a sacrifice to help the environment must perceive that these actions will make a difference. A high internal locus of control has been positively correlated to pro-environmental behavior (McCarty \& Shrum, 2001). McCarty and Shrum concluded that individuals with this trait purchase ecologically packaged products, believe that recycling is important, and engage in other environmentally responsible behavior. However, Cleveland, Kalamas, and Laroche (2005) indicate that environmental locus of control varies from behavior to behavior. In addition, the different aspects of environmental locus of control explored in their study included biospheric-altruism, corporate skepticism, economic motivation, and individual recycling efforts. While complex environmental attitudes may vary depending on the environmental behavior, the environmental locus of control is still considered an important factor. 
Cleveland et al. (2005) found significant results for behaviors linked to environmental locus of control under four categories: external locus of control for biospheric-altruism (pollution is a problem and we do not have enough natural resources), external locus of control for corporate skepticism (companies are not concerned about and do not act responsibly towards the environment), internal locus of control for economic motivation (would pay more for products that help protect the environment and pay more taxes for an environmental cleanup fund), and internal locus of control for positive attitudes on recycling (recycling is not too much trouble). A few behaviors that significantly correlated to an external locus of control for biosphericaltruism included turning off lights before leaving the house, refusing to buy products from companies that pollute, and purchasing phosphate-free detergent. Some behaviors significantly correlated to an external locus of control for corporate skepticism were turning down the thermostat, walking rather than driving to a store that is just a few blocks away, and refusing to buy products from companies that pollute. Some behaviors significantly correlated to an internal locus of control for economic motivation were buying CFL light bulbs, turning down the thermostat, walking rather than driving, refusing to buy products from companies that pollute, when buying something making sure it is wrapped in recycled materials, bringing your own bag when shopping, and buying organic. Some behaviors significantly correlated to an internal locus of control for positive attitudes on recycling were using public transport, turning down the thermostat, walking rather than driving, recycling at home, and bringing your own bag when shopping. While many of the participants of this ecological footprint study 
reported engaging in these behaviors, there were not questions on the quiz that determined if participants fell into the above environmental locus of control categories.

The literature review conducted on the body of work addressing environmental education revealed a common need to further explore why people choose proenvironmental action, in the context of environmental awareness. Conway et al. (2008) noted that "as sustainability of higher education institutions receives more attention there is a need to develop methodologies to measure a campus' level of sustainability. The ecological footprint is emerging as one potential approach" (p. 5).

\section{Related Research}

Pro-Environmental Behavior Studies at Universities. A small collection of articles has been published on pro-environmental behavior studies at universities. These studies often focus on only one aspect of sustainability at a time. The articles most relevant to this study were summarized on Table 1. Almost all U.S. collegiate campuses now have sustainability initiatives in place. Bartlett and Chase (2004) in "Sustainability on Campus: Stories and Strategies for Change" compiled narratives from colleges and universities from across the country to disseminate in-depth accounts of the struggles and successes of sustainability initiatives, as each school addresses campus sustainability in their unique way. The diverse case studies were written by "environmental champions," at just a few of the hundreds of colleges undergoing sustainability initiatives (Bartlett \& Chase, 2004). The projects included green building standard development, incorporating sustainability into curricula, raising environmental awareness, and implementation of broad sustainability initiatives. Despite the variety of case studies, the authors note that 
only a few sustainability projects begin by assessing the current level of sustainability at the university. One such initiative, detailed by Walker and Lawrence (2004), conducted a baseline assessment prior to implementation of a recycling, purchasing, and transportation initiative. One of the biggest challenges was greening a decentralized campus. The authors noted that it was imperative that emails be sent to all campus members, and again to new incoming freshman. In addition, the surveys revealed health to be a very important value to the student body. They noted that linking health to the sustainability program would increase the effectiveness of their initiative. However, at the time of publication, another survey had not yet been performed to gauge the programs effectiveness.

While all accounts included challenges and lessons learned, none of the projects detailed any ongoing quantitative assessment of the effectiveness of their sustainability efforts, such as a post-test. The presented case studies relied on anecdotal evidence when discussing the effectiveness of their programs (Bartlett \& Chase, 2004). The assumption that implementation of a sustainability project automatically equals success is extremely widespread. Accounts such as these and discussions with university sustainability coordinators has revealed that quantifying such efforts often comes as an afterthought or is completely overlooked.

In one campus sustainability outreach project researchers found that people who attended a multifaceted sustainability film series felt more informed about sustainability and reported being more inclined to make sustainable choices (Lindsay, Harrell-Blair, McDaniel, Williams, \& Reed, 2010). Surveys were handed out after each film viewing, 
to gauge the participant's environmental awareness and change in environmental knowledge. Results found that participants reported an increase in knowledge and an increase in intention to act. However, the researchers could not conclude whether this resulted in increased pro-environmental action.

Owens and Halfacre-Hitchcock (2006) conducted before and after surveys and a building waste audit in conjunction with a green building project and recycling program implementation. The researchers found that faculty showed an increase in sustainability scores, but students did not. The researchers found that recycling at this particular university was confusing and inconvenient. This may have impacted students living in dormitories most, in part explaining the lack of change in behavior. An additional recycling behavior study by Pike et al. (2003) found that when students were given recycling bins and some education about recycling there was a significant reduction in their waste stream to the landfill. Students who were only given education did not show a significant change. Meanwhile, students who were only given bins, recycled more as time went on. These studies highlight the importance of clear communication, selfevaluation, reworking strategies, and the complexity of behavior change.

Corcoran et al. (2004) found, in a review of 54 articles on campus sustainability projects, 28 used the case study method, two explained the methodology of the case study, and only two conducted an assessment of university consumption using the ecological footprint. These authors are critical of the use of the case study method, especially when the study methods are not well defined. Studies that employ quantitative 
designs were encouraged. In addition, none of the studies used the ecological footprint to measure the success level of a particular sustainability initiative.

Table 1

Studies on Sustainability Projects and Pro-Environmental Behavior at Universities

\begin{tabular}{|c|c|c|c|c|}
\hline Author(s) & Date & $\begin{array}{c}\text { Research Questions/ } \\
\text { Sustainability Project/ } \\
\text { Study Population }\end{array}$ & $\begin{array}{l}\text { Findings/Outcomes } \\
\text { / Lessons Learned }\end{array}$ & Gaps \\
\hline $\begin{array}{l}\text { Dahm, } \\
\text { Samonte, } \\
\text { \& Shows }\end{array}$ & 2009 & $\begin{array}{l}\text { Does student awareness } \\
\text { and attitudes about } \\
\text { organic foods predict } \\
\text { behaviors with regard } \\
\text { to organic food } \\
\text { consumption and other } \\
\text { healthy lifestyle } \\
\text { practices? } \\
\text { Lamar University, } \\
\text { Beaumont, Texas. }\end{array}$ & $\begin{array}{l}\text { Forty nine percent } \\
\text { of the students were } \\
\text { knowledgeable } \\
\text { about organic } \\
\text { foods. Mostly taste } \\
\text { and price } \\
\text { influenced the } \\
\text { purchase of such } \\
\text { foods. Positive } \\
\text { attitudes towards } \\
\text { organic foods } \\
\text { significantly } \\
\text { predicted similar } \\
\text { behaviors. }\end{array}$ & $\begin{array}{l}\text { This study focused } \\
\text { on students, but } \\
\text { future study should } \\
\text { also include } \\
\text { faculty and staff. } \\
\text { This study only } \\
\text { focused on organic } \\
\text { food, which is only } \\
\text { part of a person's } \\
\text { ecological } \\
\text { footprint. }\end{array}$ \\
\hline $\begin{array}{l}\text { DeLind } \\
\& \text { Link }\end{array}$ & 2004 & $\begin{array}{l}\text { This paper describes a } \\
\text { semester-long course } \\
\text { entitled "Our Place on } \\
\text { Earth: Experiencing } \\
\text { and Expressing our } \\
\text { Relationship to the } \\
\text { 'Natural Environment", } \\
\text { and how it became a } \\
\text { nexus for a sustainable } \\
\text { future. } \\
\text { Michigan State } \\
\text { University. East } \\
\text { Lansing, Michigan. }\end{array}$ & $\begin{array}{l}\text { Not only did the } \\
\text { course accomplish } \\
\text { what it set out to (as } \\
\text { seen on course } \\
\text { evaluations), it has } \\
\text { resulted in the } \\
\text { community getting } \\
\text { more involved and } \\
\text { the creation of } \\
\text { several similar } \\
\text { courses. }\end{array}$ & $\begin{array}{l}\text { This study used } \\
\text { student evaluations } \\
\text { to gauge its effects } \\
\text { on students, and } \\
\text { collected anecdotal } \\
\text { data about their } \\
\text { experience. } \\
\text { However a } \\
\text { pre/post-test } \\
\text { design was not } \\
\text { implemented to } \\
\text { measure pro- } \\
\text { environmental } \\
\text { change. }\end{array}$ \\
\hline
\end{tabular}


Table 1 (continued)

\begin{tabular}{|c|c|c|c|c|}
\hline Author(s) & Date & $\begin{array}{c}\text { Research Questions/ } \\
\text { Sustainability Project/ } \\
\text { Study Population }\end{array}$ & $\begin{array}{l}\text { Findings/Outcomes } \\
\text { / Lessons Learned }\end{array}$ & Gaps \\
\hline $\begin{array}{l}\text { Jahiel \& } \\
\text { Harper }\end{array}$ & 2004 & $\begin{array}{l}\text { This paper details the } \\
\text { formation of the green } \\
\text { task force and the } \\
\text { challenges it faced in } \\
\text { reducing its } \\
\text { university's } \\
\text { environmental } \\
\text { footprint. } \\
\text { Illinois Wesleyan } \\
\text { University. } \\
\text { Bloomington, Illinois. }\end{array}$ & $\begin{array}{l}\text { The green task } \\
\text { force expanded the } \\
\text { school's recycling } \\
\text { system, increased } \\
\text { environmental } \\
\text { awareness, oversaw } \\
\text { an energy audit, } \\
\text { and started } \\
\text { reducing paper and } \\
\text { electricity } \\
\text { consumption. }\end{array}$ & $\begin{array}{l}\text { This study claims } \\
\text { it increased } \\
\text { environmental } \\
\text { awareness, but this } \\
\text { was not captured } \\
\text { with quantitative } \\
\text { measurement. }\end{array}$ \\
\hline $\begin{array}{l}\text { Lindsay et } \\
\text { al. }\end{array}$ & 2010 & $\begin{array}{l}\text { This study asks what } \\
\text { the impact of a } \\
\text { sustainability initiative } \\
\text { that centers on a } \\
\text { sustainability film } \\
\text { series will have on its } \\
\text { students, faculty, and } \\
\text { staff. } \\
\text { University of North } \\
\text { Carolina Wilmington. }\end{array}$ & $\begin{array}{l}\text { The study found } \\
\text { that people who } \\
\text { attended the films } \\
\text { felt more informed } \\
\text { about sustainability } \\
\text { and inclined to } \\
\text { make sustainable } \\
\text { choices. }\end{array}$ & $\begin{array}{l}\text { This study found } \\
\text { that its participants } \\
\text { reported increased } \\
\text { knowledge and } \\
\text { intention to act, } \\
\text { but it did not } \\
\text { measure behavior } \\
\text { change. }\end{array}$ \\
\hline $\begin{array}{l}\text { Owens \& } \\
\text { Halfacre- } \\
\text { Hitchcock }\end{array}$ & 2006 & $\begin{array}{l}\text { This paper seeks to } \\
\text { disseminate } \\
\text { knowledge regarding } \\
\text { the experiences of as } \\
\text { student team in } \\
\text { implementing a } \\
\text { campus-level } \\
\text { sustainability } \\
\text { initiative. } \\
\text { College of Charleston, } \\
\text { South Carolina. }\end{array}$ & $\begin{array}{l}\text { There was a } \\
\text { significant increase } \\
\text { in sustainability } \\
\text { over the course of } \\
\text { the project for } \\
\text { faculty. A building } \\
\text { waste audit } \\
\text { confirmed that } \\
\text { faculty showed an } \\
\text { increase in } \\
\text { sustainability } \\
\text { scores. }\end{array}$ & $\begin{array}{l}\text { While this study } \\
\text { actually quantifies, } \\
\text { through } \\
\text { observation, and } \\
\text { the measured } \\
\text { change in } \\
\text { behavior, it is } \\
\text { limited to } \\
\text { recycling. }\end{array}$ \\
\hline
\end{tabular}


Table 1 (continued)

\begin{tabular}{|c|c|c|c|c|}
\hline Author(s) & Date & $\begin{array}{c}\text { Research Questions/ } \\
\text { Sustainability Project/ } \\
\text { Study Population }\end{array}$ & $\begin{array}{l}\text { Findings/Outcomes } \\
\text { / Lessons Learned }\end{array}$ & Gaps \\
\hline Pike et al. & 2003 & $\begin{array}{l}\text { The goals of this study } \\
\text { were to expand the } \\
\text { recycling program into } \\
\text { student areas, increase } \\
\text { awareness about the } \\
\text { program, measure if } \\
\text { students want a } \\
\text { recycling program, } \\
\text { and evaluate if they } \\
\text { will recycle. } \\
\text { Francis Marion } \\
\text { University, South } \\
\text { Carolina. }\end{array}$ & $\begin{array}{l}\text { Students living in } \\
\text { apartments } \\
\text { significantly } \\
\text { reduced their waste } \\
\text { streams when given } \\
\text { recycling bins and } \\
\text { some education } \\
\text { about recycling. } \\
\text { The educational } \\
\text { program did not } \\
\text { result in } \\
\text { significantly more } \\
\text { recycling. Students } \\
\text { who received bins } \\
\text { recycled more as } \\
\text { time went on. } \\
\text { Student feedback } \\
\text { was positive. }\end{array}$ & $\begin{array}{l}\text { This project was } \\
\text { limited to } \\
\text { recycling } \\
\text { behaviors on } \\
\text { campus. }\end{array}$ \\
\hline $\begin{array}{l}\text { Walker \& } \\
\text { Lawrence }\end{array}$ & 2004 & $\begin{array}{l}\text { The authors write } \\
\text { about the challenges } \\
\text { of greening a } \\
\text { decentralized campus. } \\
\text { A key in this project } \\
\text { was making the } \\
\text { connection to health. } \\
\text { John Hopkins } \\
\text { University. Baltimore, } \\
\text { Maryland. }\end{array}$ & $\begin{array}{l}\text { Surveys were } \\
\text { conducted to } \\
\text { benchmark current } \\
\text { environmental } \\
\text { practices. } \\
\text { Recycling, } \\
\text { purchasing, and } \\
\text { transportation } \\
\text { initiatives were } \\
\text { implemented. This } \\
\text { was advertized and } \\
\text { emails sent to all } \\
\text { incoming new } \\
\text { students, current } \\
\text { staff, and faculty. } \\
\text { The next step is to } \\
\text { include } \\
\text { sustainability into } \\
\text { the curriculum. }\end{array}$ & $\begin{array}{l}\text { This project } \\
\text { provided a } \\
\text { baseline of the } \\
\text { environmental } \\
\text { practices at the } \\
\text { university. It } \\
\text { suggests } \\
\text { implementing } \\
\text { follow-up studies } \\
\text { to measure what } \\
\text { change has } \\
\text { occurred. }\end{array}$ \\
\hline
\end{tabular}




\section{Using the ecological footprint quiz as a learning tool in the university setting.}

The strength of the ecological footprint to represent each person's impact on the environment in easily relatable terms was cited by a majority of the scholarly articles reviewed (Collins \& Flynn, 2007; Conway et al., 2008; Ryu \& Brody, 2006). An important reason for using the ecological footprint is that the results can be compared and communicated with ease to the general population. In addition, the footprint tool can be used to calculate the impact of different behaviors (Conway et al., 2008). This can be accomplished by adjusting one's answers on the quiz to observe the resulting increase or decrease in footprint. This helps individuals decide where to make lifestyle changes. Collins and Flynn (2007) pointed out that the footprint analysis is an "intuitive and attractive means of measurement, as it helps to visualize human demands on the environment in terms of our use of the earth's available land and it personalizes sustainability by focusing on consumption” (p. 299).

In addition, the participant receives immediate feedback after completing the ecological footprint quiz, often producing an emotional reaction. In a study by Cordero et al. (2008), over $50 \%$ of the students who took the ecological footprint quiz, responded that they were "surprised" or "shocked" at their results. This emotional response is something cited in environmental literature as extremely important when fostering proenvironmental behavior (Pooley \& O’Connor, 2000). The displayed "number of Earths" instantly tells the participant if his or her lifestyle is sustainable or not.

In the fall of 2005, Cordero et al. (2008) explored student misconceptions about global warming at SJSU by using a pre-test post-test questionnaire. The researchers 
explored "how, and to what extent... knowledge of and attitudes toward climate change are affected by different learning environments" (Cordero et al., p. 866). A Likert Scale questionnaire was administered to test "1) the causes of global warming and ozone depletion, 2) the relationship between global warming and ozone depletion, and 3) the link between energy use and greenhouse gas emissions" (Cordero et al., p. 866). A $t$-test was used to analyze if the results of the pre-tests and post-tests were statistically significant.

As part of the educational process, students were directed to complete an online ecological footprint quiz, use the "take action" section on the website to find how to reduce their footprint by $30 \%$, and write a short essay about how their personal actions contribute to their ecological footprint. Not all students completed this activity. Students who took the ecological footprint quiz showed an increased understanding in how home energy use affects one's ecological footprint. In addition, the researchers found that "using trial and error, most students find that food choices were the easiest change they could make to reduce their EF [Ecological Footprint]" (Cordero et al., 2008, p. 869). This unique study showed that finding out one's ecological footprint through an online quiz alone could increase environmental knowledge and comprehension.

Cordero et al. (2008) provide evidence that conducting an ecological footprint activity at the campus-wide level increases the knowledge of interconnected environmental issues. In addition, although there are no studies showing how an ecological footprint activity would affect behaviors long-term, garnering an emotional response may play a key role in creating a long lasting impression. 
Using the Ecological Footprint Quiz as a Pre-Test Post-Test Tool. Research using the ecological footprint to study the change in pro-environmental behaviors over time is limited, and was not found to be previously attempted on a large scale, such as a university (Table 2). Most prior research focused on the ecological footprint of the university as an institution (Conway et al., 2008). However, Ryu and Brody’s (2006) study was the only study found that utilized the ecological footprint as a pre-test post-test method to study pro-environmental behaviors. They concluded that using a quantitative tool afforded the ability to make statistical conclusions on the degree to which sustainability education affects behavior. The methods Ryu and Brody employed served as the main empirical framework for the methods used in this study as well.

Ryu and Brody's (2006) study group an interdisciplinary graduate course at Texas A\&M University. Their research article was particularly valuable to this thesis because the authors employed the ecological footprint analysis tool during the pre-test to determine baseline, conducted an educational period, and used the ecological footprint as the post-test to measure change. Ryu and Brody used a 16-question version of the ecological footprint quiz that was originally designed by Redefining Progress, the creators of www.myfootprint.org. Both sample populations completed the ecological footprint quiz pre-test. The test population attended the graduate level course on sustainable development, while the control group attended a graduate level course on market analysis for development (with no emphasis on sustainability). Throughout the year, the test group completed an extensive reading list and was expected to apply this knowledge to solving sustainable planning issues. At the end of the semester, both 
sample populations completed the ecological footprint quiz post-test. The pre-test and post-test data was first analyzed using paired tests of means to determine the change in footprint scores. Next, multiple regression analysis was used to identify the more important indicators explaining the size and change in ecological footprint. Both of the above analyses were employed in this thesis study.

Results of the data analysis by Ryu and Brody (2006) indicated that the control group's footprint significantly increased from 20.6 acres to 23.1 acres $(p=.026)$. In contrast, the ecological footprint of the study group decreased significantly from 19.5 acres to 16.8 acres $(p=.049)$. In other words, students in the study group reported engaging in more pro-environmental behaviors. Multiple regression analysis indicated that greater household income level, age, and distance from campus were significant predictors for larger footprints. The footprint categories where the study group showed significant decreases in footprint were transportation and goods and services. In addition, multiple regression analysis indicated that only a larger baseline footprint was a significant predictor of footprint reduction. The resulting change in footprint successfully indicated that attending a graduate course incorporating sustainability significantly increases pro-environmental behavior.

Ryu and Brody (2006) called for further research in the form of an expanded study with a larger population surveyed at several points in time. In addition, the authors recommended that studies be conducted at other universities in different geographical regions. Last, the authors pointed out that this type of pre-test post-test study might be 
particularly susceptible to an interaction between selection and history. In other words, events other than treatment could have affected the study group.

Table 2

Studies Using the Ecological Footprint to Measure Behavior Change at Universities

\begin{tabular}{|c|c|c|c|c|}
\hline Author(s) & Date & $\begin{array}{c}\text { Research } \\
\text { Questions/Study } \\
\text { Population } \\
\end{array}$ & Findings & Gaps \\
\hline $\begin{array}{l}\text { Cordero } \\
\text { et al. }\end{array}$ & 2008 & $\begin{array}{l}\text { What is the effect of } \\
\text { action-oriented learning } \\
\text { on climate change } \\
\text { literacy? } \\
\text { Study population was } \\
\text { over } 400 \text { Students } \\
\text { enrolled in Weather } \\
\text { and Global Climate } \\
\text { Change at SJSU. }\end{array}$ & $\begin{array}{l}\text { Emphasizing the } \\
\text { personal connection } \\
\text { between the } \\
\text { student, energy, and } \\
\text { climate change } \\
\text { using the ecological } \\
\text { footprint } \\
\text { significantly } \\
\text { improved } \\
\text { understanding of } \\
\text { that connection. }\end{array}$ & $\begin{array}{l}\text { This study did not } \\
\text { use the ecological } \\
\text { footprint to } \\
\text { measure } \\
\text { behavioral } \\
\text { change, but solely } \\
\text { as a learning tool. } \\
\text { Classroom } \\
\text { population size, } \\
\text { not university } \\
\text { scale. }\end{array}$ \\
\hline $\begin{array}{l}\text { Ryu \& } \\
\text { Brody }\end{array}$ & 2006 & $\begin{array}{l}\text { What effect does a } \\
\text { graduate level course } \\
\text { on sustainability have } \\
\text { on behaviors, as } \\
\text { measured by a pre-test } \\
\text { post-test ecological } \\
\text { footprint analysis? } \\
\text { Study population was } \\
22 \text { students in a } \\
\text { sustainable } \\
\text { development course at } \\
\text { Texas A\&M and } 28 \\
\text { students in a } \\
\text { development course } \\
\text { with no emphasis on } \\
\text { sustainability. }\end{array}$ & $\begin{array}{l}\text { Results indicate } \\
\text { that that graduate- } \\
\text { level education can } \\
\text { significantly } \\
\text { increase students' } \\
\text { sustainable } \\
\text { behavior as } \\
\text { measured by their } \\
\text { Ecological } \\
\text { Footprint and that } \\
\text { specific } \\
\text { socioeconomic and } \\
\text { proximity-based } \\
\text { variables contribute } \\
\text { to this observed } \\
\text { phenomenon. }\end{array}$ & $\begin{array}{l}\text { Study is done on } \\
\text { a relatively small } \\
\text { scale and calls for } \\
\text { continued study } \\
\text { of a larger study } \\
\text { group, in various } \\
\text { settings. }\end{array}$ \\
\hline
\end{tabular}




\section{Problem Statement}

Efforts must be taken to increase and measure sustainability at universities, which are often a central hub for education and change in the community (Cordero et al., 2008; Ryu \& Brody, 2006). The ecological footprint can be used to characterize the sustainability of individuals at a university, inform future policy, and transform a university's extensive sustainability goals into concrete actions (Conway et al., 2008). As a vehicle for this process, the ecological footprint analysis was used at SJSU to challenge campus members to calculate their ecological footprint and reduce it by $10 \%$ over the course of an academic year.

The ecological footprint shows promise in promoting pro-environmental behaviors in individuals, while at the same time collecting quantifiable data and measuring behavioral change (Cordero et al., 2008; Ryu \& Brody, 2006). This research measures the effects of outreach efforts by investigating the distribution of the ecological footprints of students, faculty, and staff over time. This study investigated the use of the ecological footprint tool, as a pre-test and post-test in a large-scale outreach effort on sustainability. Furthermore, this study used focus groups to investigate how individual participants reacted to the ecological footprint survey, and why they changed their behaviors during the course of the study. These select participants had their ecological footprints calculated again 1 year later to measure if the reported behavior change was temporary or sustained. 


\section{Objectives}

The goals of this thesis study were to measure the distribution and change of ecological footprints of the SJSU community and to measure the impact of promoting sustainability practices on campus. The following research questions were explored during the ecological footprint challenge at SJSU.

\section{Research Questions}

Q1: What is the ecological footprint of students, faculty, and staff at SJSU?

Q2: Did the size of the reported ecological footprints of participants decrease significantly during a university-wide competition employing the ecological footprint tool to challenge participants to increase their level of pro-environmental behavior?

Q3: What changes occurred in the ecological footprints of participants who engaged in the online quiz and participated in concurrent educational outreach efforts?

Q4. What reasons did participants have for changing or not changing their proenvironmental behavior?

Q5. Did participants sustain changes in pro-environmental behavior after the challenge concluded? 


\section{Method}

\section{Study Site and Sampling Frame}

The study site was SJSU's main campus, located on 154 acres in downtown San Jose, California. All students, faculty, and staff were encouraged to participate in the study. In 2009, SJSU had about 31,000 students, 2,000 faculty, and 3,500 staff. Most students commute to school, and in 2009 only 2,900 students were on-campus residents. The campus is located in an urban city center with easy access to public transportation and restaurants.

\section{Quantitative Research Methods}

Study design. Many different strategies were employed to recruit as many participants as possible for the SJSU Ecological Footprint Challenge. An invitation to participate in the SJSU ecological footprint challenge, via a message through the University's online registration website (mysjsu.edu), was sent to all SJSU students, faculty, and staff. This was combined with the snowball method of requesting the department heads, dorm residence advisors, and sports team coaches to pass the challenge information along via emails. Following Conway et al.'s (2008) methods to increase participation, the team tabled at the student union with laptops, had pizza parties in the dorms, and made other announcements to get the word out about the challenge (Figure 2). Also, following Esterberg's (2002) methods, the emails, sustainability website, and announcement flyers included details about random prize drawings worth $\$ 100$ for three participants who entered the challenge. In addition, grand prizes worth around $\$ 300$ were 
offered to each student, faculty, and staff that had the lowest overall footprint or reduced their footprint the most over the course of the year (six grand prizes in total).

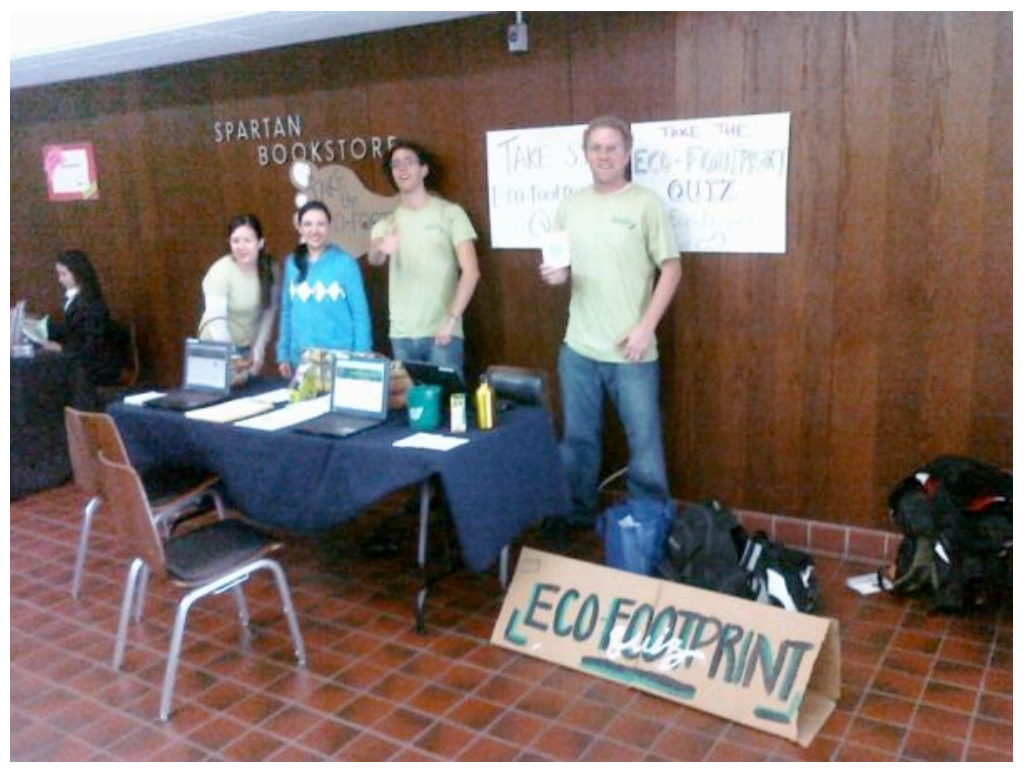

Figure 2. Ecological Footprint Challenge Tabling, October 2009. Photograph by Anna Le.

Small prizes were also given to some individuals who entered the challenge at tabling events. To increase the amount of on-campus residents participating in the challenge, pizza parties and cupcake parties were held in the common room at each dorm. Laptops were set up for participants and students were encouraged to bring their own laptops (Figure 3). 


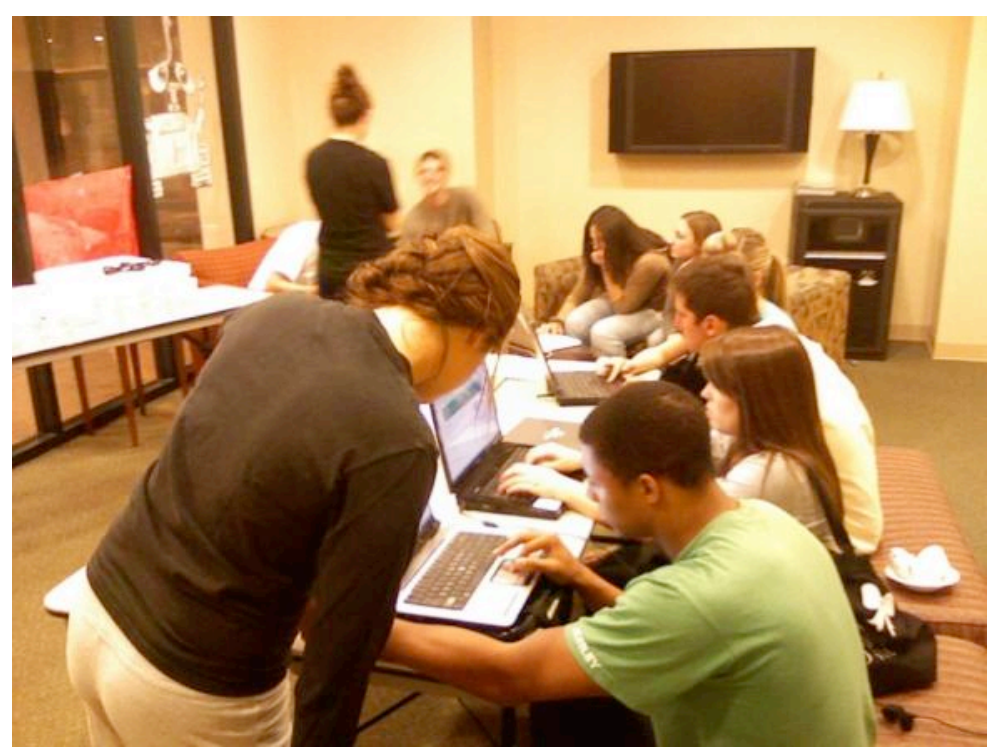

Figure 3. Ecological Footprint Challenge Pizza Party, November 2009.

Student volunteers also made announcements to classrooms and sports teams. Finally, a banner was displayed at the center of campus announcing the footprint challenge. Reminder emails were sent to participants who registered, but had not completed the online quiz and saved their data.

Baseline ecological footprint data collection. The ecological footprint (Wackernagel \& Rees, 1996) of each participant was determined through an online quiz on the Redefining Progress website (www.myfootprint.org/sjsu) (Ryu \& Brody, 2006). SJSU and Redefining Progress staff modified the quiz website (Appendix A) to provide on-campus residents some of the answers related to their dorms. The website was also modified to be more applicable to residents of Northern California and to provide more information about sustainability initiatives at SJSU. Before going through the online quiz, participants were asked to register, create a login and password, and answer a few 
demographic questions. This allowed for the data to be tracked so that participants could revisit the site at the end of the year and determine if their footprint had changed.

The calculated baseline ecological footprint and each quiz answer participants selected during the online quiz were stored in a database. Computations to find the ecological footprint were performed by the proprietary software of the Center for Sustainable Economy. Each participant's ecological footprint was calculated by taking the average per capita American carbon, food, housing, and goods and services ecological footprint and adjusting it up or down based on each quiz answer. These footprint values were generated by the global footprint calculator housed at Redefining Progress using data published by international agencies like the Food and Agriculture Organization of the United Nations and the World Bank. Venetoulis and Talberth (2005) developed the methodology for the per capita footprint. While the calculation may not be accurate to the square foot, it is very effective at calculating the relative footprints of a large group of individuals. The ecological footprint calculator provided the total footprint as an aggregate of carbon footprint, food footprint, housing footprint, and goods and services footprint (Figure 4). The footprint was also presented as the cumulative Cropland, Pastureland, Marine Fisheries, and Forestland required for that person's lifestyle. Once the baseline data was collected it was downloaded into a database. 
Quiz results

If everyone on the planet lived my lifestyle, we would need:

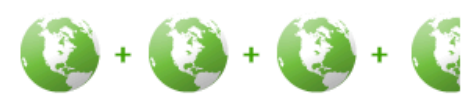

3.62 Earths

Important! To fully participate in the challenge, please save your results here

Save Results as 2009 Baseline

Save Results as 2010 Final

This button will be available in the Spring of 2010

to record your final footprint scores.

\section{Don't Save Result:}

Getting to your $10 \%$

MY FOOTPRINT IN GLOBAL ACRES BY CONSUMPTION CATEGORY

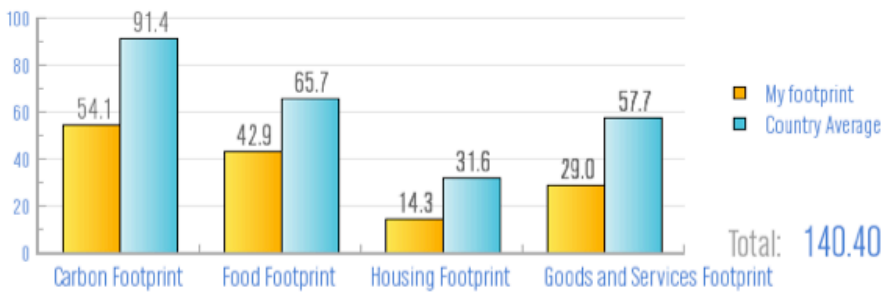

MY FOOTPRINT SHARE BY BIOME

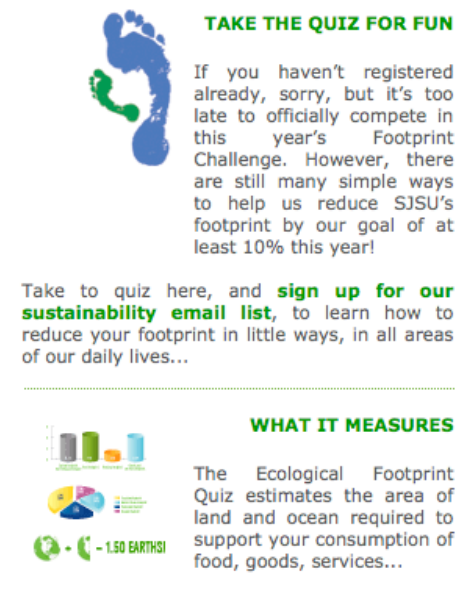

Figure 4. Baseline Ecological Footprint Results Page.

This information was used to target areas for educational outreach and develop a

"Getting to Your 10\%" handout that suggested actions the "average" participant could take to reduce their footprint by $10 \%$ (Appendix B). The areas that had the largest footprint were targeted. Ryu and Brody (2006) refer to this as the "low hanging fruit." 
The challenge. This campaign challenged all individuals to reduce their footprint by $10 \%$. Participants also competed to win the grand prizes by having the lowest overall footprint or reducing their footprint the most. Participants received a tip sheet for reducing their footprint by $10 \%$ (Appendix B). Each sheet given included the written statement "I commit to reducing my footprint by 25 points (10\%) or more!" This pledge was an intention to act, which has been shown to increase the frequency of proenvironmental behavior (Darner, 2009). Participants were encouraged to explore the website further to learn more about what constitutes their ecological footprint and what more they can do to reduce their impact on the planet.

Environmental education outreach efforts. During the educational period, footprint participants who signed up to receive emails were notified of monthly sustainability lectures and emailed informational material on sustainability topics. In addition, emails were sent to department heads, staff managers, and other faculty members, to publicize the lecture series. Flyers were posted in departments all across campus to announce the next sustainability lecture. The "Sustainability Matters" lecture series addressed topics of: Transportation, Food, Trash, Global Climate Change (2010 Copenhagen Proceedings), Water, Environmental Justice, and Urban Ecology (Table 3). These events started with an introduction to the topic by a panel of experts followed by a section connecting this information to the SJSU campus. The lectures always provided next steps, pro-environmental actions the attendees could take, and an extended question and answer period. Attendees were encouraged to interact with each other afterwards to continue the dialog. Each event had sign in sheets to track attendance and collect contact 
information from people who wanted more information or wanted to form a working group.

Table 3

Sustainability Matters Lecture Series Topics and Attendance

\begin{tabular}{|c|c|c|c|}
\hline Date & Event Title & $\begin{array}{l}\text { People } \\
\text { Signed } \\
\text { In }\end{array}$ & $\begin{array}{c}\text { Footprint } \\
\text { Challenge } \\
\text { Participants }\end{array}$ \\
\hline $10 / 8 / 09$ & Bike Sharing Programs, from Paris to San Jose & 35 & 23 \\
\hline $11 / 9 / 09$ & $\begin{array}{l}\text { Where Does Our Food Come From? Food, } \\
\text { Farming, \& SJSU }\end{array}$ & 136 & 52 \\
\hline $12 / 7 / 09$ & The Path of Our Trash & 89 & 54 \\
\hline $1 / 26 / 10$ & $\begin{array}{c}\text { How Low Can We Go? Updates on UN } \\
\text { Summit On Climate Change in Copenhagen }\end{array}$ & $\begin{array}{c}250- \\
300\end{array}$ & NR \\
\hline $2 / 16 / 10$ & $\begin{array}{l}\text { A Way Forward for Water: Understanding } \\
\text { Water supply, Use, and Reuse }\end{array}$ & 107 & 67 \\
\hline $3 / 2 / 10$ & $\begin{array}{l}\text { Not In Anyone's Backyard: Equity, } \\
\text { Environmental Justice \& e-Waste }\end{array}$ & 109 & 48 \\
\hline $4 / 6 / 10$ & Urban Ecology- The Other Among Us & $50-100$ & NR \\
\hline
\end{tabular}

Lectures tried to engage attendees to think about how these issues specifically relate to their lives and the SJSU campus (Ryu \& Brody, 2006). In addition, a Town Hall Meeting was held for all ecological footprint challenge participants to learn more about what they could do to reduce their footprints, discuss their experiences, and meet other participants, thus creating a sense of community among participants (Figure 5 and Figure $6)$. 
Each lecture generally began with an introduction to the topic by the moderator, which provided an overview and detailed system-knowledge on the topic. Next, each panel member presented on a topic specific to a certain aspect of the lecture theme, to provide insight and depth related to their particular expertise. Often the panel members included a discussion on what actions could be taken and which would be most effective in an effort to increase sustainability. A question and answer period was held at the end of each session to engage the audience. In this way the lectures served as an educational tool that included system-knowledge, action-knowledge, and effectiveness knowledge. Presentations from groups involved in the topic often included display and description of emotionally moving issues, stressing the need for change.

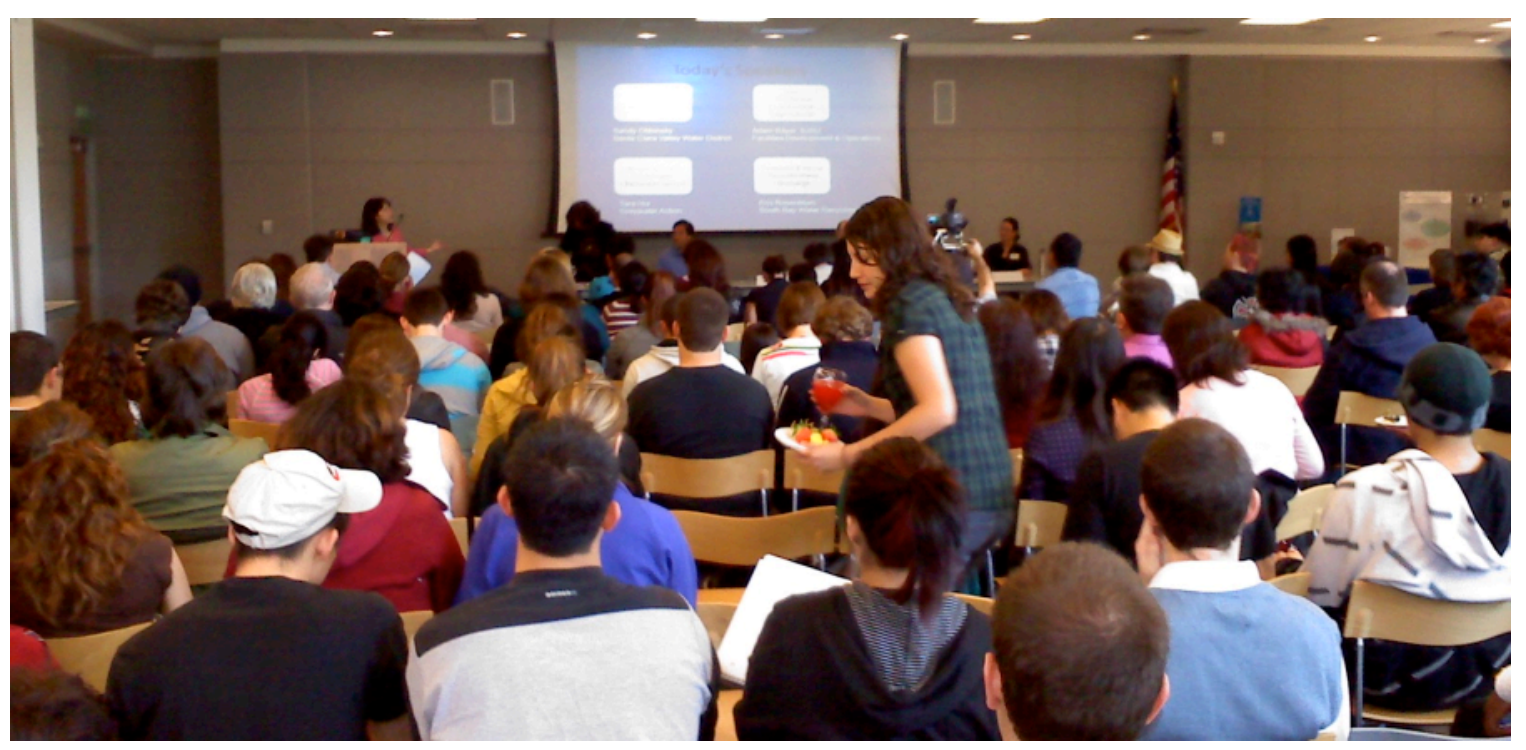

Figure 5. Sustainability Matters Lecture, March 2010.

Local and organic refreshments were served in reusable cups and plates during the lunchtime lectures to entice students, faculty, and staff to give up their lunch breaks to 
engage in the sustainability topic. In addition, environmentally friendly prizes were raffled off at each event, such as a community supported agriculture (CSA) box of local organic fruits and vegetables.

Community building, sustainability electronic mailing list, and feedback. In addition to participants meeting and interacting at our monthly lecture series events (Figure 6), the formation of the sustainability electronic mailing list may have acted to foster community building. Sign up sheets at each event offered individuals the chance to join a focus group and the electronic mailing list. At each event comments and questions were collected from the community to gather feedback. The sustainability initiative team's contact information was available on all handouts, emails, and websites to allow the community to provide feedback. These efforts were taken to help form a sense of social involvement with the footprint challenge and to help foster proenvironmental behavior (Olli et al., 2001).

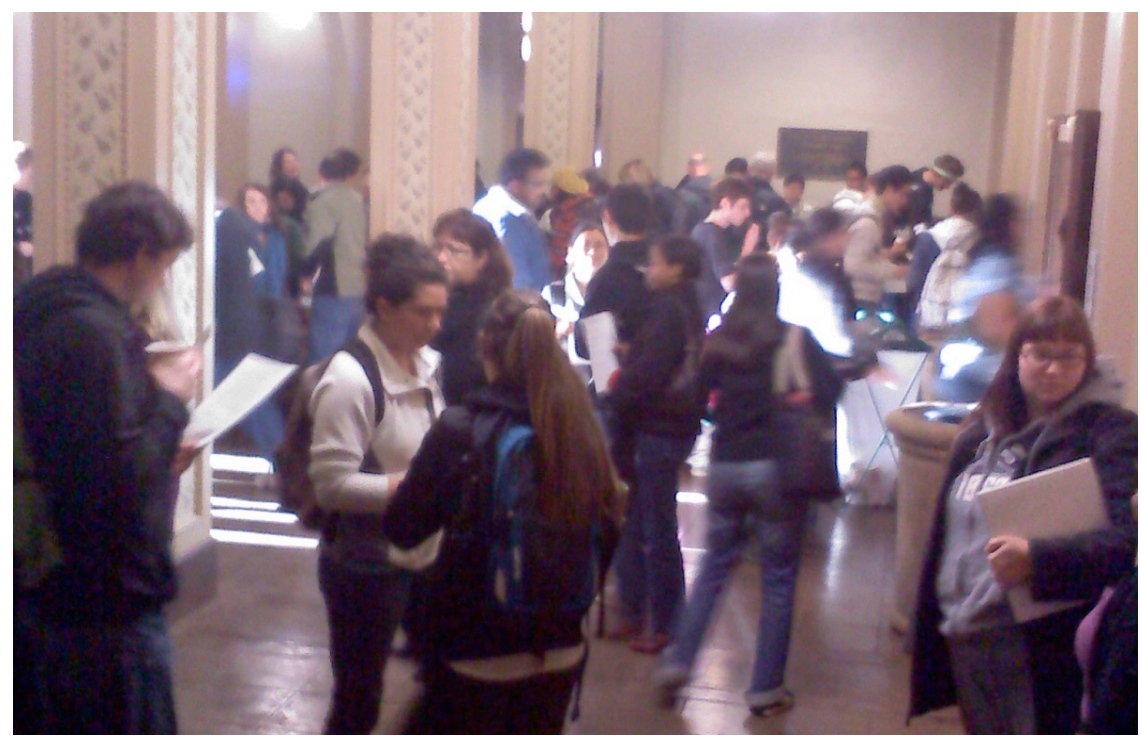

Figure 6. Town Hall Meeting Foyer, January 2009. 
End of school year final data collection. Leading up to the data collection period, at the end of the academic year, reminder emails were sent to all participants, flyers were again distributed, and a banner hung in the center of campus (Figure 7). Reminder emails challenged participants to return and complete their second ecological footprint quiz to see how their ecological footprint had changed. These emails were personalized and contained reminders of their login to the website. Weekly prize drawings were conducted to give away a CSA box of fresh local fruits, vegetables, and a dozen free-range eggs. The weekly emails acted as announcements of the previous week's winner, as well as a reminder to return and complete the quiz. Again, talks were given to classrooms, lecture halls, and sports teams as a reminder to complete the challenge.

\section{Reduced your Footprint?}

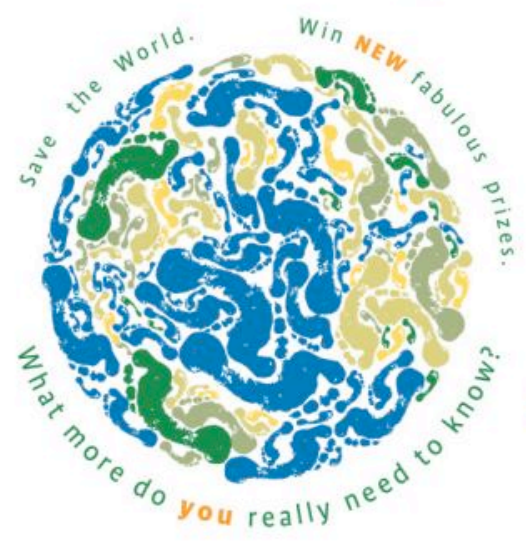

Stay eligable to win more even prizes! Including one of our Grand Prizes...

2a 6-speed Alloy Folding
MTA Metrobike by Citizen Bike

s a Dell Inspiron Mini 1ov Netbook Computer

, a Sony e-Book Reader

\section{Retake the quiz,}

March 1 - April 9, 2010

SJSU Ecological Footprint Challenge

www.sjsu.edu/myfootprint

Figure 7. Ecological Footprint Challenge Flyer, 2010.

Flyer developed by Lisa Benham 
Participants then went to the ecological footprint quiz website (Appendix A), logged in, and completed the quiz. Once they completed the quiz, participants saved this data as their final footprint. At this point participants saw the screen describing how their footprint had changed since the beginning of the year. The contract for use of the online ecological footprint database was limited to two data collection periods only.

Long term ecological footprint change data collection. Participants that took part in the focus groups were asked about their intentions to permanently incorporate changes they had made in their life to reduce their ecological footprint. Focus group participants also completed an additional ecological footprint quiz. The data collected from the focus groups in September 2011 represented a third point in time 1.5 years after the completion of the footprint challenge to see if changes in behavior were sustained.

\section{Qualitative Research Methods}

Focus groups. Focus groups were conducted in September 2011 to further explore motivations and the qualitative aspect of reported changes in pro-environmental behavior. They examined the level of awareness to sustainability participants had before entering the challenge. Participants were invited to take part in the focus groups through their email contact information, and were offered incentives to participate. Participants whose footprint remained near the national average throughout the study, people who had the lowest footprint, and people who decreased their footprint the most were asked to participate in focus groups. This helped gain insight into why these groups did, or did not, make a change to their pro-environmental behaviors (Esterberg, 2002). Focus groups with selected participants had the same semi-structured format to ensure the same 
questions are asked to each focus group (Appendix C). This semi-structured style allowed focus group participants to openly express their opinions and ideas in their own words and for the researcher to further explore interesting topics that arise. This format was used because it is best adapted to understand what life experiences are like from another person's perspective (Esterberg, 2002).

The focus group guides were structured to cover the following topics: the person's lifestyle before the challenge, what caused the person to make changes to their footprint (if any), what the person did during the educational period, their lifestyle after the behavior changes, their environmental literacy, changing relationships with their social groups, and future plans. These groupings were chosen because they contain topics important to the study. The order was chosen because this would be the logical way that the focus groups progress (Esterberg, 2002). Specific focus group questions focused largely on the participants' reactions to their ecological footprint result, what efforts, if any, they made to reduce their footprint, and if they expected these changes to be permanent. Questions were designed to be open-ended and get participants talking in depth about their experience with the challenge and their lifestyle choices (Esterberg, 2002).

\section{Limitations}

Study limitations associated with these methods were as follows. First, participants self-selected to participate in the study. Steps were taken to counter this effect, including tabling around campus with laptops and offering prize incentives. Still, people voluntarily entering the challenge may have been more environmentally conscious 
or already interested in environmental issues thus skewing the sample population composition. Second, participants may have lost motivation to re-enter their footprint data during the second data collection period because they perceived that over the year they had not reduced their ecological footprint. Anecdotal evidence during the second data collection period suggested that this was part of the reason for the drop off in participants. An additional consequence of this study being conducted as a challenge was that participants might have exaggerated their self-reported pro-environmental behaviors because they were being encouraged to improve. Self-reported data always has the additional limitation that user error or confusion may have been a factor.

\section{Data Analysis}

In October 2009, the Ecological Footprint Challenge participants completed the online quiz, and their baseline ecological footprint (footprint) data were stored in an online database. The footprint tool used answers from the online quiz to calculate each participant's ecological footprint. Information about the ecological footprint calculation methods are available online at www.myfootprint.org under the FAQ and Future Improvements page. Next these data were analyzed using descriptive statistics to find the average for each footprint category and the percentage of participants choosing each quiz answer. These statistics were also broken down into students, faculty, and staff.

Data collected during the final data collection period, in March 2010, were compared against the baseline footprint data to determine the percent change in footprint and how participants changed their behaviors. Descriptive statistics were employed and averages were calculated for all quiz answers and calculated ecological footprints. In 
addition, the data analysis for pre-test and post-test data used a method similar to Ryu and Brody (2006). This approach utilized paired tests of means to assess the change in participant footprints from the beginning to the end of the academic year for each participant. Additionally, the data analysis method applied multiple regression analysis to individual quiz answers to identify the factors associated with changes in the participants' ecological footprints.

A database program was used to manage the database and calculate the averages and the percentage of participants that engaged in each behavior. All other statistical analyses were performed using SPSS Statistics (Version 19). First the KolmogorovSmirnov (K-S) Test was employed to test if the samples met the parametric assumptions of paired sampled $t$-tests. If the data met the parametric assumptions, the paired-samples $t$-test was used to determine if the change in footprint was statistically significant for individuals that completed the quiz during both data collection periods. If the data did not meet the parametric assumptions, the Wilcoxon signed-ranked test was used to determine significance. The footprint measure of Earths was used during this comparison. The ecological footprint software calculated the number of Earths based on an output of acres of footprint. The conversion factor used by the calculator to calculate the number of Earths equivalent to a participant's footprint was 38.8139 acres per earth. Focus group data were analyzed by the long table method. Audio for the focus group discussions were recorded and transcripts were created. Data collected in the focus groups were codified to explore the potential meanings of the data. The process of coding was developed after the focus groups were conducted so the process of coding 
could reveal possible meanings in the group's responses (Esterberg, 2002). This method of data analysis looked for themes, representative feedback, and categories of common experiences. Data gathered in these focus groups helped the researcher gain insight into answering why participants made certain changes to their behaviors. 


\section{Results}

\section{The Baseline Ecological Footprints of Students, Faculty, and Staff at SJSU}

The number of students, faculty, and staff who entered the Ecological Footprint Challenge was 2,739 , or approximately $8 \%$ of SJSU students, faculty, and staff (Table 4). The average overall baseline footprint of all participants was 173.11 acres. If everyone on the planet had this footprint, 4.46 Earths would be needed to sustainably provide the resources for such a demand (Table 5). The lowest reported footprint was 0.4 Earths, whereas the highest reported footprint was 13.65 Earths. Ecological footprint quiz answer percentages are provided in Appendix D.

Out of the total baseline study population, 2,343 participants were students, which was $7.5 \%$ of the student body (Table 4 ). The average student footprint was 173.77 acres. If everyone on the planet had this footprint, 4.48 Earths would be needed to sustainably provide the required resources (Table 5). Faculty accounted for 132 participants during baseline data collection, which was $6.7 \%$ of the total faculty (Table 4 ). The average faculty footprint was 154.84 acres. If everyone on the planet had this footprint, 3.99 Earths would be needed to sustainably provide the required resources (Table 5). Staff accounted for 264 participants during baseline data collection, which was $4.8 \%$ of the total campus staff (Table 4). The average staff footprint was 176.40 acres. If everyone on the planet had this footprint, 4.55 Earths would be needed to provide the required resources in a sustainable manner (Table 5). 
Table 4

Ecological Footprint Challenge Participants

\begin{tabular}{|c|c|c|c|c|}
\hline Group & $\begin{array}{c}\text { People } \\
\text { Entering } \\
\text { Footprint } \\
\text { Challenge Data } \\
\text { in October } \\
2009\end{array}$ & $\begin{array}{l}\text { Percentage of } \\
\text { Total Campus } \\
\text { Population for } \\
\text { Baseline }\end{array}$ & $\begin{array}{c}\text { People } \\
\text { Re-entering } \\
\text { Footprint } \\
\text { Challenge } \\
\text { Data in April } \\
2010\end{array}$ & $\begin{array}{c}\text { Percentage of } \\
\text { Original Participants } \\
\text { Re-entering } \\
\text { Footprint Data }\end{array}$ \\
\hline $\begin{array}{c}\text { Student } \\
N=31,280^{*}\end{array}$ & 2,343 & $7.5 \%$ & 573 & $24.5 \%$ \\
\hline $\begin{array}{c}\text { Faculty } \\
N=1,976^{* *}\end{array}$ & 132 & $6.7 \%$ & 51 & $38.6 \%$ \\
\hline $\begin{array}{c}\text { Staff } \\
N=3,538 * * *\end{array}$ & 264 & $7.5 \%$ & 115 & $43.6 \%$ \\
\hline $\begin{array}{l}\text { All Participants } \\
\qquad N=36,794\end{array}$ & 2,739 & $7.4 \%$ & 738 & $26.9 \%$ \\
\hline
\end{tabular}

Note.

* = Data source is the SJSU Office of Institutional Research Fall 2009 Student

Characteristics (http://www.oir.sjsu.edu/Students/QuickFacts/20102QuickFacts.pdf)

$* *$ = Data source is the SJSU Office of Institutional Research Fall 2009 Faculty

Characteristics http://www.oir.sjsu.edu/Faculty/quickfacts/2009.pdf

*** = Data source is the February 2009 SJSU Human Resources Department 2008/2009

Annual Report (http://www.sjsu.edu/hrar/0809_ar/pics/Demographics.pdf)

Table 5

Ecological Footprint Baseline Results

\begin{tabular}{ccccc}
\hline & Earths & Standard Deviation & Acres & \% of U.S. Average* \\
\hline Students & 4.48 & 1.28 & 173.77 & 71 \\
Faculty & 3.99 & 1.24 & 154.84 & 63 \\
Staff & 4.55 & 1.21 & 176.40 & 72 \\
\hline ALL & 4.46 & 1.28 & 173.11 & 70 \\
\hline
\end{tabular}

Note. The U.S. Average Footprint is 6.35 Earths or 246 acres. 
The baseline footprints of students and staff were very similar, with the average footprint of students being 2.63 acres less than the average staff footprint. In addition, the baseline footprint of faculty was $11 \%$ less than the average student footprint and $12 \%$ less than the average staff footprint. The standard deviation of the baseline ecological footprints for all three subgroups were between 1.21 and 1.28 (Table 5). This standard deviation was relatively large, as it was about $29 \%$ of the total footprint. In addition, analysis with the K-S test determined that the distribution of all ecological footprints, as well as the subgroups of students, faculty, and staff, was not normally distributed. The frequency of footprints was rounded to the nearest quarter footprint and presented graphically in Figures 8 through 11. 


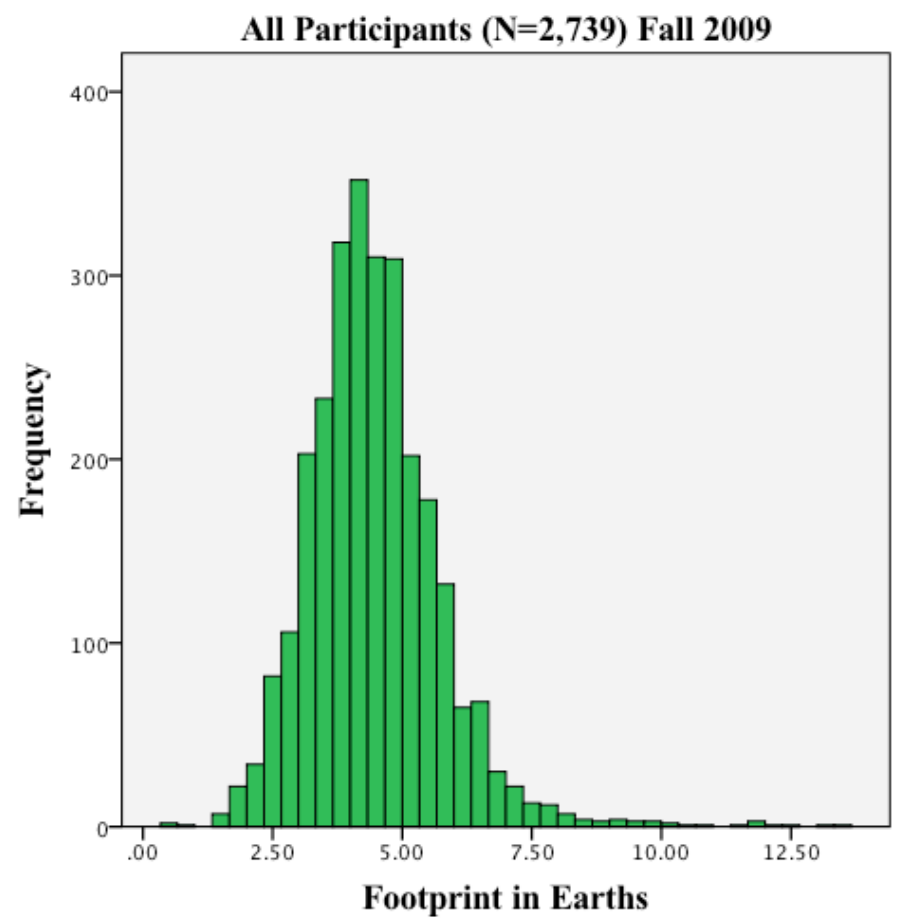

Figure 8. Ecological Footprint Baseline Distribution - All Participants.

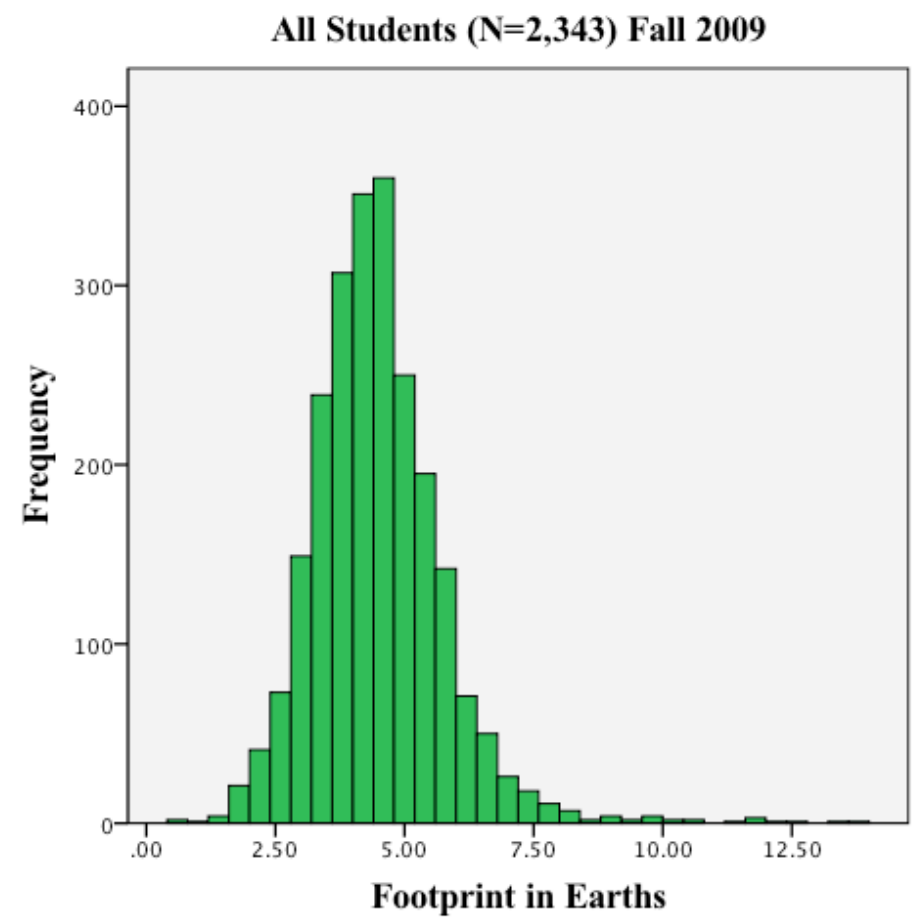

Figure 9. Ecological Footprint Baseline Distribution - Students. 


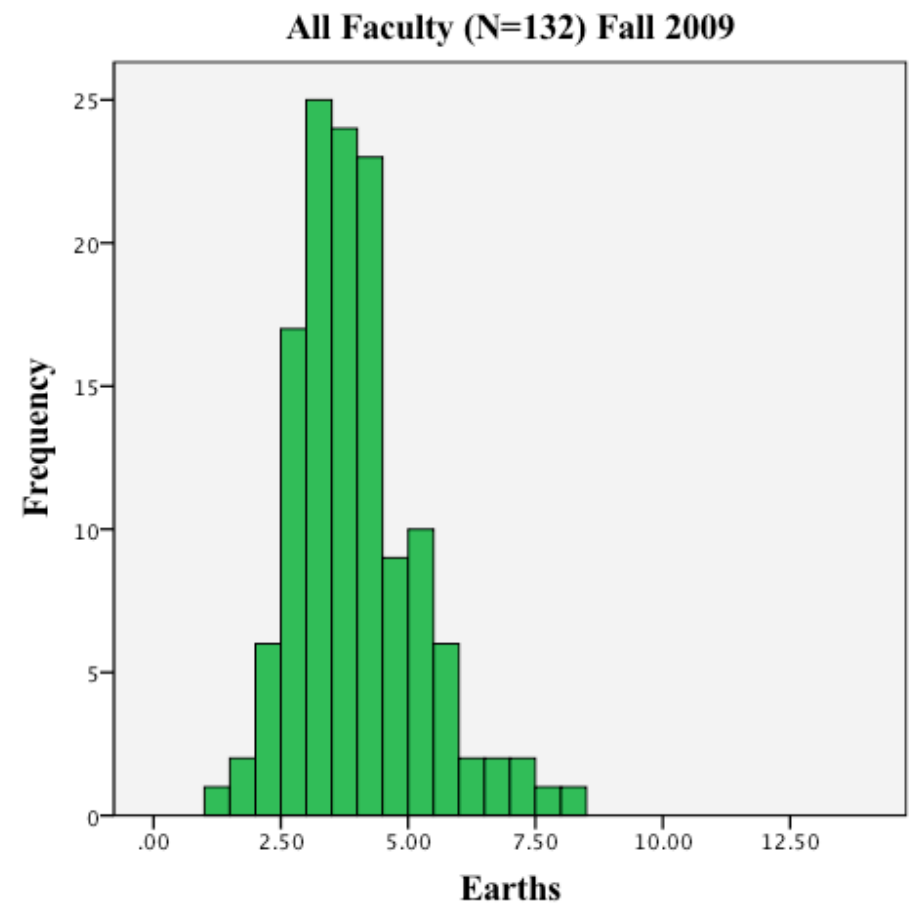

Figure 10. Ecological Footprint Baseline Distribution - Faculty.

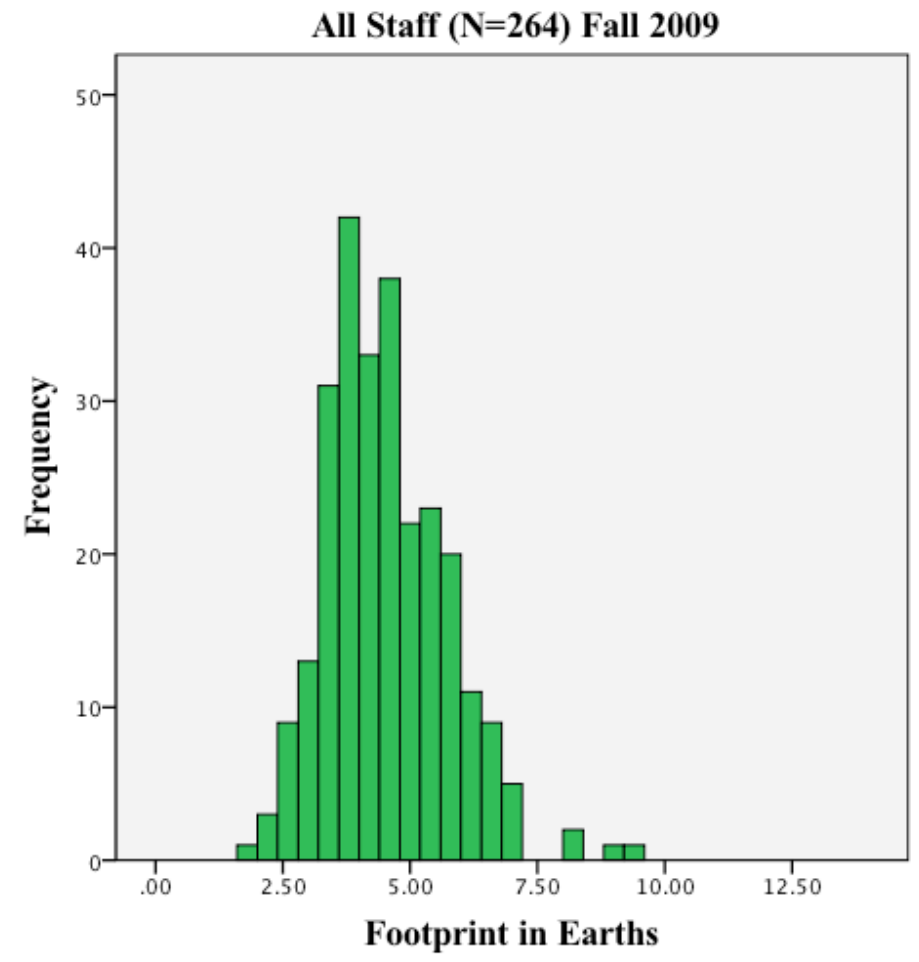

Figure 11. Ecological Footprint Baseline Distribution - Staff. 
In 2009, the estimated ecological footprint of an average American was 6.35 Earths (Center for Sustainable Economy). The baseline 2,739 participants in this study had a footprint that was $30 \%$ lower than the national average, at 4.46 Earths. For comparison, the average ecological footprint result for this study was similar to the ecological footprint of the average European (4.7 Earths) (Global Footprint Network, 2010). However, the average footprint of individuals surveyed at SJSU was still far from sustainable.

\section{Change in Ecological Footprint During the Ecological Footprint Challenge}

In the spring of 2010, 739 participants out of the original 2,739 returned to the ecological footprint quiz website to re-enter their footprint data approximately seven months after taking the initial footprint quiz. This was $27 \%$ of the original participant pool. Individuals that entered their footprint data in Fall 2009 but did not re-enter their data again in spring 2010 were not included in the following calculations. The average reported ecological footprints of the challenge participants reduced by $10.3 \%$, meeting the goal of a $10 \%$ reduction (Figure 12). Table 6 shows the baseline footprint, final footprint, average change in footprint, and p-value for these participants.

As shown in Figures 13-16, the average reported ecological footprint of students, faculty, and staff reduced from the baseline, in October 2009, to the final footprint, in April 2010. The footprint reductions ranged from $8.1 \%$ reduction for staff to $11 \%$ reduction for students. The $p$-values $(p)$ ranged from $p<.001$ to $p=.001$. Since the $p$-values were less than alpha (.05) the change in footprint was significant. These findings match the trends found in the studies by Ryu and Brody (2006) and Cordero et 
al. (2008). The greatest footprint reduction was seen in the student group, which reduced its footprint by 0.47 Earths.

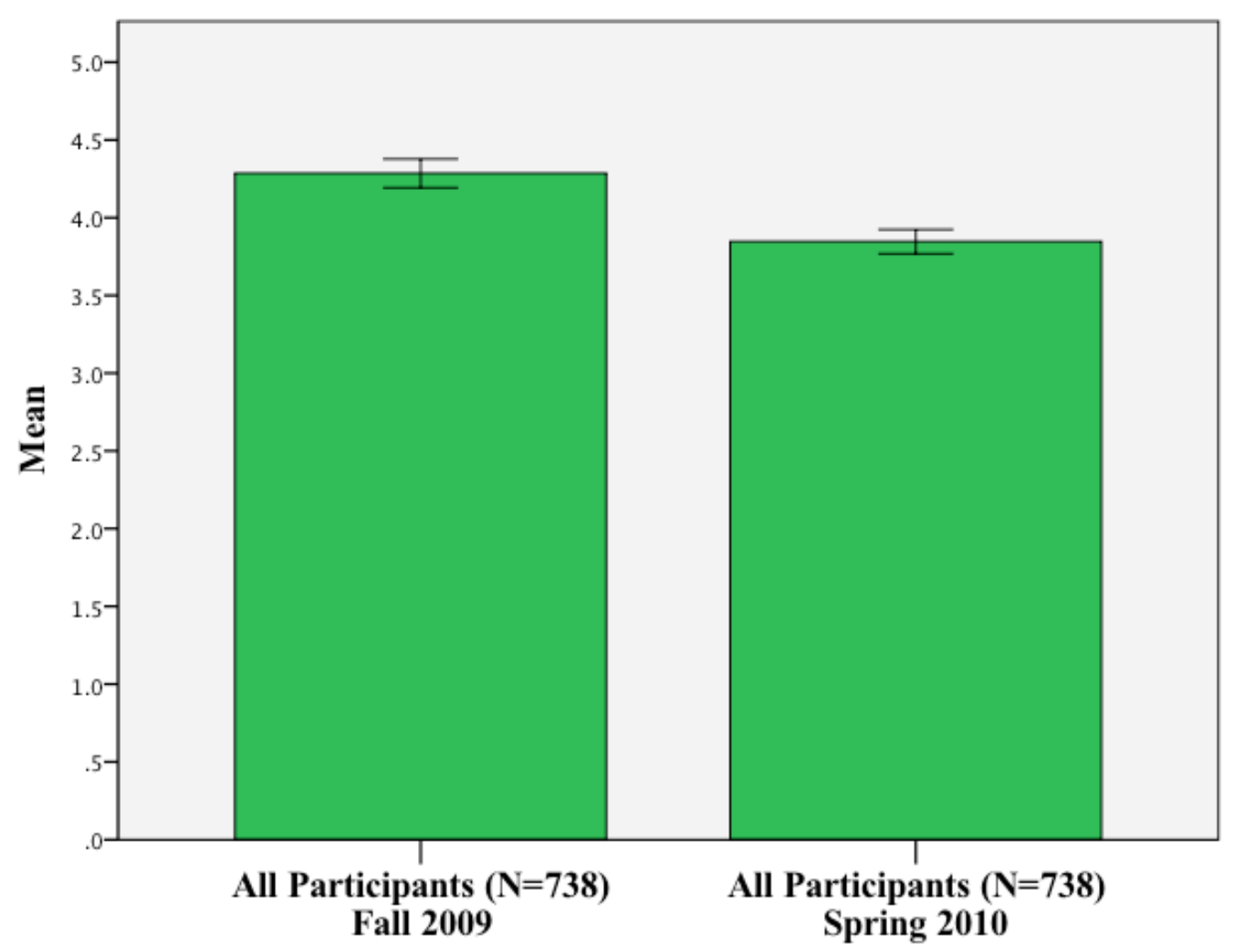

Error bars: $95 \%$ Confidence Interval

Figure 12. Change in Average Ecological Footprint - All Returning Participants. 


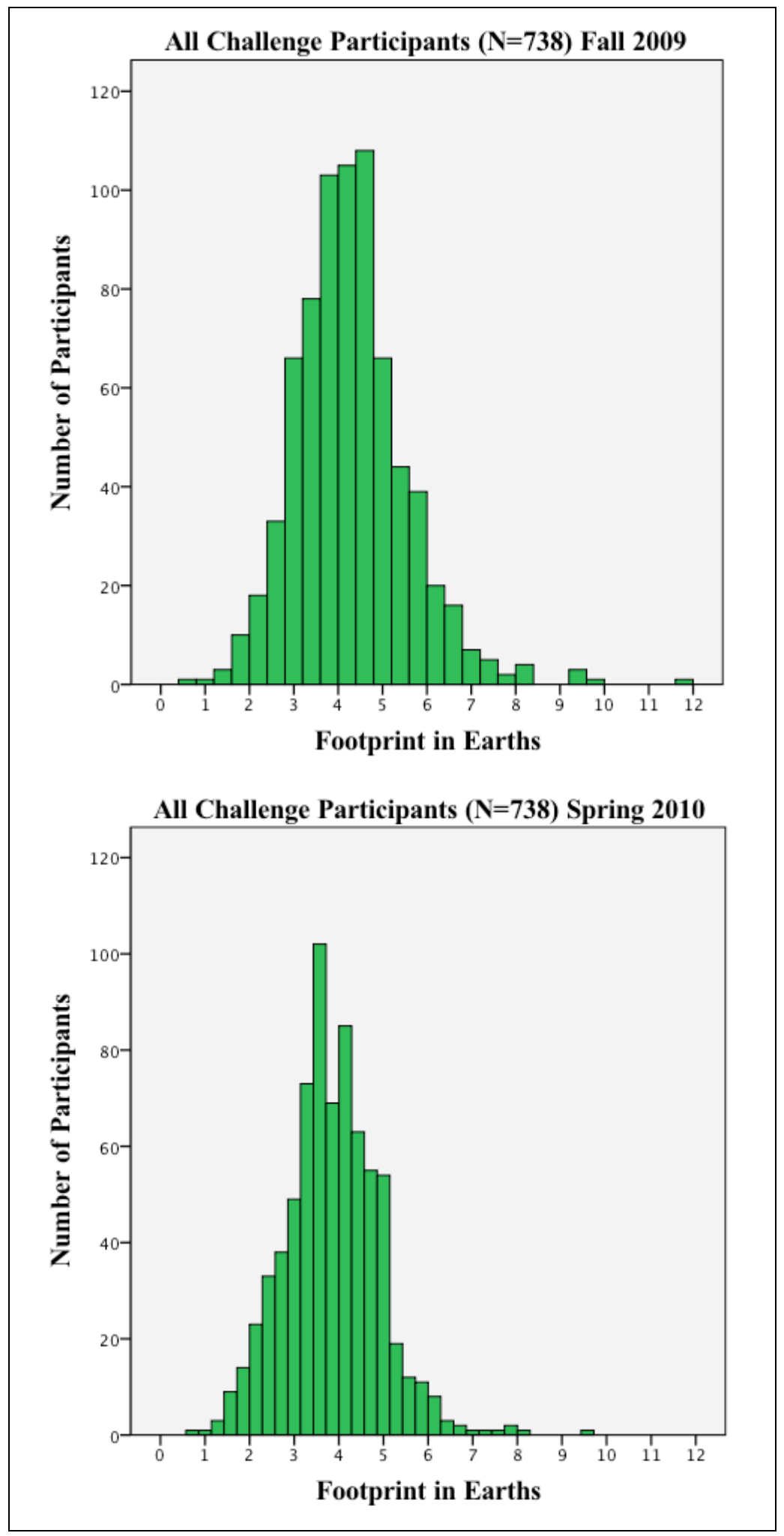

Figure 13. EF Distribution - All Participants: Fall 2009 versus Spring 2010. 


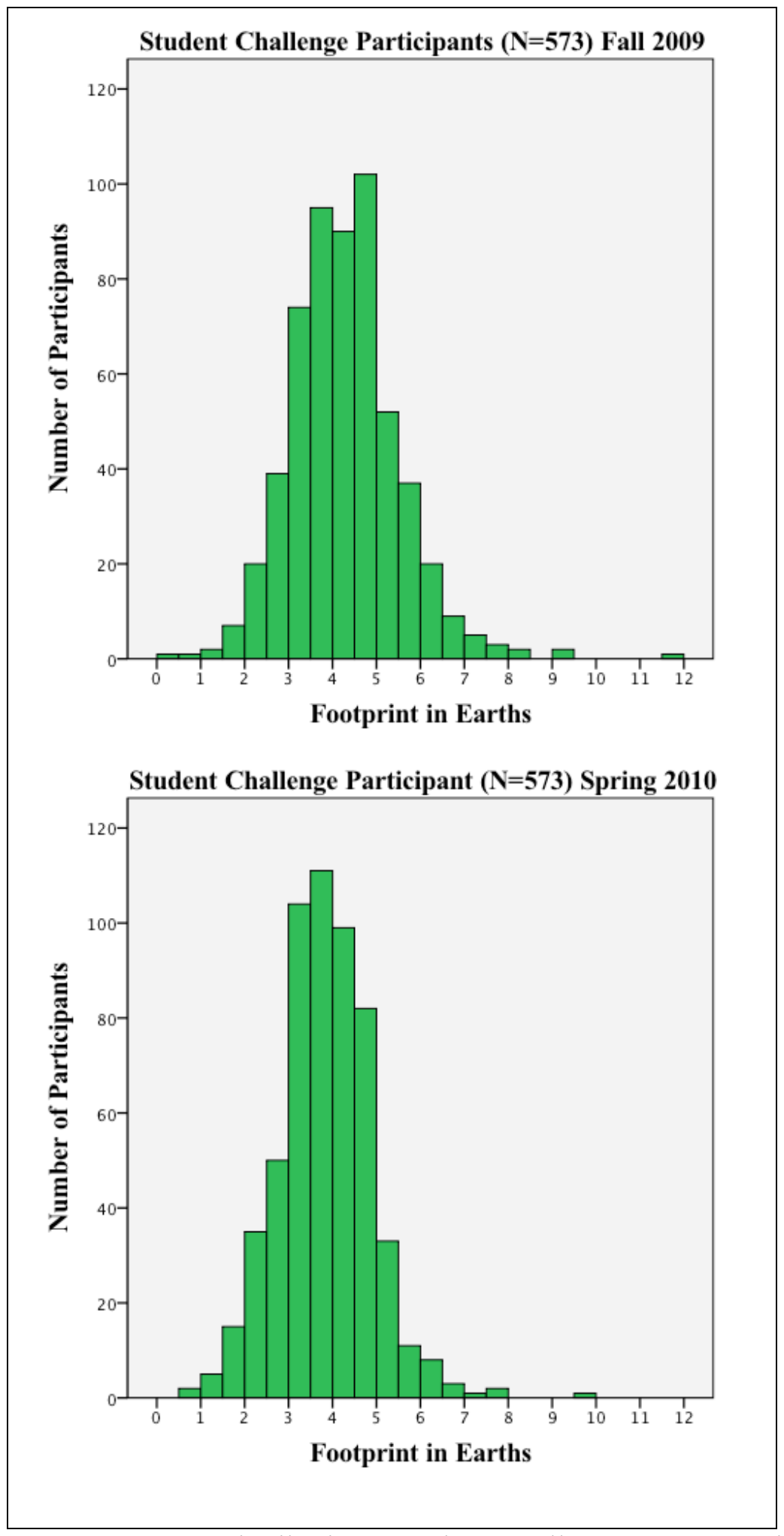

Figure 14. EF Distribution - Students: Fall 2009 versus Spring 2010. 


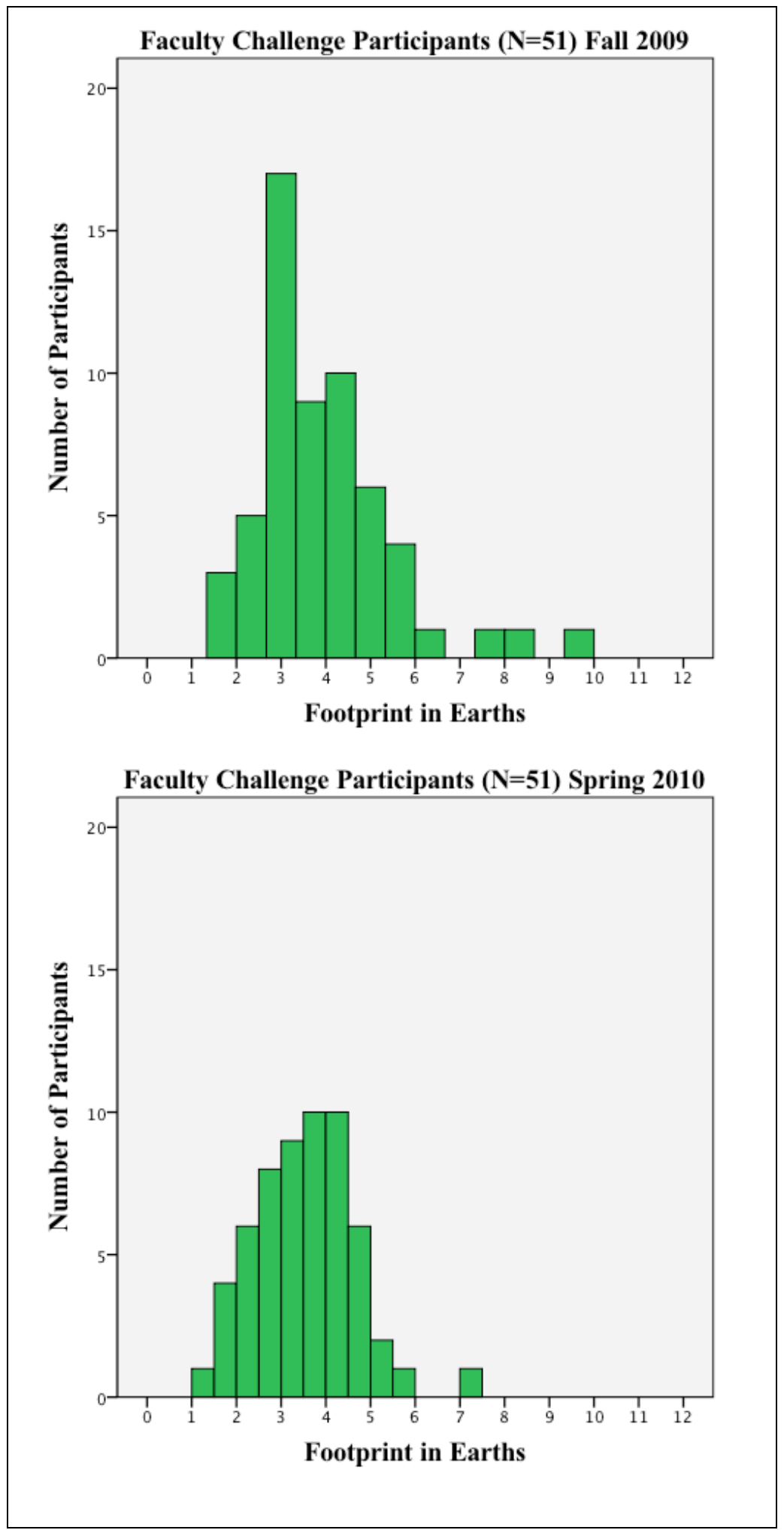

Figure 15. EF Distribution - Faculty: Fall 2009 versus Spring 2010. 


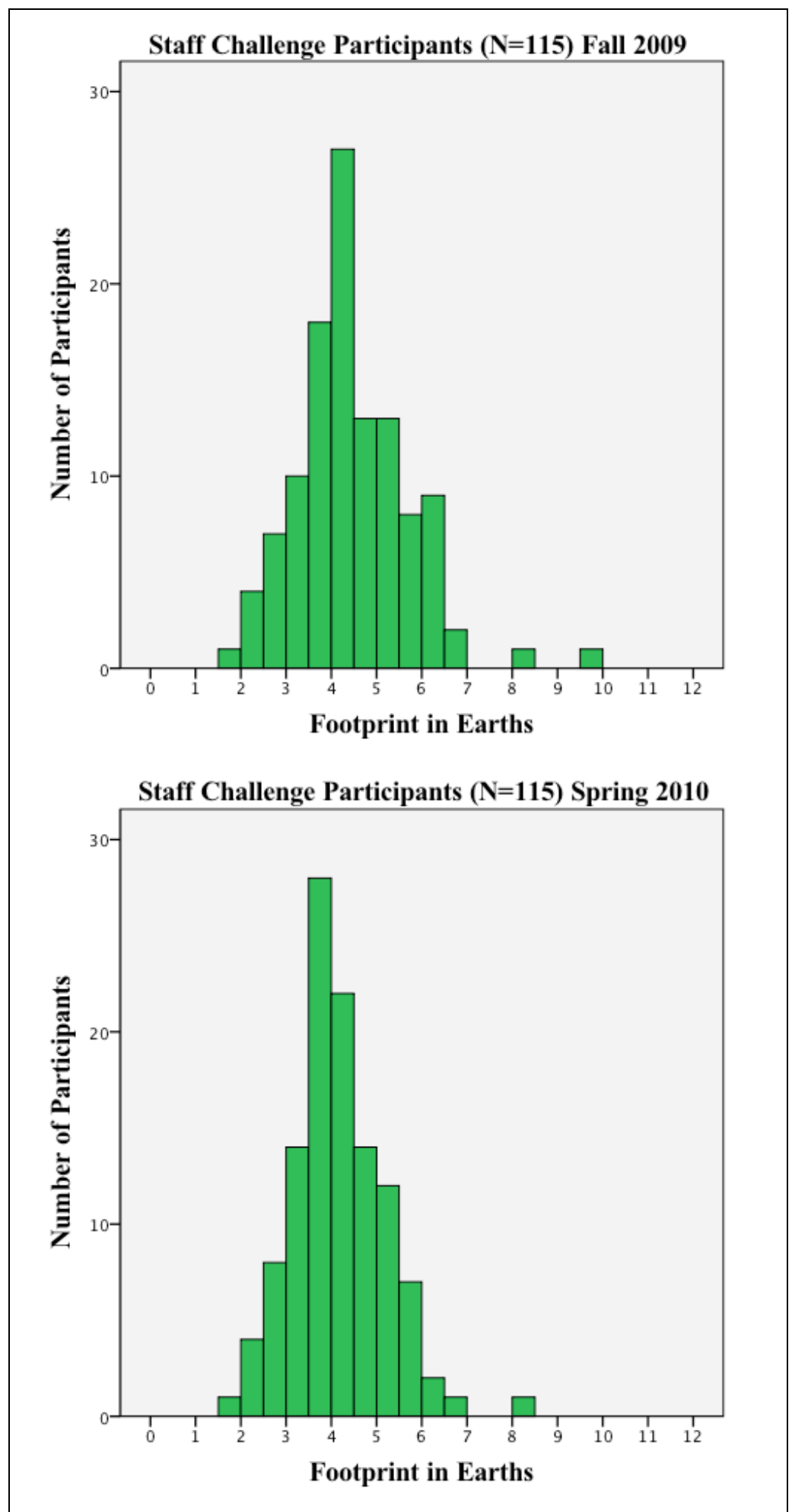

Figure 16. EF Distribution - Staff: Fall 2009 versus Spring 2010. 
Table 6

Change in Ecological Footprints for Returning Participants

\begin{tabular}{ccccccc}
\hline & $N$ & $\begin{array}{c}\text { Oct. 2009 } \\
\text { Footprint } \\
\text { (Earths) }\end{array}$ & $\begin{array}{c}\text { April } \\
2010 \\
\text { Footprint } \\
\text { (Earths) }\end{array}$ & $\begin{array}{c}\text { Average } \\
\text { Change } \\
\text { (Earths) }\end{array}$ & $\begin{array}{c}\text { Average } \\
\text { Footprint } \\
\text { Reduction }\end{array}$ & $p$ \\
\hline Student & 573 & 4.29 & 3.82 & -0.47 & $11.0 \%$ & .000 \\
Faculty & 51 & 3.79 & 3.45 & -0.34 & $9.00 \%$ & .001 \\
Staff & 115 & 4.51 & 4.14 & -0.36 & $8.10 \%$ & .001 \\
\hline ALL & 738 & 4.29 & 3.85 & -0.44 & $10.3 \%$ & .000 \\
\hline
\end{tabular}

The categories of the greatest and least ecological footprint reductions. Each

of the ecological footprint quiz questions corresponded to a footprint category. The footprint quiz questions and results can be seen organized by category in Appendix E. Overall, the goods and services footprint reduced the most at $14 \%$, followed by a $13 \%$ reduction in housing footprint, and a $10 \%$ reduction in food footprint. The category with the least reduction overall was the carbon footprint (Table 7). Each of the footprint subcategories were normally distributed 
Table 7

Change in Ecological Footprint by Category

\begin{tabular}{ccccccccc}
\hline & \multicolumn{2}{c}{ Carbon EF } & \multicolumn{2}{c}{ Food EF } & \multicolumn{2}{c}{ Housing EF } & \multicolumn{2}{c}{ Goods and } \\
& Change & $p$ & Change & $p$ & Change & $p$ & Change & $p$ \\
\hline Student & $-6 \%$ & .000 & $-11 \%$ & .000 & $-13 \%$ & .000 & $-16 \%$ & .000 \\
Faculty & $-7 \%$ & .016 & $-10 \%$ & .000 & $-12 \%$ & .007 & $-1 \%$ & .412 \\
Staff & $-2 \%$ & .413 & $-7 \%$ & .006 & $-11 \%$ & .000 & $-9 \%$ & .534 \\
\hline ALL & $-6 \%$ & .000 & $-10 \%$ & .000 & $-13 \%$ & .000 & $-14 \%$ & .000 \\
$N=738$ & & & & & & & &
\end{tabular}

Students reduced their footprint the most in the goods and services category, at a $16 \%$ reduction, whereas their category with the least reduction was the carbon footprint, at a $6 \%$ reduction. In contrast, the smallest change in the faculty footprint was in Goods and Services, at a $1 \%$ reduction, and the greatest reduction was the housing footprint, at a $12 \%$ reduction. Staff housing footprint also saw the greatest change, at an $11 \%$

reduction, while the smallest change in footprint was seen in the carbon footprint, at a $2 \%$ reduction. It is notable to point out that student, faculty, and staff average footprints reduced in every category. All changes in footprint subcategory showed a significant reduction except for faculty goods and services ( $1 \%$ reduction), staff carbon $(2 \%$ reduction), and staff goods and services ( $9 \%$ reduction). This is in contrast to the Ryu and Brody (2006) study where none of the subcategories showed a significant reduction.

While the percentage of footprint for each category gives a broad picture of the different things contributing to the footprint of the average person at SJSU, examining 
each quiz answer individually provides more detailed information. It is in the answers to these questions that the amount of people engaging in a pro-environmental activity can be identified.

Change observed in all participants' ecological footprint quiz answers. By examining the change in answers provided to the ecological footprint quiz we can explore the biggest changes participants made to their lifestyles within the categories listed on Table 7. The quiz answers were only examined for participants who completed both phases of the data collection. However, the quiz answers from the returning 738 people were still very similar to those of the larger baseline group of 2,737. In all but a few cases, the quiz answers of the subgroup of 738 participants were within $10 \%$ of the group of 2,737 . The main differences were that the returning 738 participants reported recycling paper more often, filling less garbage cans, having bigger gardens, and traveling more miles each year by car, bus, train, and plane.

The change was analyzed using nonparametric tests since the data was not normally distributed. For the ecological footprint, the biggest change in proenvironmental behavior for all participants from the baseline measurement to the end of the challenge was a reported significant reduction of miles travelled by air and rail by $20 \%$ and $15 \%$ respectively. However, a significant $170 \%$ increase in miles travelled by bus was also seen.

In the food footprint category $12.2 \%$ more people reported eating organic at least sometimes. The smallest change observed was a $2.9 \%$ increase in vegetarian/vegan diets. The change to both answers was significant. For the housing footprint, the largest 
significant change was a $13 \%$ increase in participants whose household furnishings were made from recycled materials. In contrast, no change was seen in the amount of people who had rainwater catchment systems. In the goods and services footprint category, the biggest significant difference observed was a $7.8 \%$ increase in people recycling their electronic waste. The smallest change was a $1.1 \%$ increase in participants who recycled a fair amount or almost all of their plastics (Appendix E).

Change observed in student ecological footprint quiz answers. One trend observed was that students made a greater change to their habits, than to areas where a large monetary investment was required. Students chose to travel more miles by bus ( $215 \%$ increase), while decreasing their auto, rail, and air miles by roughly $20 \%$ each. All of these changes were significant except for the decrease in rail miles. Rather than buying more expensive energy or water saving features in their homes, students made more changes to their water saving habits. In general, much of the student body does not own their own homes and would not be able to make investments in their homes. The greatest change in habits was an increase in the use of power strips to turn off stand-by lights in computers, etc. and unplugging appliances while not in use. These were measured to be significant increases of $10.5 \%$ and $11 \%$ respectively.

In addition, a significant change of $11.4 \%$ more students reported looking for and fixing water leaks regularly, and $10 \%$ more reported minimizing shower time and toilet flushing. Students significantly increased their use of water saving fixture technology by $12.8 \%$. In the area of food footprint, $18 \%$ more students reported choosing to shop at 
natural food markets and farmers markets at least some of the time and $13.3 \%$ more students ate organic foods at least sometimes $(p<.001)$.

In some areas of the ecological footprint little change was observed. For example, only $1 \%$ more students reported driving a hybrid or compact car. There was also very little change seen in students habits to turn off lights when they leave the room, as the percentage of students who do this was already at $99 \%$. Areas where lifestyle choices showed little change were student recycling of paper, aluminum, glass, and plastics. An increase in recycling of less than $2.8 \%$ was observed for all of the above. Only $1.2 \%$ more students reported buying carbon offsets, a behavior that only $2.3 \%$ of students reported doing. Purchasing carbon offsets involves paying a third party to plant trees, generate renewable energy, or conserve energy to offset carbon emissions. This may be cost prohibitive to students. When it came to saving water less than $2.5 \%$ more students installed rainwater catchment systems, grey water recycling systems, or instant water heaters on sinks at the end of the school year (Appendix F).

\section{Change observed in faculty ecological footprint quiz answers. A few}

interesting results in the area of carbon footprint were that $7.7 \%$ less faculty reported driving sports utility vehicles (SUVs) or trucks, and $11.5 \%$ more faculty carpooled ( $p=$ .008). Reported auto and air miles decreased while bus and rail miles travelled increased. Use of compact fluorescent light (CFL) bulbs increased by 1.9\%, resulting in 100\% of faculty reporting that they use CFL light bulbs in their homes. In addition, $15.4 \%$ more faculty reported minimizing the use of power equipment when landscaping $(p=.046)$, and $11.5 \%$ more faculty reported using insulating blinds $(p=.052)$. 
In the area of food footprint $13.5 \%$ more faculty reported having a vegetable garden, and $5.8 \%$ more faculty ate organic food most of the time, both significant changes. Under the housing footprint category $13.5 \%$ more faculty reported that a fair amount of their home furnishings were made from recycled materials $(p=.004)$ and $15.4 \%$ more faculty reported having drought tolerant landscaping $(p=.046)$. In the area of goods and services there were no significant changes.

There were numerous reported areas where faculty participants did not make large reductions to their ecological footprint. These items included $1.9 \%$ less faculty reporting driving compact cars, $1.9 \%$ less faculty using energy efficient appliances, $3.8 \%$ less faculty having extra insulation, $1.9 \%$ less faculty turning off lights when leaving the room, and 3.8\% less faculty shopping at natural food markets (stores with more local organic options). In addition, $2 \%$ fewer faculty reported having low flow showerheads, instant water heaters, or rainwater catchment systems at the end of the challenge. Also, little self-reported change was seen in the percentage of faculty composting, minimizing shower times, washing cars, hosing down their driveways, or running their clothes or dishwashers only when full (Appendix G).

Change observed in staff ecological footprint quiz answers. While other categories saw an increase in the number of bus miles traveled, staff reported decreased bus miles travelled by $14.7 \%(p=.051)$. In contrast, staff reported a $17.6 \%$ increase in the amount of miles travelled by rail $(p=.065)$. The greatest reported behavior change was a $12.3 \%$ increase in staff using water saving fixtures $(p=.016)$ and $12.3 \%$ more staff unplugging appliances when not in use $(p=.013)$. 
As for other aspects of the footprint, 12.3\% less staff participants categorized their diet type as carnivore or "top of the food chain" at the end of the challenge period $(p=.001)$. Furthermore, $9.6 \%$ more faculty ate organic foods sometimes or most of the time $(p=.006)$. Staff reduced their housing footprints with more than $10 \%$ of staff making significant changes in four water saving technology categories. Reported change included: $11.4 \%$ more staff reporting using low flow toilets, $10.5 \%$ more staff having low flow shower heads/faucets, $16.7 \%$ more staff minimizing shower time, and $14.9 \%$ more staff fixing leaks. Though no changes in the category of goods and services were significant, $12.3 \%$ more staff reported buying natural clothing or renewable paper products and 5.3\% more staff reported recycled glass almost all of the time.

Little change $(<3 \%$ change) was reported in the vehicles staff drove, the use of energy efficient appliances, installation of solar panels, use of storm doors and windows, moving to rural areas, becoming vegan, or becoming vegetarian. In addition, few staff reported installing instant water heaters, rainwater catchment, or grey water recycling systems. While no change was observed, over $90 \%$ of staff reported continuing to run the dishwasher or washing machine when full. The recycling habits of staff did not vary more than 5\%, with the exception of glass recycling (Appendix $\mathrm{H}$ ).

\section{Other trends and correlations between behaviors and ecological footprint}

change. Stepwise linear regression analysis was run to analyze the correlation between all footprint quiz answers and the change in footprint to reveal any additional underlying trends of those participants who reduced their footprint the most. All the quiz questions were compared to the overall change in footprint measured as Earths. The importance 
factor was expressed in terms of percent variance explained by the variable. None of the variables had an importance factor of over $10 \%$. Since the importance factor was so low, no further analysis was performed on the full set of variables.

Instead, stepwise linear regression was re-run only using the variables that were significant. As in the study by Ryu and Brody (2006), participants with a large baseline footprint had a greater overall decrease in footprint than those that were already at a low footprint. Participants that started with a larger footprint could make easy changes to reduce their footprint since it was initially inflated. As shown in Table 8, the variables which were significant $(p<.05)$ were: never eating organic, eating three large meals per day, having a carnivore diet, having three garbage cans of trash per day, frequently replacing belongings, high auto miles travelled, living in a large house or ranch home, high air miles travelled, not minimizing shower time or toilet flushing, and driving a large vehicle (minivan, SUV, or large truck).

Other demographic information collected by the footprint quiz was also analyzed using a stepwise linear regression. These variables included living on campus, distance from zip code to campus, and weekly expenses. None of these demographic variables were determined to be significant to the change in ecological footprint. 
Table 8

Multiple Linear Regression Ecological Footprint Answers and Demographics - All Participants

\begin{tabular}{ccccccc}
\hline Source & $\begin{array}{c}\text { Sum of } \\
\text { Squares }\end{array}$ & $D f$ & $\begin{array}{c}\text { Mean } \\
\text { Square }\end{array}$ & $F$ & Sig. & Importance \\
\hline Eat Organic & 27.615 & 16 & 13.807 & 16.811 & .000 & .102 \\
Meal Frequency & 22.825 & 2 & 11.412 & 13.895 & .000 & .101 \\
Diet (Vegan - Carnivore) & 22.171 & 2 & 7.390 & 8.998 & .000 & .101 \\
Weekly Garbage Amount & 17.641 & 3 & 8.820 & 10.739 & .000 & .100 \\
Frequency of Replacing & 16.900 & 2 & 8.460 & 10.300 & .000 & .100 \\
Things & 15.993 & 2 & 15.993 & 19.472 & .000 & .100 \\
Auto Miles & 11.296 & 1 & 11.296 & 13.753 & .000 & .099 \\
Home Size & 11.092 & 1 & 11.092 & 13.504 & .000 & .099 \\
Vehicle Type & 9.763 & 1 & 9.763 & 11.887 & .001 & .099 \\
Air Miles & 4.038 & 1 & 4.038 & 4.916 & .027 & .098 \\
$\begin{array}{c}\text { Minimize Shower and } \\
\text { Flushing }\end{array}$ & & & & & & \\
\hline
\end{tabular}

\section{The Effect of Concurrent Educational Outreach on the Ecological Footprint}

Sign in sheets at the Sustainability Matters Lecture Series indicated a growing attendance rate. The most popular event was "Where Does Our Food Come From: Food, Farming, and SJSU" with 136 attendants. The least attended event was the first event, titled "Bike Sharing Programs, from Paris to San Jose," with 35 attendants. Table 4 provides a breakdown of event attendance, electronic mailing list signups, and the number of ecological footprint challenge participants attending. 
In addition to email addresses collected at these events, an electronic mailing list was formed from people taking the online ecological footprint quiz. During the first phase of the footprint challenge 2,665 participants signed up to receive emails from the sustainability team. The electronic mailing list grew as the year went on. People signed up for the electronic mailing list at the outreach events and heard about the email list through their friends and the website. At the end of the footprint challenge, participants who elected to receive emails were cross-referenced with their ecological footprint data. This data was analyzed to see if signing up for the electronic mailing list was correlated with a greater decrease in footprint.

\section{Footprint change in participants who signed up for the electronic mailing}

list. Out of the 738 participants who participated in the ecological footprint challenge (pre and post-test), 303 elected to be added to the electronic mailing list. Results showed that individuals who elected to sign up to receive more information via email, reduced their footprint by $7.2 \%$ while those opting out reduced their footprint by $6.3 \%$ (Figure 17). The $K-S$ test for distribution showed a $p$-value of less than .05 , therefore the data was not normally distributed. The parametric assumptions were not met and the nonparametric Mann-Whitney test was used. This test revealed that there was not a significant difference in footprint change $(p=.271)$ for people who joined the electronic mailing list (Table 9). 
Table 9

Mann-Whitney Test Statistics for Electronic Mailing List

Ecological Footprint Change in Earths

\begin{tabular}{cc}
\hline Mann-Whitney & 62182.500 \\
Wilcoxon W & 108238.500 \\
$\mathrm{Z}$ & -1.101 \\
Asymp. Sig. (2-tailed) & .271 \\
\hline
\end{tabular}

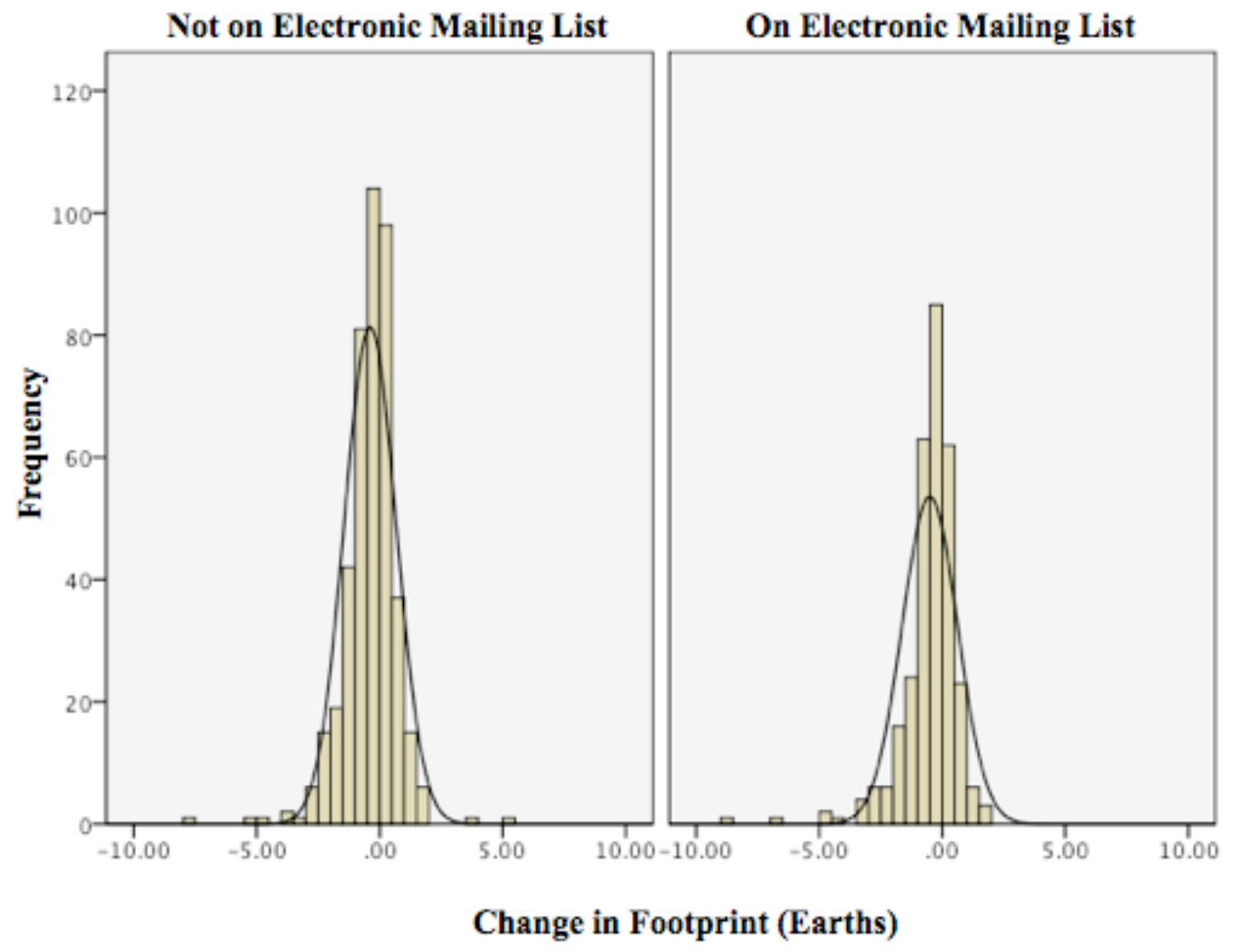

Figure 17. Footprint Distributions for Electronic Mailing List Members. 
Footprint change in participants who attended workshops. Out of the 738 participants who completed the ecological footprint challenge, 97 attended the Sustainability Matters Lecture Series workshops at least once, while 641 did not attend a workshop. The average change in footprint was -0.57 Earths for those who attended lectures, and -0.42 Earths for those who did not (Figure 18). In other words, those who attended our workshops reduced their footprint by $13.3 \%$ while those who did not attend, reduced their footprint by $6.1 \%$. The $K-S$ test was used to test for normality. Since the $p$-value in the $K-S$ test was less than .05 the data was not normally distributed and did not meet the parametric assumptions needed to run the $t$-test. Therefore, the Mann-Whitney Test was used to test for significance (Table 10). The $p$-value was .097 , slightly exceeding the standard significance level of .05. In other words this change was significant within a $90 \%$ confidence interval instead of the standard $95 \%$. This result corresponds to the findings of Ryu and Brody (2006) that found that attending a graduate level class on sustainability resulted in a significant decrease in footprint.

Table 10

Mann-Whitney Test Statistics for Workshop Attendees

\begin{tabular}{cc}
\hline & Ecological Footprint Change in Earths \\
\hline Mann-Whitney & 27661.500 \\
Wilcoxon W & 32414.500 \\
Z & -1.662 \\
Asymp. Sig. (2-tailed) & .097 \\
\hline
\end{tabular}




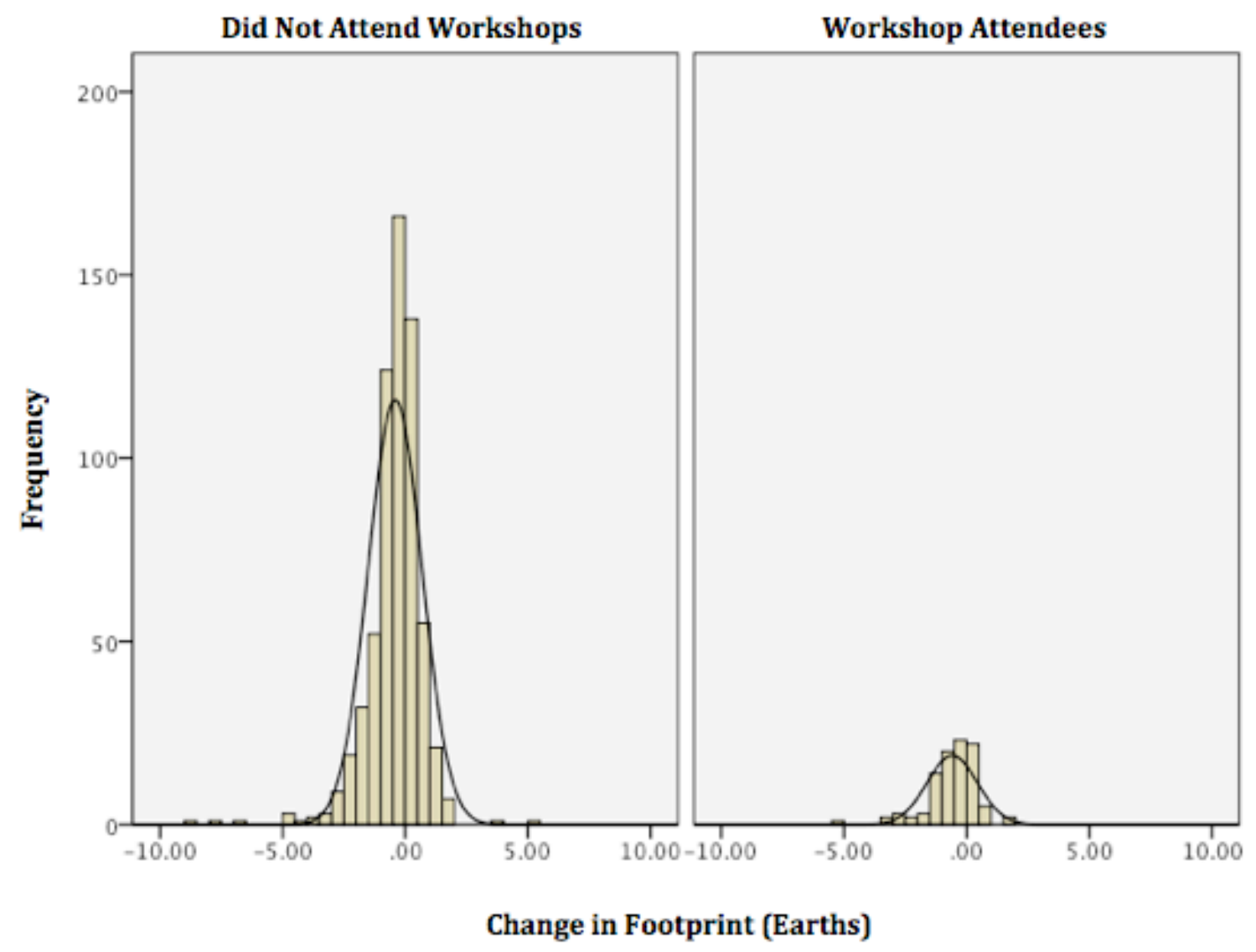

Figure 18. Footprint Distributions for Workshop Attendees.

\section{Reasons Participants Did or Did Not Change Behaviors}

Focus group with participants of average, unchanged ecological footprints.

A focus group was conducted with participants whose ecological footprint remained unchanged or increased during the footprint challenge period (Appendix C). The goal of this focus group was to explore further why these participants did not make a reduction to their ecological footprints. In addition, this focus group was used to check in with participants 1.5 years after the footprint challenge to gauge its medium to long-term impact. 
An email was sent to all participants that completed the challenge with an unchanged or increased ecological footprint. The volunteers were three students and three staff. The three students included, a nursing student, a dietician, and environmental studies student. The changes in footprint for this group ranged from a decrease of 0.03 Earths to an increase of 0.81 Earths. While this group overall did not show a reduction in footprint, their baseline footprint was about $85 \%$ of the participant baseline average $(N=738)$, at 3.64 Earths. In addition, the April 2010 footprint for the group was 3.95 Earths, slightly above the participant final average $(N=738)$ of 3.89 Earths.

Level of knowledge before the footprint quiz. Three out of six of the focus group participants reported that before taking the quiz they lacked knowledge of the full range of factors that impact a person's ecological footprint. Some reported unfamiliarity with the terms used on the ecological footprint quiz, while others had never before taken the quiz. This indicates an absence of system knowledge and action knowledge as defined by Frick et al. (2004). As reported by one of the participants, "What I found in taking the survey is that there are also things in which I am very ignorant, I don't have the language... even when filling it out I don't know what this or that option means to me." A majority of the participants expressed a desire to lower their footprint, but did not really know how.

The impact of the ecological footprint quiz website. Even participants that did not show a large reduction in footprint over the course of the challenge reported feeling an impact from taking the quiz. Three out of six in the focus group reported being shocked at the size of their ecological footprint. Others noted that the quiz showed them many 
specific areas where they could increase the sustainability of their lifestyle. One person commented, "I liked how it gave you the score at the end... it really made you think that you really need to improve." Participants reported that seeing their calculated footprint was an impetus to make a change. The same reaction was reported in the study by Cordero et al. (2008) which found that over $50 \%$ of students were shocked or surprised to see how large their footprint was.

Not only did the quiz provide a shock factor of sorts, participants also noticed that it provided information on how one could reduce their footprint. As in Cordero et al. (2008), participants discovered some easy actions they could take to reduce their footprint. On this topic, one comment was "I did see a few tips on the side, 'oh this is what you can do to reduce emissions,' and I looked to the biggest percent that my footprint went to and focused on that... It is something you can think back on when you are doing your everyday actions." On the topic of learning from the quiz questions themselves one person said, "Because you take the quiz, you learn about terminology, and you learn how to change it. So next year you take the quiz again, you have the tools to improve yourself." These comments showed that people did explore the informational and interactive parts of the online quiz. Participants reported remembering what they learned through the action of taking the quiz. As reported by the focus group, participants increased their action-knowledge and effectiveness knowledge by taking the quiz, an essential part of pro-environmental behavior change according to Frick et al. (2004). 
Barriers to footprint reduction. Though these participants reported that the footprint quiz had an impact on them, they did not show a reduction in footprint. While some participants reported that they did not know how to reduce their footprint or find more information, others reported problems with motivation. One person stated "We live in a big house, just my husband and I... because it is comfortable... when you have the chance to live more comfortably you do... when you are living around other people that live comfortable it is like going against the stream, it's hard." It was a common theme throughout the group that their spouse or roommates were reluctant to make changes to their lifestyles. As many lived on shared income and did not make all the financial decisions for their homes, it was harder to make changes. This fits the findings by McCarty and Shrum (2001) that individuals with a high external locus of control on an environmental issue would be less likely to make a behavior change.

When asked to create a ranked list of the top barriers to sustainable change, the items agreed upon by the group (most important first) were: lack of education, cost, comfort, fatigue, too busy, and lack of sustainable options provided by corporations. Cost as a barrier was mentioned specifically in reference to owning a home and buying organic/local foods. One participant stated "I knew right off the bat that my footprint wouldn't be reduced as much because I don't own my home, I rent a townhouse. I knew I was limited on what I could change there." One student reported that while budget was a constraint in some areas it was also an impetus in others: "As a student we have limited time and limited budget... The things that you can control are transportation and what 
you choose to eat... which is why I use VTA [Valley Transit Authority] every single day... I've only paid for gas three times this summer."

While a majority of the focus group reported that they would like more information about the ecological footprint of certain actions and products, most were quite knowledgeable about sustainability issues. An additional barrier to reduction in footprint for this group, in consideration of their ecological footprints, was that their footprints started at an average of 3.64 Earths. With footprints already 0.65 Earths lower than the starting SJSU average, further reductions meant incrementally increasing costs, decreasing perceived comfort, and being further outside the social norm. Their reported footprint in April 2010 rose to become equal with the average SJSU ecological footprint.

Focus group with participants that most reduced their ecological footprints.

A focus group was conducted with participants who reported a sizable decrease in their ecological footprint during the footprint challenge period (Appendix C). The goal of this focus group was to explore further what caused these participants to choose to make more pro-environmental choices in their lifestyles.

Emails were sent to all participants that completed the challenge with a reduced ecological footprint over the original data collection period inviting them to take part in a focus group. Of the focus group participants, three were students and two were staff. Of the three students one was in the business department, one in the animation department, and one was a retiree in the business department with a minor in environmental studies. The changes in footprint for this group ranged from a decrease of 1.74 Earths to a decrease of 0.13 Earths. The average baseline footprint for this focus group was above 
the SJSU average at 5.09 Earths and the final footprint was below the SJSU average at 3.92 Earths.

Level of knowledge before the footprint quiz. Participants generally were aware of some areas of the ecological footprint, but were lacking knowledge in other areas. Two out of five people had a background in environmental issues or had taken an environmental studies class. Two people reported that they were not aware of how great of an impact diet can have on the environment. On this topic one participant reported "... I had no idea what my food consumption was doing to things other than me. So learning that was an important one." The ecological footprint website provided information about how a diet high in meat and other conventionally farmed food makes a big impact. In addition participants stated that they did not know what their ecological footprint was previously, but thought it would be a good idea to learn more about it and "keep an eye on it." In addition, some said they needed more tools to determine which of their actions were good and which were bad for the environment.

The impact of the ecological footprint quiz website. The focus group with participants who greatly reduced their footprint reported having a very strong reaction to completing the footprint quiz and seeing the footprint results page. This topic sparked an intense conversation around the table. The first comment was "What I thought was most poignant about it was right at the end where it showed me how many worlds- I thought, ok, I better just start thinking about this." To this comment another participant agreed and a third stated "It was a very graphic way of realizing it." This points to the idea of visual impact and intergenerational equity as possible "hooks" to encourage further pro- 
environmental behavior. Even two years later the participants had a clear and vivid memory of the moment they saw their footprint. The fact that we only have one earth, and each person's footprint was well over one earth, was a trigger, as mentioned in the study by Cordero et al. (2008).

Others recalled that not only did the quiz produce a jarring result; it was informative about along the way. One person stated, "The quiz was a learning experience... I was taking a class at the time, and what I was learning became more real to me as I was taking the quiz." The focus group also pointed out that the footprint quiz shows you different options and you are able to see which changes might be easy to make. Thus, the quiz provided action-knowledge and effectiveness-knowledge as defined by Frick et al. (2004). Many, before taking the footprint quiz, thought their footprint was better than what it really was. The results showed the entire focus group panel that there were a lot of things in their life that could still be improved to live more sustainably.

Another common theme on what spurred people to take action was that if they were using the equivalent of multiple Earths; they are borrowing from future generations and other people around the world. Some were worried about "using up my kids worlds and their kids worlds. I'm using up future generations' [worlds]." Ensuring that there were resources for future generations was very important to participants, along with using resources in a sustainable way. Again, intergenerational equity is cited as a factor. In addition, participants reported reasons for change that correspond to a high internal locus of control, believing their actions now will help protect resources for future generations. 
Furthermore, the difference between the uses of resources per capita in the U.S. versus the developing world was a concern. One subject stated "I don't think the quiz presented it this way, but you know the 3 or 4 worlds that you're burning up is borrowed from other countries in the world that today isn't using them, but tomorrow will be."

Impetus to make a reduction in ecological footprint. When asked what spurred them to make a lifestyle change and reduce their footprint, two people reported that it was an environmental studies class or a climate change class that opened their eyes. This was also the case in the study by Ryu and Brody (2006), which used the ecological footprint to test the impacts of a sustainability related course. In addition, a majority of the focus group reported that financial issues were a driving factor. One person was planning a wedding, while the others were on a fixed income. In addition, sometimes a reduction in footprint just came along with a change in living situation. For example, one participant reported that her and her husband had "moved from South San Jose and bought a house in Willow Glen. So now our commute is 3 miles." Trying to be a better role model for their kids and in their community was also mentioned as being important.

Some participants reported that a strong impetus to save money during the recession of 2010 happened to align with choices to act more sustainably. As budgets tightened, people looked to areas where they could save money. Gallup poll results from 2009 showed that of those taking steps to improve efficiency in their homes, $70 \%$ reported doing it for economic reasons, and 26\% for environmental reasons (Gallup, 2009a). The footprint challenge results mirrored national trends. 
One particular comment was interesting to the evaluation impact of the ecological footprint challenge to foster pro-environmental behavior. One participant said, "Knowing I was going to be assessed again, I was like, I should be better at this. I better improve!" In this case, the participant was motivated to improve because of the challenge and knowledge that they would be tested again. In addition, this statement conveys a sense of guilt about the size the person's ecological footprint. At the same time, the person expressed that they had control over their ecological footprint and would be able to improve, indicating a high internal locus of control.

When asked what they thought helped overcome barriers to sustainable change, participants listed education, saving money, future generations, being healthier/feeling better, and public policy that addresses environmental issues as the top five factors. On the topic of public policy, focus group participants related the concept that some environmental issues could not be completely addressed on the individual level and policy, like plastic bag bans, are needed to make real impacts. These responses aligned with the unchanged footprint group and were a common theme throughout the focus groups as shown side-by-side on Table 11. Common themes on this aspect of behavior change emerged throughout the focus groups, but each group framed these themes differently. 
Table 11

Common Themes from Focus Groups

\begin{tabular}{cc}
\hline $\begin{array}{c}\text { Barriers to Change } \\
\text { (Cited by Unchanged Group) }\end{array}$ & $\begin{array}{c}\text { Incentives to Change } \\
\text { (Cited by Greatest Reduction Group) }\end{array}$ \\
\hline Lack of Education & Increased Education \\
Cost & Saving Money \\
Comfort/Too Busy & Healthier/Feel Better \\
Not Socially Acceptable & Sharing with Friends/Joining Groups \\
Lack of Sustainable Options Provided & Public Policy Changes \\
Feeling Helpless & Protect for Future Generations \\
\hline
\end{tabular}

\section{Long-Term Ecological Footprint Trends of Focus Group Participants}

Unchanged, average footprint group. The footprint of the first group of participants was closer to the SJSU average final footprint, and did not show much change over the course of the challenge. As shown in Table 12, the average ecological footprint of these focus group participants increased by 0.32 Earths between the start and finish of the ecological footprint challenge. During the 1.5 years after the ecological footprint challenge, the reported ecological footprint decreased slightly, dropping by 0.07 Earths. 
Table 12

Descriptive Statistics - Average Unchanged Footprint Group

\begin{tabular}{cccc}
\hline Date & Mean & Std. Deviation & Number in Focus Group \\
\hline October 2009 & 3.64 & 0.281 & 6 \\
March 2010 & 3.96 & 0.603 & 6 \\
September 2011 & 3.89 & 0.467 & 6 \\
\hline
\end{tabular}

The change over time was analyzed using multiple comparisons in SPSS.

Mauchly's Test of Sphericity tests the variance of the differences between the groups and it showed that the variance was not equal, as the $p$-value is greater than .05 (Table 13).

Table 13

Mauchly's Test of Sphericity - Average Unchanged Footprint Group

\begin{tabular}{ccccccccc}
\hline \multirow{2}{*}{$\begin{array}{c}\text { Within Subjects } \begin{array}{c}\text { Mauchly's } \\
\text { Effect }\end{array} \\
\text { W }\end{array}$} & $\begin{array}{c}\text { Approx. } \\
\text { Chi-Square }\end{array}$ & $d f$ & $p$ & \multicolumn{3}{c}{ Epsilon } \\
\cline { 6 - 8 } & .875 & .536 & 2 & .765 & .889 & 1.000 & .500 \\
\hline
\end{tabular}

As the variance was not equal, the significance of change in footprints over time was analyzed with the Tests of Within-Subjects Effects. As $p=.195$ in the Sphericity Assumed test, this change was not significant $(p>.05)$ (Table 14). This was expected because this group was pre-selected as the group that did not show a change in footprint. 
Table 14

Tests of Within-Subjects Effects - Average Unchanged Footprint Group

\begin{tabular}{|c|c|c|c|c|c|c|}
\hline & Source & $\begin{array}{l}\text { Type III } \\
\text { Sum of } \\
\text { Squares }\end{array}$ & $d f$ & $\begin{array}{l}\text { Mean } \\
\text { Square }\end{array}$ & $F$ & $p$ \\
\hline \multirow{4}{*}{ Earths } & $\begin{array}{l}\text { Sphericity } \\
\text { Assumed }\end{array}$ & .333 & 2 & .167 & 1.936 & .195 \\
\hline & $\begin{array}{l}\text { Greenhouse- } \\
\text { Geisser }\end{array}$ & .333 & 1.777 & .187 & 1.936 & .201 \\
\hline & Huynh-Feldt & .333 & 2.000 & .167 & 1.936 & .195 \\
\hline & Lower-bound & .333 & 1.000 & .333 & 1.936 & .223 \\
\hline \multirow{4}{*}{$\begin{array}{c}\text { Error } \\
\text { (factor1) }\end{array}$} & $\begin{array}{l}\text { Sphericity } \\
\text { Assumed }\end{array}$ & .860 & 10 & .086 & & \\
\hline & $\begin{array}{l}\text { Greenhouse- } \\
\text { Geisser }\end{array}$ & .860 & 8.886 & .097 & & \\
\hline & Huynh-Feldt & .860 & 10.000 & .086 & & \\
\hline & Lower-bound & .860 & 5.000 & .172 & & \\
\hline
\end{tabular}

Greatest reduction footprint group. This group of individuals had the lowest overall final footprints, and some showed a large decrease in footprint. As shown in Table 15, the average ecological footprint decreased by 1.17 Earths between the start and finish of the ecological footprint challenge. One and a half years later the reported ecological footprint increased slightly, by 0.05 Earths. 
Table 15

Descriptive Statistics - Greatest Reduction, Lowest Footprint Group

\begin{tabular}{cccc}
\hline & Mean & Std. Deviation & $N$ \\
\hline Fall 2009 Footprint & 5.09 & .986 & 5 \\
Spring 2010 Footprint & 3.92 & .813 & 5 \\
Fall 2011 Footprint & 3.97 & .668 & 5 \\
\hline
\end{tabular}

The normality of the samples was tested to evaluate these changes. The Kolmogorov-Smirnov test shows that the samples were normally distributed because $p>.05$ (Table 16).

Table 16

Tests of Normality - Greatest Reduction, Lowest Footprint Group

\begin{tabular}{lccccccc}
\hline & \multicolumn{3}{c}{$\begin{array}{c}\text { Kolmogorov- } \\
\text { Smirnov }\end{array}$} & & \multicolumn{3}{c}{ Shapiro-Wilk } \\
& Statistic & $d f$ & $p$ & Statistic & $d f$ & $p$ \\
\hline Fall 2009 Footprint & .147 & 5 & $.200^{*}$ & .995 & 5 & .994 \\
Spring 2010 Footprint & .177 & 5 & $.200^{*}$ & .985 & 5 & .961 \\
Fall 2011 Footprint & .235 & 5 & $.200^{*}$ & .908 & 5 & .453 \\
\hline $\begin{array}{l}\text { Note. } \\
*\end{array}$ This is a lower bound of the true significance. & & & & &
\end{tabular}

As the samples were normally distributed, multiple comparison tests were carried out (Table 17). The Bonferroni test was used to account for the loss in power during multiple comparisons. The adjusted alpha was .016. The $p$-value for the change in ecological footprint for this group equaled .007 for the change during the ecological footprint challenge, and equaled .015 for the change from the first data collection to the 
focus groups. The footprints of participants did not significantly change from Spring 2010 to Fall 2011. These results, although the sample size was small, suggests that participants who reduced their footprint during the ecological footprint challenge sustained this behavior long-term.

Table 17

Paired Samples T-Test - Greatest Reduction, Lowest Footprint Group

\begin{tabular}{|c|c|c|c|c|c|c|c|c|}
\hline & \multirow[t]{2}{*}{ Mean } & \multirow[t]{2}{*}{$\begin{array}{c}\text { Std. } \\
\text { Deviation }\end{array}$} & \multirow[t]{2}{*}{$\begin{array}{l}\text { Std. } \\
\text { Error } \\
\text { Mean }\end{array}$} & \multicolumn{2}{|c|}{$\begin{array}{c}5 \% \text { Confidence } \\
\text { Interval of the } \\
\text { Difference } \\
\end{array}$} & \multirow[t]{2}{*}{$t$} & \multirow[t]{2}{*}{$d f$} & \multirow[t]{2}{*}{$\begin{array}{c}p \text {-value } \\
\text { (2-tailed) }\end{array}$} \\
\hline & & & & Lower & Upper & & & \\
\hline $\begin{array}{c}\text { Footprint } \\
\text { Change From } \\
\text { Fall } 2009 \text { to } \\
\text { Spring } 2010\end{array}$ & 1.176 & .51743 & .2314 & .53353 & 1.81847 & 5.082 & 4 & .007 \\
\hline $\begin{array}{c}\text { Footprint } \\
\text { Change From } \\
\text { Spring } 2010 \text { to } \\
\text { Fall } 2011\end{array}$ & -.054 & .67125 & .3001 & -.88747 & .77947 & -.180 & 4 & .866 \\
\hline $\begin{array}{l}\text { Footprint } \\
\text { Change From } \\
\text { Fall } 2009 \text { to } \\
\text { Fall } 2011\end{array}$ & 1.122 & .61540 & .2752 & .35788 & 1.88612 & 4.077 & 4 & .015 \\
\hline
\end{tabular}




\section{Discussion}

This study demonstrated a significant increase in sustainable behaviors of individuals participating in an ecological footprint challenge. Not only did the frequency of sustainable behaviors increase, the overall ecological footprints significantly decreased. This research shows that an ecological footprint challenge can be successfully scaled up from the classroom scale to a university-wide scale. Participants reported that the knowledge gained through taking the ecological footprint quiz and attending sustainability related lectures and classes had a profound impact in their choices. A majority of the focus group participants reported that finding out the size of their ecological footprint was jarring. Though there were grand prize incentives for lowest footprint and greatest reduced footprint, most focus group participants instead internalized the challenge. Many in the focus group also reported that saving money in the process of becoming more sustainable was an important driver to changing their lifestyle. The significant decrease in overall ecological footprint was measured six months after the initial footprint quiz was taken. However, further longitudinal data is needed to determine if these behavior changes were permanent.

This ecological footprint study resulted in a moderate but statistically significant behavior change. This behavior change showed an increase in pro-environmental behaviors and the overall sustainability of lifestyle choices for participants. However, it must be noted that behaviors were self-reported. Table 7 shows students reduced their goods and services footprint the most (-16\%), while faculty and staff reduced their housing footprints the most (-12\% and $-13 \%$, respectively). Students had the highest 
goods and services footprint and therefore, they had a lot of room to improve. Though there was not a single behavior that stood out under the goods and services footprint, students made behavioral changes across the board from small increases in recycling paper, to $10 \%$ increases in buying natural clothing products and recycling e-waste. This was the category of the greatest change, however, about $25 \%$ of students were still not recycling all of their paper, plastic bottles, aluminum, and glass. This category is one area of "low hanging-fruit" for fostering an increase in sustainable behavior in students. Recycling is shown to be an entry-level activity for helping to protect the environment and can often lead to other pro-environmental behaviors (Cleveland et al., 2005).

Students, faculty, and staff all decreased their housing footprint by more than $10 \%$. However, this was done in different ways. Students who generally cannot invest in energy saving or water saving technologies showed an increase in sustainable behaviors rather than technology. Students reported adjusting energy saving and water saving habits to be more sustainable. Students may not have realized that these choices had an impact on their ecological footprint before completing the footprint quiz.

Students also reported greatly reducing their miles travelled by automobile, while increasing the use of public buses. Each semester, students, as well as school employees, receive an Ecopass, a pass for rides on local public bus and light rail service. One influence may be that many new students would choose to use the Ecopass to get to campus instead of driving and paying for on-campus parking. While there was not much change in the amount of students who rode public transportation at least once during the challenge, there was a large increase in bus miles travelled. 
In addition, faculty self-reported installing drought tolerant landscapes, energy saving technologies, and water saving fixtures at their residences. A larger reported adoption rate seen in faculty may be because they are in a position to own a home. Since they are homeowners, these actions are investments they can make to save energy and water. Providing information to faculty and staff about home improvements could be an effective way to foster sustainability in these individuals. In addition, a group buy program for solar panels or drought tolerant landscapes may be another way to tap into a willingness to make changes to the housing footprint.

A theory presented by Frick et al. (2004) helped explain the increase in proenvironmental behavior measured in this study. Their theory of pro-environmental behavior posits that in order to effect change in pro-environmental behavior people must be presented with system-related knowledge, action-related knowledge, and effectiveness-related knowledge. The important factors being that raising awareness about how a certain ecosystem is being impacted by humans does not directly result in a change in behavior. People must be provided the possible actions they can take and the effectiveness of each action to increase the adoption of behavior change.

The environmental outreach performed by the campus sustainability team sought to keep this in mind at all of its outreach events. Tabling demonstrations about environmental issues were accompanied with information about the actions people could take and the associated reduction in ecological footprint. The monthly sustainability lecture series titled "Sustainability Matters," was always formatted to enlighten attendees about the environmental issues associated with the topic and the actions they could take if 
they wanted to make a difference. Plenty of time was provided for question and answer sessions and networking after the presentations so that personalized information could be provided. Participants who attended the monthly lecture series were shown to have reduced their footprint by $4.9 \%$ more than other participants. Statistical analysis revealed this difference to be significant within a $90 \%$ confidence interval.

Follow-up focus groups conducted for this study revealed that many participants were aware of environmental issues from hearing about them in the news or the classroom. What they reported to be lacking was knowledge of the links between choices made in their daily lives and those environmental issues. People reported in the focus groups that the quiz showed them options to reduce their footprint that they had never thought of before. Many participants also reported that they were able to use the interactive nature of the quiz to see real-time how much their choices affected their ecological footprint. By building off of a base knowledge and a general concern about environmental issues the ecological footprint quiz inherently raised the action-related and effectiveness knowledge of sustainable behaviors in participants. The final data collection showed a small but significant reported increase in pro-environmental behavior and a greater than $10 \%$ average reduction in ecological footprint.

Background research suggests that this ecological footprint challenge was the first attempt to use the ecological footprint tool to characterize the behavior change of individuals on a university-wide scale over the course of a school year. In fact, this research project sought to build on a study by Ryu and Brody (2006) who employed the footprint quiz as a pre-test post-test measurement tool on a classroom-sized study 
population. They used the ecological footprint quiz to measure the changing footprints of students attending a sustainable development course and students in a control group. Though a certain element of this type of comparison is included in this study in the form of comparing those who attended sustainability lectures with those who did not, the campus-wide scale did not allow for such a clean comparison. Unlike Ryu and Brody, this study showed that even people who did not attend sustainability lectures had a significant decrease in footprint. In fact, every footprint category in this study significantly decreased, as opposed to the Ryu and Brody study where only transportation and goods and services categories showed significant decreases.

This study expanded on Ryu and Brody's (2006) use of the ecological footprint quiz by using it with a larger study population in a different geographical area. The focus of this study was shifted to measuring and exploring the change in ecological footprint rather than the relative difference between a test and control group. Influences on the study population beyond the implemented outreach efforts could not be accounted for because of the large population size. In contrast to Ryu and Brody's findings, this study indicated that household income and distance from campus were not significant predictors for change in footprint. Furthermore, age may have been a significant predictor for change in footprint in this study, as opposed to Ryu and Brody. While age was not directly collected in this study, students did show a greater reduction in footprint than faculty and staff (who are generally older than students).

During the course of this project participants reported that the ecological footprint results empowered them to take action. As in the study by Cordero et al. (2008), this 
research project provides further evidence that people who complete the ecological footprint quiz, report feeling an emotional response to completing the quiz and seeing their footprint results page. The results often came as a shock as to how many Earths would be needed if everyone on the planet lived like them. In addition, focus group participants reported gaining knowledge about sustainable activities by taking the ecological footprint quiz. This is supported by the findings of Cordero et al. where students who completed the quiz had a better understanding of the causes of global warming and the link between energy use and greenhouse gas emissions.

While this study suggests that the footprint quiz increased knowledge about sustainability, it is how participants internalize this knowledge that governs their evolving everyday choices. Though this was not a psychological study, theories from psychology may help to explain the changes observed in participant behaviors. The reasons provided by focus group participants for why they modified their behavior fit closely with the psychological framework of the locus of control. This theory states that the degree to which individuals take action in certain situations depend on perceived control of the outcome (Lefcourt, 1982).

While the locus of control is an underlying psychological factor to an individual's perception of empowerment to act, some studies have shown that overtime it can be improved. Research by Hungerford and Volk (1990) indicate that locus of control can be improved by teaching skills needed to act as good citizen. When such skills are applied successfully in the community an increased perception of internal locus of control may 
result. In fact, Hungerford and Volk conclude that the research clearly indicates that environmental education can develop responsible citizens.

A review of related research finds that locus of control is not a fixed personality trait. Coming into the ecological footprint quiz participants had an established set of perceptions of control. However, it is possible that with positive enforcement the footprint quiz may improve locus of control. As shown in Table 11, focus groups participants who had a greater reduction in footprint made comments indicating a higher level of internal locus of control. It appears that the group that made footprint reductions perceived possible negatives (or barriers to pro-environmental behavior) as positives (or incentives to change behavior). Those who reported a reduced ecological footprint valued the money they were able to save, reported feeling healthier, and did not mind putting in the effort if it would make a difference. They felt healthier when they ate local and organic foods, and felt better about themselves and their decisions to have less impact on the environment. In contrast, participants who did not make changes felt that making such a change would impact their comfort level and take more time out of their busy schedules. However, the complexities of measuring how an ecological footprint challenge can modify locus of control is a question that should be studied further. 
There could be many reasons that some participants did not reduce their footprint. For example, participants with below average footprints face incrementally increasing costs or decreasing perceived comfort to further reduce their footprint. Focus group participants, in this situation reported wanting to lower their footprint, but were unable to do so. Some individuals, who wanted to act more sustainably, felt that they were unable to do so because they did not own their home, did not live near a convenient public transit line, or could not change their diets because of a spouse. Though these issues are not in the direct control of the individual, more creative efforts could be made to increase their overall sustainability. If the individual was really motivated they could talk to their landlord, find a car-share, relocate, or work out a compromise at the dinner table. However, these changes may be harder to make because they require more effort and may not be as socially accepted. To garner increased sustainable lifestyle choices in such inflexible individuals, more specialized education, economic incentives, and increased ease in use of sustainable technologies and actions will be required. Further study is needed to determine if providing these things would be effective in such cases.

One trend that was observed in this study is that economic factors play a large role in the size of one's ecological footprint. Many students, faculty, and staff in the California State University system are on a limited budget, without a great deal of disposable income to spend on higher impact activities. A large percentage of students live within walking distance to the university and more often share rooms. As students are on a fixed income, often from academic loans, they must live within their means to avoid financial problems. One observation during the focus groups, was that being frugal 
aligns with several sustainable behaviors, notably taking advantage of the public transit pass provided, limiting home energy use, purchasing used products, and repairing things rather than replacing them.

In addition, increases in gas prices during this period also caused people to travel less and have less expendable income. When asked questions about transportation, one in four Americans said they planned to travel less during the summer that year (Gallup, 2009b). This study found that, overall, participants reported driving $20 \%$ less auto miles in 2010 as opposed to 2009. Furthermore, focus group participants ranked money as second only to education in prompting behavior change.

Community building was an important part of this project, which had lasting impacts to sustainability at San Jose State University. At each lecture effort was taken to bring people together to start new sustainability projects on campus. These lectures brought staff members from different parts of the food system, or energy system and got dialog going about changes that could be made at SJSU. With each lecture, sustainability team members provided information on the relationship between that topic and SJSU, bringing all the relevant information together in one place. This brought back in the concepts of not only providing system related knowledge, but action related knowledge as well.

This study showed that when a large group of individuals make small changes to the sustainability of their lifestyles the impact is considerable. The sum of the footprint reduction of the 738 individuals who participated in the SJSU ecological footprint challenge was 6,567 acres, which equals 26.57 square kilometers or 4,966 football fields. 
With this knowledge, the footprint challenge participants were able to see that the actions they took had a significant benefit to the planet.

\section{Recommendations}

After completing this research project, a few key recommendations can be made for campuses that want to implement their own ecological footprint challenge. The first recommendation addresses ways to maximize the participant rate and return rate.

Maximizing the number of participants strengthens the representativeness of the data and increases the environmental benefits of the outreach efforts. It is important to try to reach people who have higher footprints and may not be very concerned about their impact on the environment. The focus groups indicated that offering prizes for participation in the survey was very important. In addition, people reported participating because they saw the footprint challenge banner or people tabling around campus. Some students reported that their professors made entry into the challenge mandatory, or worth extra credit. The focus groups indicated that some people who entered were already interested in sustainability or the ecological footprint.

Based on this feedback, the best way to increase participation in the challenge would be to make it mandatory, or at least make it part of new student orientation, an idea first mentioned in the focus groups. This would set the tone that the university takes sustainability seriously and provide an introduction for students who were new to the concept of sustainability. Students would learn about the role each of them plays in moving toward greater sustainability and take habits they form throughout this process with them when they graduate. 
If making the ecological footprint challenge mandatory is not an option, then it is very important to offer a multitude of desirable incentives for participation. The administration could work with all professors to encourage extra credit for those who join the challenge. Other effective incentives were gift cards to the bookstore, laptop computers, and even food. These incentives must be effectively advertized through all possible avenues of contact. People should get multiple reminders through email, social networking, or web postings to join the challenge. These avenues are most effective because all people have to do is click on a link that takes them to the ecological footprint quiz. While the initial participation rate is important, the return rate is just as important. Again, short of making participation mandatory, it must be clear that people returning to take the quiz again could win prizes just for participating.

A second recommendation is to expand the demographic information gathered about all participants and identify those people least likely to participate in the footprint challenge or reduce their footprint. Identifying why the message is not reaching these people would be important to creating a design that would reach everyone. Custom outreach may need to be developed to convince people who are resistant to change. Moreover, knowing what classes or programs participants took would allow researchers to identify variables, other than the efforts of the study, that had an impact on individuals during the study period. Environmental issues in the news or personal experiences with pollution may also have large impacts, which should be accounted for.

A third recommendation is to gather more longitudinal data by having participants enter their footprints on a periodic basis (e.g., monthly, quarterly, or yearly) and 
extending the time frame of the challenge. Gathering data from more points in time could illuminate more trends, increase the strength of the model, and even measure the effect of individual events. In addition, taking the ecological footprint quiz multiple times may have a greater impact on increasing sustainable behaviors.

While focus group participants reported that their footprint reductions were permanent and would continue to decline, this can only be verified by a longitudinal study. Long-term behavior changes are seldom tracked in environmental education due to the resources required to conduct a long-term study and the logistics of following participants for many years. Since such studies are rare, the fields of behavior change and environmental education would benefit greatly from tracking the ecological footprints of individuals over multiple years. Furthermore, a study about the level of exposure to environmental messages and their impact on individuals' pro-environmental behavior could be gathered through a long-term ecological footprint study. The last recommendation would be to integrate the ecological footprint challenge with social media. The presence of social media in the everyday lives of college students is expanding. Having someone's footprint regularly in front of them on their home page would be a great reminder to reduce their impacts. As more people post about the changes they were making and how it made them feel, their friends may be encouraged to adopt the same behaviors. This would be a great experiment in social norm building, which research has shown to be very important in changing collective behaviors (Darner, 2009). Social media also provides evidence of such social interactions, which can be collected and analyzed. In a world where there is an app for everything, providing 
mobile tools to calculate the ecological footprint of different actions or products could have a great influence and would be valuable to study. In fact, during the focus groups, participants expressed a desire to have a mobile software application that could track their daily ecological footprint, much like a calorie counter for dieting. Clearly there is more research needed on the capabilities of the ecological footprint to be paired with social media to prompt behavior change. 


\section{Conclusion}

Encouraging behavior change on the individual level is one important aspect of reducing humanity's ecological footprint and reversing human-induced climate change. However, many people have an aversion to being told how to live their lives.

Unfortunately, climate change cannot be reversed solely by changes to policies, regulations, or practices by large corporations. As evident in recent climate talks, change comes very slowly to entrenched institutions and financial systems that depend on carbon dioxide emissions, among other externalities. Widespread demand from the people and lifestyle shift on the individual level are needed.

Common arguments against an individual taking action include "I am only one person. How can my actions alone make a difference to the big picture?" or "Other people aren't making sacrifices in their lifestyle, so why should I?" Sentiments such as these must be addressed in environmental outreach in order to spark widespread change. Grass roots movements are often the strongest forces for change. When large groups of people vote with their purchasing power, corporations often respond swiftly to the changing demand. A variety of techniques are needed to highlight the connection between a person's everyday choices and the environment. The ecological footprint can do just that.

Small changes in one's lifestyle might seem insignificant, but when these changes are made on a regional or national scale, the cumulative effects can make a real difference. The findings of this study showed that the ecological footprint was an effective tool in fostering behavior change while simultaneously measuring that change. 
The measured change, while small for each individual, was significant when multiplied by the number of participants. By providing actual numbers on the amount of land "saved" over time, the ecological footprint informed people that the changes they make do have an impact.

The ecological footprint quiz proved to be an effective tool to educate the general population at a university about environmental impacts. In addition, participants in this study reported using the ecological footprint quiz to evaluate the impact of their behaviors. Not only did the online quiz provide participants with alternative behaviors that are better for the environment, it allowed them to discover the relative effectiveness of these behavior choices in units of land area.

Further research is needed over an extended timeframe to determine if the ecological footprint quiz is effective in garnering long-term change. For universities, employers, and cities hoping to raise environmental awareness, the ecological footprint challenge provides an easily implemented initiative that addresses all areas of sustainability and provides quantifiable data. While many universities and other organizations want to take action to "go green" and raise environmental awareness, efforts are often haphazard and results are seldom tracked.

Implementation of the ecological footprint quiz on a larger scale could make a real quantifiable impact on the reduction of the group's ecological footprint. The next step is scaling up this study to the citywide level. It would be extremely valuable to study the results of using an ecological footprint challenge with a general population. The key to doing this will be reaching every resident and persuading them to participate in the 
online quiz. Monetary incentives and prizes are the key to increasing the participation rate and return rate. At the same time participants must be convinced that their personal information will be kept confidential, perhaps by a third party consultant. A database must be maintained to evaluate the effectiveness of the campaign from the baseline through future data collection. This study showed that outreach is an important component of the ecological footprint campaign. Therefore, concurrent outreach and announcements of informative events will also need to be organized. Promoting and taking advantage of all environmental education events, educational material, and classes on sustainability would help enrich the experience of the footprint challenge. Integration into social networking sites and updates on footprint reduction should be provided to create a sense of community and responsibility.

Although the San Jose State Ecological Footprint Challenge was successful in reducing the ecological footprint of its participants by over $10 \%$, the sustainability outreach efforts must not stop here. All campuses should continue to strengthen their environmental outreach, expand sustainability curricula, set measurable goals, and quantify their results. Everyone should know what their ecological footprint is and more organizations should implement footprint challenges. However, this alone will not help protect ecosystems or reverse climate change. Conscious, organized, and quantifiable efforts are needed around the globe to spur behavior change in individuals who do not currently comprehend the direct impact their lifestyles have on the environment. 


\section{References Cited}

Bagliani, M., Galli, A., Niccolucci, V., \& Marchettini, N. (2008). Ecological footprint analysis applied to a sub-national area: The case of the Province of Siena (Italy). Journal of Environmental Management, 86, 354-364.

Bartlett, P. F., \& Chase, G. W. (2004). Sustainability on campus: Stories and strategies for change (Eds.). Cambridge, Massachusetts: The MIT Press.

Cleveland, M., Kalamas, M., \& Laroche, M. (2005) Shades of green: linking environmental locus of control and pro-environmental behaviors. The Journal of Consumer Marketing, 22, 198-212.

Collins, A., \& Flynn, A. (2007). Engaging with the Ecological Footprint as a DecisionMaking Tool: Process and Responses. Local Environment, 12, 295-312.

Conway, T. M., Dalton, C., Loo, J., \& Benakoun, L. (2008). Developing ecological footprint scenarios on university campuses: A case study of the University of Toronto at Mississauga. International Journal of Sustainability in Higher Education, 9, 4-20.

Corcoran, P. B., Walker, K. E., \& Wals, A. E. (2004). Case studies, make-your-case studies, and case stories: a critique of case-study methodology in sustainability in higher education. Environmental Education Research, 10, 7-21.

Cordero, E., Todd, A., \& Abellera, D. (2008). Climate Change Education and The Ecological Footprint. Bulletin of the American Meteorological Society, 89, 865872.

Dahm, M. J., Samonte, A. V., \& Shows, A. R. (2009). Organic Foods: Do Eco-Friendly Attitudes Predict Eco-Friendly Behaviors? Journal of American College Health, 58, 195-202.

DeLind, L. B., \& Link, T (2004). Place as a nexus of a sustainable future: A course for all of us. In P. F. Bartlett \& G. W. Chase (Eds.), Sustainability on campus: Stories and strategies for change (pp. 121-137). Cambridge, Massachusetts: The MIT Press.

Darner, R. (2009). Self-Determination theory as a guide to fostering environmental motivation. The Journal of Environmental Education, 40(2), 39-49.

Esterberg, K. G. (2002). Qualitative methods in social research. United States of America: McGraw-Hill Higher Education. 
Frick, J., Kaiser, F. G., \& Wilson M. (2004). Environmental knowledge and conservation behavior: exploring prevalence and structure in a representative sample.

Personality and Individual Differences, 37, 1597-1613.

Gallup. (2009a, November 20-22). Savings Trumps Environment for Making Homes Greener. Retrieved from http://www.gallup.com/poll/124619/Savings-TrumpsEnvironment-Making-Homes-Greener.aspx

Gallup. (2009b, May 18-19). Recession Altering Plans for Half of Summer Travelers. Retrieved from http://www.gallup.com/poll/118597/Recession-Altering-PlansHalf-Summer-Travelers.aspx

Global Footprint Network. (2009). National Footprint Accounts 2009. Oakland, CA: Author.

Global Footprint Network. (2010). Ecological Footprint Atlas 2010. Oakland, CA: Author.

Hungerford, H. R., \& Volk, T. L. (1990). Changing learner behavior through environmental education. Journal of Environmental Education, 21(3), 8-22.

Jahiel, A. R., \& Harper, G. (2004). The green task force: Facing the challenges to environmental stewardship at a small liberal arts college. In P. F. Bartlett \& G. W. Chase (Eds.), Sustainability on campus: Stories and strategies for change (pp. 4966). Cambridge, Massachusetts: The MIT Press.

Krajhanzl, J. (2010). Environmental and proenvironmental behavior. School and Health, Health Education: International Experiences. 21, 251-274.

Lefcourt, H. M. (1982). Locus of Control: Current Trends in Theory and Research $\left(2^{\text {nd }}\right.$ ed.). NJ: Lawrence Erlbaum Associates

Lindsay, N., Harrell-Blair, K., McDaniel, L., Williams, C., \& Reed, D. (2010). “Green on the screen" promoting sustainability through a campus film series. About Campus, 15(2), 26-29.

McCarty, J. A., \& Shrum, L. J. (2001). The influence of individualism, collectivism, and locus of control on environmental beliefs and behavior. Journal of Public Policy \& Marketing, 20, 93-104.

Olli, E., Grendstad, G., \& Wollebaek, D. (2001). Correlates Of Environmental Behaviors Bringing Back Social Context. Journal of Environment and Behavior, 33, 181208. 
Owens, K. A., \& Halfacre-Hitchcock, A. (2006) As green as we think? The case of the College of Charleston green building initiative. International Journal of Sustainability in Higher Education, 7, 114-128.

Pike, L., Shannon, T., Lawrimore, K., McGee, A., Taylor, M., \& Lamoreaux, G. (2003). Science education and sustainability initiatives: A campus recycling case study shows the importance of opportunity. International Journal of Sustainability in Higher Education, 4, 218-229.

Pooley, J. A., \& O'Connor, M. (2000). Environmental education and attitudes: emotions and beliefs are what is needed. Environment and Behavior, 32, 711-723.

Rees, W., \& Wackernagel, M. (1996). Urban ecological footprints: Why cities cannot be sustainable and why they are a key to sustainability. Environmental Impact Assessment Review, 16, 223-248.

Roorda, M. (2000). Auditing sustainability in engineering education with AISHE. ENTREE 2000 Proceedings. EEE Network, Brussels, (13-30).

Rosenburg, S., Vedlitz, A., Cowman, D. F., \& Zahran, S. (2010). Climate change: a profile of US climate scientists' perspectives. Climate Change, 101, 311-329

Ryu, H., \& Brody, S. D. (2006). Examining the impacts of a graduate course on sustainable development using ecological footprint analysis. International Journal of Sustainability in Higher Education, 7, 158-175.

Staats, H., Harland, P., \& Wilke, H. A. (2004). Effecting durable change a team approach to improve environmental behavior in the household. Environment and Behavior, $36,341-367$.

Venetoulis, J., \& Talberth, J. (2005). Refining the ecological footprint. Environment, Development and Sustainability, 10, 441-469.

Wackernagel, M. (2009). Methodological advancements in footprint analysis. Ecological Economics, pp. 1925-1927.

Wackernagel, M., Monfreda, C., Schulz, N. B., Erb, K., Haberl, H., \& Krausmann, F. (2004). Calculating national and global ecological footprint time series: resolving conceptual challenges. Land Use Policy, 21, 271-278.

Wackernagel, M., \& Rees, W. (1996). Our Ecological Footprint. Gabriola Island: New Society Publishers. 
Walker, P., \& Lawrence, R. S. (2004). Challenges of greening a decentralized campus: Making the connection to health. In P. F. Bartlett \& G.W. Chase (Eds.), Sustainability on campus: Stories and strategies for change (pp. 259-270). Cambridge, Massachusetts: The MIT Press.

Wright, T. S. A. (2003), A Tenth Year Anniversary Retrospect: The Effect of the Halifax Declaration on Canadian Signatory Universities. Canadian Journal of Environmental Education, 8, 233-248. 
APPENDIX A: Baseline Ecological Footprint Quiz

\section{Now, we will estimate your carbon footprint. Your carbon \\ footprint is the area needed to absorb carbon emissions \\ generated by your home energy use and transportation.}

Spotlight on SJSU Sustainability: What are we already doing?

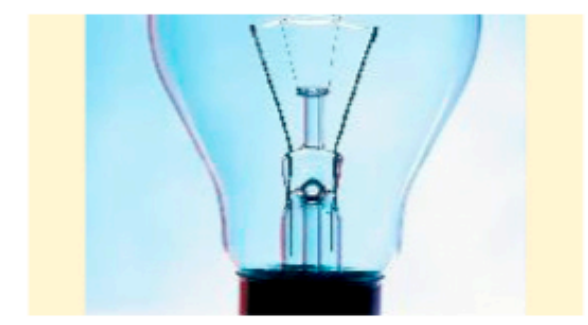

Campus Energy Efficiency

Over the past 5 years, Energy Efficiency projects undertaken at SJSU have resulted in annual savings of over 8 million $\mathrm{kWh}$ and 150,000 therms of natural gas valued at $\$ 1.4$ million per year. As a result of these projects, SJSU has avoided nearly 4,000 metric tons of $\mathrm{CO} 2$ emissions per year. 


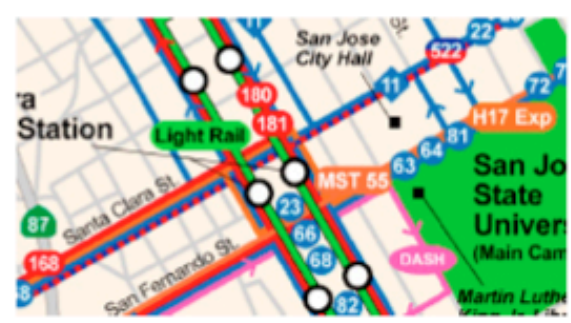

Transportation Solutions

Associated Students' Transportation Solutions is dedicated to serving the commute needs of the students, faculty, and staff at SJSU. Over the past 8 years, the organization 's innovative work has led to a $300 \%$ increase in the use of alternative transportation at SJSU. Your one-stop-shop for commuting information, check out Transportation Solutions for your free (for students) or low cost (\$25 for faculty and staff) bus and light rail pass, transit schedules, secure bike parking, and rideshare and vanpooling services.

\title{
3. What is the size of your dorm room, apartment, or home?
}

500 - 1000 square feet or less (dorm room, studio or apartment)

1000 - 1500 square feet (small home, approximately 2-3 bedrooms)

$\odot 1500$ - 2000 square feet (average home, approximately 3 bedrooms)

2000 - 2500 square feet (large home, approximately 4 bedrooms)

2500 square feet or larger (very large home)

\section{What energy sources do you use in your residence? On-campus residents select "electricity" and "natural gas."}

\author{
Đelectricity \\ Natural gas, propane, or liquefied petroleum gas \\ $\square$ Heating oil \\ $\square$ Wood or biomass
}

\section{If your residence uses electricity, what percentage is generated from renewable hydropower, wind, biomass, or solar sources? The initial value is the state average. On-campus residents enter $4.5 \%$. \\ $24.70 \%$ \\ 6. Please enter the number of miles you travel per year for each mode of transportation:}


2000 Automobiles, including personal vehicles, taxis, and carpools

1000 Bus, including metro and long distance service

200 Rail, including subways, inner-city light rail, cross country trains

5000 Air travel

\title{
What best describes the vehicle you most often drive or ride in?
}

\author{
A hybrid \\ O A small or compact car (2 door) \\ $\odot$ A mid size car (4 door sedan) \\ $O$ A large car (including vans and minivans) \\ A pickup truck or sport Utility Vehicle (SUV)
}

\section{Do you usually share rides with at least one other person?}

$\odot$ Yes
No
Back Next




\section{Your carbon footprint, continued.}

\section{Spotlight on SJSU Sustainability: What are we already doing?}

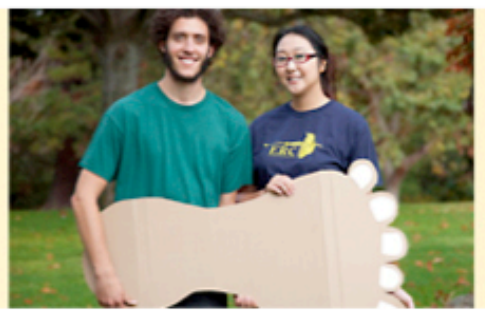

\section{Environmental Resource Center (ERC)}

ERC is a student-led organization for student research and activism on campus environmental issues. Best known for organizing the annual Sustainability Week, ERC does much more than that. Students all over campus can earn course credit and work on real world environmental issues by taking the course EnvS 181 . This year, the ERC team will address native plant landscaping, bike commuting, and food sustainability on campus.

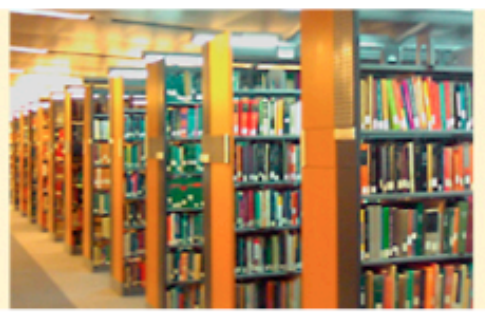




\title{
Energy Efficient Lighting
}

In Spring 2006, SJSU began the changeout of over 50,000 lighting fixtures to fluorescent energy-efficient alternatives. This dropped total peak energy demand for lighting by $15 \%$. Planned lighting retrofits in King Library include motion sensor and more energy efficient lamps. Combined, these efforts will save over one million kilowatt hours per year, $(\$ 150,000)$ - approximately $10 \%$ of the King Library electricity bill.

7. Which energy saving features do you have in your residence? Check all that apply. Please skip if you live on campus, the default choices are already entered.

\section{Energy saving features}

『Compact fluorescent bulbs

『 Energy efficient appliances

च Extra insulation

$\square$ Insulating blinds

$\square$ Solar panels

$\square$ Storm doors and windows

(v) Water saving fixtures

\section{Energy saving habits}

\author{
v Turn off lights when leaving rooms \\ จ Use power strips to turn off stand-by lights \\ $\checkmark$ Turn off computers and monitors when not in use \\ $\square$ Dry clothes outside whenever possible \\ $\square$ Keep thermostat relatively low in winter \\ (v) Unplug small appliances when not in use \\ $\square$ Minimal use of power equipment when landscaping \\ Small lifestyle changes make a big difference. Find out more.
}

\section{Which of the following best describes where your residence is located? On-campus residents select "inner city."}

\author{
Inner city \\ $\odot$ Older suburb \\ Newer suburb \\ ORural
}


More about sprawl and climate change

9. Have you purchased offsets for carbon emissions associated with your home energy use and transportation?

$\odot$ Yes

O No

\title{
What company did you purchase offsets from?
}

\author{
AgCert/Driving Green \\ Atmosfair \\ Carbon Neutral \\ Climate Care \\ Climate Trust \\ $\mathrm{Co} 2$ Balance \\ Native Energy \\ Terra Pass \\ $\odot$ Sustainable Travel/ My Climate \\ Other, Please specify: \\ More about carbon offsets $\square$ \\ Back Next
}




\section{Next, we estimate your food footprint. Your food footprint includes \\ the area needed to grow crops, fish, and graze animals and absorb carbon emissions from food processing and transport.}

Spotlight on SJSU Sustainability: What are we already doing?

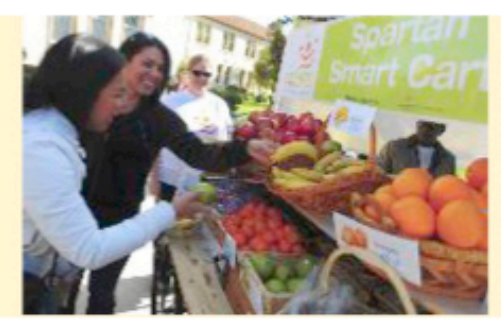

Spartan Smart Cart

To simplify our lives while enriching our palate, the Spartan Smart Cart is bringing the flavor of fresh fruits and vegetables to the SJSU community. Whether you are looking for healthful snack foods or dinner fixings, stop by and check out the selection. Fall offerings include mandarian oranges, locally grown strawberries and raspberries, peaches, and fresh fruit cups. You can find them outside of Clark Hall on Tuesdays from 10:15-1:30pm near the SJSU Olympic Statues. Be entered into a raffle for a \$25 gift card by visiting the cart in October and mentioning sustainability. 


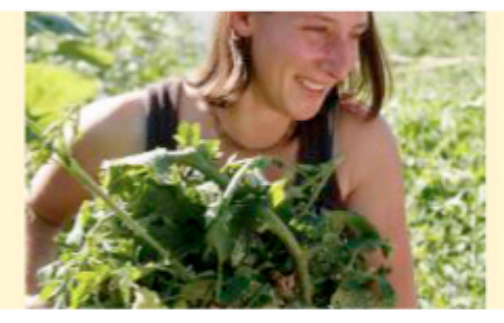

Learn More!

SJSU offers many classes on nutrition and sustainability including ... Issues in Food Toxicology (NUFS 115 Nutrition and Food Science) Hunger and Environmental Nutrition (NUFS 139 - Nutrition and Food Science) Food Supply and Agricultural Systems (GEOG 120 - Geography) Sustainable Agriculture (ENVS 154 Environmental Studies)

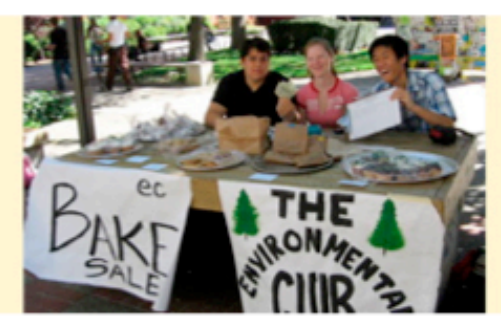

\section{Environmental Club}

This student-led group is working to make SJSU a greener place. Learn more about environmental issues and get hands-on experience by organizing and participating in the Club's Fall events: Sustainable Food Day, Recycling Day, and Bike to School Day. The Club meets on Thursdays at 5:30pm in Building BB, 2nd Floor Conference Room. Projects include hosting E-waste recycling events, organizing trail restorations, and participating in park cleanups.

\section{What best describes your diet?}

$\bigcirc$ Vegan - Plant based foods only

$\odot$ Vegetarian - Primarily plant based foods, but some dairy

$\bigcirc$ Omnivore - An assortment of meat, seafood, vegetables, dairy, and grains

$\bigcirc$ Carnivore - Meat, seafood, and dairy several times a week

Top of the food chain - Meat, seafood, or dairy at almost every meal

My diet and my footprint

\section{Where do you obtain most of your food?}


Farmers markets, gardens, cooperatives, and other local and fresh sources

$\odot$ Natural foods markets

Supermarkets for some items, natural food stores for others

Supermarkets, convenience stores, and prepared foods from restaurants

$\bigcirc$ Restaurants, fast foods, and take out

Food miles, packaging, and where I shop

\section{How often do you select foods that are certified organic or sustainably produced?}

Most of the time

$\odot$ Sometimes

Almost never

\section{Which choice best describes how much you normally eat?}

One large meal and a couple of light snacks per day

$\odot$ Two large meals and two or three light or medium sized snacks per day

$\bigcirc$ Three large meals and several hefty sized snacks in between

\section{Do you have a garden or share one to grow your own vegetables and herbs?}

$\odot$ Yes

No

\section{What is the approximate size of your garden plot?}

20 square feet

The growing importance of community gardens and local food 


\section{The next step is your housing footprint. Your housing footprint includes the area occupied by your home and the area needed to supply resources used in construction and household maintenance.}

\section{Spotlight on SJSU Sustainability: What are we already doing?}

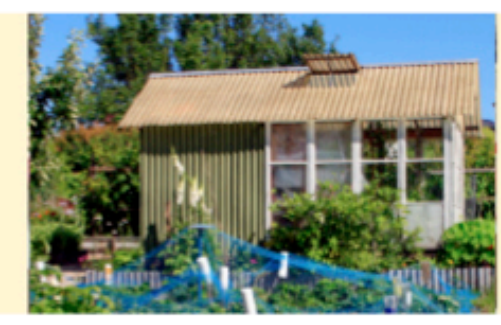

Architecture 2030

2030's mission is to rapidly transform the U.S. and global building sector from a major contributor of greenhouse gas emissions to a central part of the solution to the global-warming crisis. 2030's goal is straightforward: to achieve a dramatic reduction in the global-warming-causing greenhouse gas (GHG) emissions of the building sector by changing the way buildings and developments are planned, designed and constructed. 


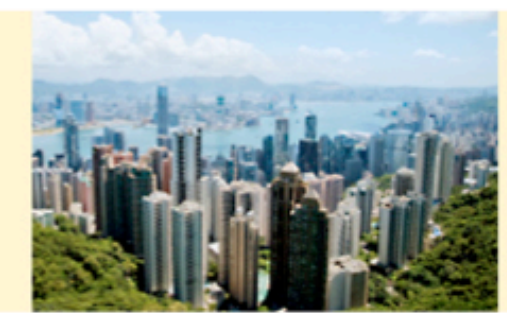

\title{
Center for New American Dream
}

CNAD works with individuals, institutions, communities and businesses to conserve natural resources, counter the commercialization of our culture and promote positive changes in the way goods are produced and consumed. CNAD provides a wealth of information on how to reduce ecological impacts associated with home improvements, water and energy use, landscaping, cleaning, furniture, and appliances.

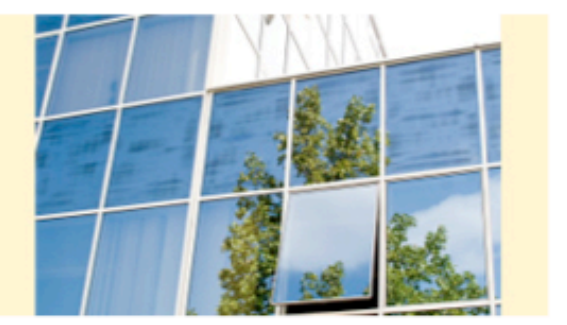

\section{LEED Green Building Rating System}

The U.S. Green Building Council's Leadership in Energy and Environmental Design (LEED) rating system is the most respected standard for the design, construction, and operation of state of the art green buildings. LEED certification provides verification that a building project is environmentally responsible and a healthy place to live and work.

\section{Which best describes your residence?}

\author{
An estate, ranch or farm \\ A free standing single family house \\ $\odot$ A house or building with 4 or fewer units \\ A small apartment building or dorm (5 - 20 units) \\ $\bigcirc$ A large apartment building or dorm (20+ units)
}

\section{Was your residence or any portion of it built with recycled materials, wood certified as sustainably harvested, or any other green design features? On-campus residents select "No."}


$\odot$ Yes

No

Not sure

More on green buildings

17. Approximately what share of your furniture and other unattached home furnishings are second hand or made from recycled materials? On-campus residents select "Almost all."
Almost none
$O$ A few
$\odot$ A fair amount
O Almost all

18. Which water saving features do you have in your residence? Check all that apply. Please skip if you live on campus, the default choices are already entered.

\title{
Water saving features
}

\author{
$\nabla$ Low flow toilets \\ $\nabla$ Low flow shower heads and faucets \\ $\square$ Instant water heaters on sinks \\ $\square$ Rainwater catchment system \\ Grey water recycling system \\ Drought tolerant landscaping
}

\section{Water saving habits}

\author{
Compost rather than use garbage disposal \\ $\square$ Minimize shower time and toilet flushing \\ $\checkmark$ Run clothes and dish washers only when full \\ $\nabla$ Wash cars rarely \\ \Look for and fix leaks regularly \\ $\square$ Avoid hosing down decks, walkways, driveways \\ The footprint of water consumption
}

19. How often do you select cleaning products that are biodegradable or non-toxic?
Almost never
Sometimes
$\odot$ Most of the time 
Back Next

Lastly, we estimate your goods and services

footprint, which includes the

area needed to supply consumer items you purchase

and absorb carbon emissions

from their manufacturing, transport, and disposal.

Spotlight on SJSU Sustainability: What are we already doing?

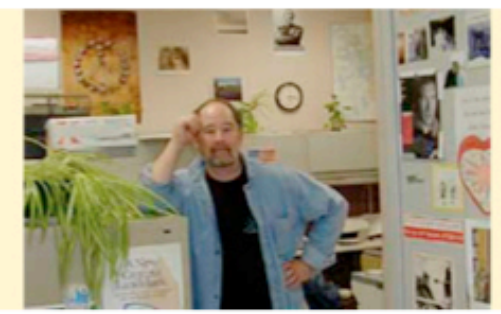

Center for the Development of Recycling (CDR)

Are unwanted books, dead batteries, burnt-out lightbulbs, and too many pairs of shoes cluttering up your life? A simple call or e-mail to SJSU's own CDR will connect you with local organizations that will re-use, recycle, or properly dispose of your unwanted stuff. A joint collaboration between SJSU's Environmental Studies Department and Santa Clara County, the Center teaches students marketable skills by enabling them to staff the Recycling Hotline (408-924-5453), provide a valuable service to the community, and earn academic credit. 


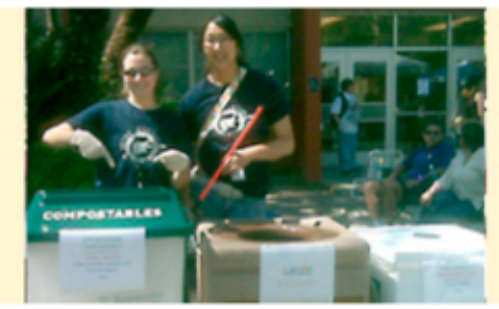

\title{
Recycling and Waste Reduction
}

Our campus-wide diversion rate (percentage of solid waste not entering landfill) for 2009 so far is over $90 \%$ ! In 2008, San Jose State recycled over 95 tons of paper through its mixed paper recycling program. Each ton (2000 pounds) of recycled paper can save 17 trees. At the 2009 San Jose State/Metro Blues Festival, approximately $1,040 \mathrm{lbs}$ of recycling (plastic, aluminum and glass containers), and $920 \mathrm{lbs}$ of compostable serveware and food waste were diverted from the waste stream! SJSU's garbage hauler takes our waste that is not otherwise collected in the various recycling programs to their material recovery facility, or "MRF", where recyclable and compostable items are removed and processed. This service helped SJSU increase our percentage of waste diverted from landfill from $68 \%$ in 2007 to $86 \%$ in 2008 .

\section{What best describes your spending and saving habits?}

I tend to spend all of my income and then some.

$\odot$ I generally live within my means.

I am a frugal spender, and regularly save money for the future.

\section{How often do you buy new things to replace old ones?}

$\odot$ I tend to use things until I genuinely need to replace them.

Some items I use for years, others I replace before I need to.

I frequently replace belongings even if they are in good condition.

$\underline{\text { Planned obsolescence and our economic footprint }}$

\section{How many standard size garbage bins do you fill each week? On-campus residents select "Less than one."}

\author{
$\odot$ Less than one \\ One or two \\ More than two
}

\section{What proportion of the following wastes do you recycle?}


None

Paper

Aluminum

Glass

Plastic

Electronics

O

$\mathrm{O}$
A fair amount

Almost all

O

$\odot$

$\odot$

$\odot$

$\odot$

0

$\odot$

Towards a zero-waste society $\square$

24. When you buy clothing or paper products, how often do you select items labeled as recycled, natural, organic, or made of alternative fibers such as hemp or Tencel?

Almost never

$\odot$ Sometimes

Almost always

Back Next 


\section{APPENDIX B: Getting to Your 10\% Footprint Reduction Form Getting to Your 10\% Footprint Reduction \\ I commit to reducing my ecological footprint by 10 points or more!}

Groceries (Don't forget to bring reusable shopping bags!)

o Shop for food grown locally for most of your groceries

- Farmer's market (Fri. 10am-2pm, San Pedro Square)

- Spartan Smart Cart (Tues. 10:15am-1:30pm, Student Union)

o Buy organic for most of your food purchases

- Order a CSA Produce Box! (Community Supported Agriculture)

See: www.JPOrganics.com

- Trader Joe's, and Safeway, have organic options now, at good prices!

o Eliminate meat from your diet

- Even in restaurants, it's easy. Ask for the same pasta, burrito, etc, but no meat!

At Home

- Use biodegradable or non-toxic cleaning products

- Check out 7th Generation or use vinegar and baking soda.
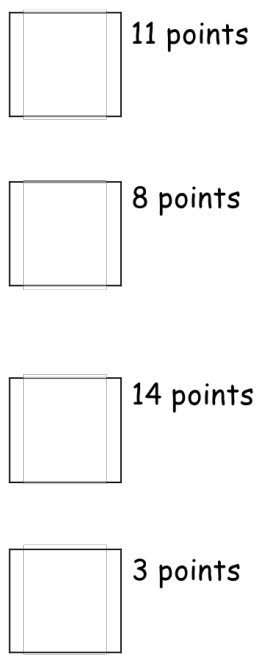

o Put in power strips \& insulating blinds: don't use the hose for cleaning

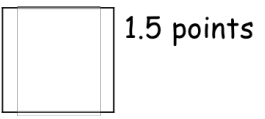

\section{School}

- Drive $10 \%$ fewer miles by car.

- Check out public transit schedules and routes at 511.org

o Drive to campus with 2 or more people in your car.

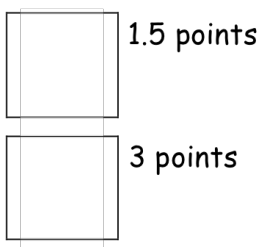

o Purchase carbon offsets for home energy use \& transportation.

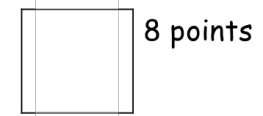

Weekend

o Check out Craigslist.org, Freecycle.org, and the thrift shops!

- Buy, sell, and donate used clothes, household items, and electronics instead of buying new.

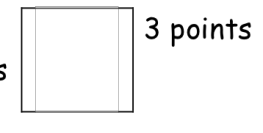




\section{APPENDIX C: Focus Group Informed Consent Form and Semi-Structured Guides}

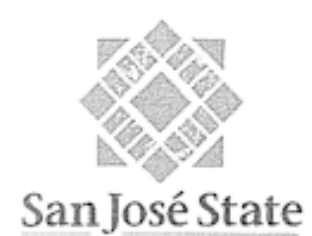

UNIVERSITY

Department of Environmental Studies

One Washington Square San Jose, CA $95192-0115$ Voice: $408-924-5450$ Fax: 408-924-5477
The Calitarnis State University:

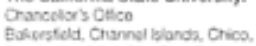
Domingusz Hels, East Eay, Frosno. Fulator, Himbitat. Leng Beach. Los Angeles, Matima Acsdermy. Tortevey Hsy. Wortividjo. Pomora,

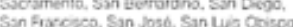
Son Marcos, Sonema Stanistus

\author{
Informed Consent Form \\ San Jose State University Ecological Footprint Challenge: \\ Focus Group Study
}

\author{
Responsible Investigators: Matt Lambert (SJSU Masters Student) \\ Katherine Cushing (SJSU Faculty)
}

You are being asked to participate in a study of ecological footprint challenge participants. This research seeks to understand the experience of people participating in a challenge to reduce their ecological footprint.

This focus group meeting will take approximately two hours and will take place at a location on campus. During the focus group, lifestyle choices will be discussed and participants are asked to keep personal information confidential.

I will be taking an audio recording and notes throughout the focus group session; your name or other indentifying information will not be included on my notes.

Although disclosure of your identity is a possible risk, every precaution will be taken to protect your privacy and the confidentiality of any records generated by this research. Only the principal investigator (Matt Lambert) and his thesis committee will have access to notes from this interview. The results of this study may be published. While pseudonyms will be used, if you do not want your position or department/unit to be included, please check the box below.

Questions about the research are welcome at any time and may be directed to Matt Lambert (mattelambert@gmail.com). Complaints about the research may be presented to Lynne Trulio, Department Chair, Environmental Studies, at (408) 924-5445. Questions about a research subjects' rights, or research-related injury may be presented to Pamela Stacks, Ph.D., Associate Vice President, Graduate Studies and Research, at (408) 9242427.

No service of any kind, to which you are otherwise entitled, will be lost or jeopardized if you choose not to participate in the study. Your consent is given voluntarily. You may refuse to participate in the entire study or in any part of the study. You have the right not to answer questions you do not wish to answer. If you decide to participate in the study, you are free to withdraw at any time without any negative effect on your relations with San Jose State University. There is no compensation offered for participation in this study.

At the time that you sign this consent form, you will receive a copy of it for your records, signed and dated by the investigator. The signature of a subject on this document indicates agreement to participate in the study. The signature of a researcher on this document indicates agreement to include the above named subject in the research and attestation that the subject has been fully informed of his or her rights.

$\overline{\text { Research Participant }} \quad$ Date

Researcher Date

$\square$ I do not want my position or department/unit associated with information I provide in this focus group. 
Focus Group Interview Guide A: For Participants that Most Reduced their Ecological Footprints.

\section{General Topics:}

Lifestyle changes throughout the year

Campus outreach period

Lifestyle after they made these changes

Environmental background

Changing relationships with family and friends

Where do you go from here?

\section{Questions:}

A. Lifestyle changes throughout the year

a. How did a typical day in your life change and what change that you made was the most important to you?

b. What did you think about the ecological footprint quiz and what made you enter the challenge?

c. What was your experience when answering the questions and seeing your results?

B. Why did people reduce their footprint and what did they learn through campus outreach? 
a. During the time between your ecological footprint quiz entries, what sparked a change in your day-to-day lifestyle?

b. What were the most important influences that made you act in a more environmentally friendly manner?

c. Were you learning new things about environmental actions? Through campus outreach? Someplace else?

d. What steps did you take to learn more about your footprint? Did you learn about what would be the most cost-effective way to reduce your footprint?

e. Tell me about the moment or process you went through in deciding to make these changes?

f. What was the most memorable experience you had throughout this process?

C. Lifestyle and plans after they made these changes

a. How do you feel about the changes you have made in your life?

b. What differences do you notice day to day?

c. Do you feel like these changes will be long lasting?

d. What are your plans for the future? How do you factor in your ecological footprint?

e. Will you continue to use the footprint quiz as a measuring device?

f. What would you say to someone else who is trying to reduce his or her footprint?

D. Environmental background 
a. How did you learn about how your actions impact the environment?

b. What was your family's lifestyle like growing up? Do you think this was a big influence in your current lifestyle? (Energy use, transportation, diet, recycling).

c. What is your department or major? Do you think this correlates someone's lifestyle choices?

E. Changing relationships with family and friends
a. How did others view your lifestyle changes?
b. Did others support your decisions? Who?
c. How did your changes impact others around you?
d. How do you respond to the reactions of others?

F. Is there anything else you would like to add or revisit? 
Focus Group Interview Guide B: For Footprint Challenge Participants With Average, Unchanged Ecological Footprints.

\section{General Topics:}

Lifestyle before this year

Campus outreach period

Lifestyle today

Environmental background

Relationships with family and friends

Future Plans

\section{Questions:}

A. Lifestyle changes throughout the year:

a. What was your lifestyle like last year? What was a typical day like? (i.e. Where did you live? How much did you travel? What was your diet? What was your water and energy use like?)

b. What did you think about the ecological footprint quiz and what made you enter the challenge?

c. What was your experience when answering the questions and seeing your results? Did you understand what they meant?

B. Why did people's footprints remain the same and what did they learn through campus outreach? 
a. During the time between your ecological footprint quiz entries, did anything change in your life?

b. Did you attend campus outreach efforts? Or attend a sustainability related class.

c. What steps did you take to learn more about your footprint?

d. What was the most memorable experience about the ecological footprint challenge?

C. Lifestyle today

a. How do you feel about your current lifestyle?

b. How did you feel after entering your results for the second time and seeing your footprint?

c. Do you see your lifestyle as sustainable or environmentally friendly?

D. Environmental background

a. How did you learn about how your actions impact the environment?

b. What was your family's lifestyle like growing up? Do you think this was a big influence in your current lifestyle? (Energy use, transportation, diet, recycling).

c. What is your department or major? Do you think this correlates with someone's lifestyle choices?

E. Relationships with family and friends

a. Did other people you know also participate in the footprint challenge?

b. Do your friends recycle or take steps to conserve energy or water? 
F. What are your plans for the future?

a. Would you like to make changes to your lifestyle? If so what would they be?

b. How do you factor in your ecological footprint into your future plans?

c. Will you continue to use the footprint quiz as a measuring device?

d. What would you say to someone that is looking to reduce their ecological footprint?

G. Is there anything else you would like to add or revisit? 


\begin{tabular}{|c|c|}
\hline \multicolumn{2}{|l|}{ Carbon Footprint Category } \\
\hline \multicolumn{2}{|l|}{ Miles Travelled By... } \\
\hline Auto & 6365 miles \\
\hline Bus & 513 miles \\
\hline Rail & 548 miles \\
\hline Air & 2446 miles \\
\hline \multicolumn{2}{|l|}{ Car Type Owned } \\
\hline Hybrid & $3.6 \%$ \\
\hline Small or compact car & $20.1 \%$ \\
\hline Mid sized car & $65.5 \%$ \\
\hline Large car (including vans and minivans) & $3.3 \%$ \\
\hline Pickup truck or sport utility vehicle & $7.5 \%$ \\
\hline Car Share & $45.1 \%$ \\
\hline \multicolumn{2}{|l|}{ Energy Saving Features } \\
\hline Compact fluorescent bulbs & $93.4 \%$ \\
\hline Energy efficient appliances & $52.5 \%$ \\
\hline Extra insulation & $20.1 \%$ \\
\hline Insulating blinds & $14.0 \%$ \\
\hline Solar panels & $3.0 \%$ \\
\hline Storm doors and windows & $11.9 \%$ \\
\hline Water saving fixtures & $29.5 \%$ \\
\hline \multicolumn{2}{|l|}{ Energy Saving Habits } \\
\hline Turn off lights when leaving rooms & $98.3 \%$ \\
\hline Use power strips to turn off stand-by & $27.6 \%$ \\
\hline Turn off computers and monitors when & $70.3 \%$ \\
\hline Dry clothes outside whenever possible & $25.6 \%$ \\
\hline Keep thermostat relatively low in winter & $62.7 \%$ \\
\hline Unplug small appliances when not in use & $50.8 \%$ \\
\hline Minimal use of power equipment when & $41.5 \%$ \\
\hline \multicolumn{2}{|l|}{ Residence Is Located in... } \\
\hline The inner city & $37.0 \%$ \\
\hline The older suburb & $48.2 \%$ \\
\hline The newer suburb & $11.3 \%$ \\
\hline A rural area & $3.5 \%$ \\
\hline \multicolumn{2}{|l|}{ Carbon Offsets } \\
\hline Purchased Carbon Offsets & $1.5 \%$ \\
\hline \multicolumn{2}{|l|}{ Food Footprint Category } \\
\hline Diet Type & \\
\hline Vegan & $1.0 \%$ \\
\hline
\end{tabular}


Vegetarian $\quad 8.9 \%$

Omnivore $\quad 76.7 \%$

Carnivore $\quad 8.1 \%$

Top of the food chain $\quad 5.3 \%$

Shop at...

Farmers markets, gardens, co-ops, etc $\quad 4.7 \%$

Natural foods markets $\quad 5.9 \%$

Supermarkets for some items, natural $\quad 51.5 \%$

Supermarkets, convenience stores, and $\quad 34.1 \%$

Restaurants, fast foods, and take out $\quad 3.8 \%$

Eat certified organic...

Most of the time $\quad 19.3 \%$

Sometimes $\quad 60.3 \%$

Almost never 20.4\%

Meal eaten per day...

One large meal and 2 light snacks $\quad 27.4 \%$

Two large meals and 2-3 light/medium $\quad 67.3 \%$

Three large meals and several hefty sized $\quad 5.3 \%$

Vegetable Gardens

Have a garden $\quad 27.4 \%$

Garden size $\quad 87 \mathrm{sq} \mathrm{ft}$

\begin{tabular}{lc}
\hline Housing Footprint Category & Original \\
\hline House Type & \\
An estate, ranch or farm & $0.8 \%$ \\
A free standing single family house & $27.8 \%$ \\
A house or building with 4 or fewer units & $33.4 \%$ \\
A small apartment building or dorm $(5-$ & $19.1 \%$ \\
A large apartment building or dorm $(20+$ & $18.8 \%$ \\
Green Design & \\
Yes & $4.9 \%$ \\
No & $34.6 \%$ \\
Not sure & $60.4 \%$
\end{tabular}

Household Furnishings Made From

Almost none $\quad 15.9 \%$

A few $25.9 \%$

A fair amount $\quad 31.1 \%$

Almost all 27.1\%

Water Saving Features

Low flow toilets $\quad 79.4 \%$

Low flow shower heads and faucets $\quad 79.2 \%$

Instant water heaters on sinks $\quad 6.7 \%$

Rainwater catchment system $\quad 4.2 \%$ 
Grey water recycling system $\quad 1.8 \%$

Drought tolerant landscape $\quad 16.6 \%$

Water Saving Habits

Compost rather than garbage disposal $\quad 19.5 \%$

Minimize shower time and toilet flushing $\quad 56.8 \%$

Run clothes and dish washers only when $\quad 74.0 \%$

Wash cars rarely $\quad 76.9 \%$

Look for and fix leaks regularly $\quad 42.6 \%$

Avoid hosing down decks, walkways, $\quad 59.1 \%$

Non-toxic Cleaning Materials

Almost never $\quad 12.1 \%$

Sometimes $\quad 59.6 \%$

Most of the time $\quad 28.3 \%$

Spending Habits Are...

Spend all of income and then some $\quad 6.9 \%$

Live within means $\quad 60.6 \%$

Frugal spender and save money $\quad 32.5 \%$

Goods and Services Footprint Category

Replacing things...

I tend to use things until I genuinely need $\quad 56.0 \%$

Some items I use for years, others I $\quad 41.9 \%$

Often replace belongings in good 2.1\%

Garbage Bins Filled Per Week

Less than one $\quad 49.7 \%$

One or two $\quad 46.0 \%$

More than two $\quad 4.3 \%$

Recycle Paper

Almost all $\quad 61.0 \%$

A fair amount $\quad 31.4 \%$

None $\quad 7.6 \%$

Recycle Aluminum
Almost all

A fair amount $\quad 24.3 \%$

None $\quad 6.0 \%$

Recycle Glass

Almost all $\quad 69.3 \%$

A fair amount $\quad 23.6 \%$

None $\quad 7.0 \%$

Recycle Plastics

Almost all $\quad 71.4 \%$

A fair amount $\quad 24.6 \%$

None $\quad 4.0 \%$ 
Recycle Electronics

Almost all

$33.2 \%$

A fair amount

$43.8 \%$

None

$22.9 \%$

Purchase Natural Clothing/Paper Products

Almost never

$27.4 \%$

Sometimes

$64.1 \%$

Almost always

$8.4 \%$ 


\section{APPENDIX E: Change in Ecological Footprint Quiz Answers - All 738 Participants}

\begin{tabular}{|c|c|c|c|c|}
\hline Carbon Footprint Category & Baseline & Final & Change & P-Value \\
\hline \multicolumn{5}{|l|}{ Miles Travelled By... } \\
\hline Auto & & $6811 \mathrm{mi}$ & $-16 \%$ & 0.000 \\
\hline Bus & & $2193 \mathrm{mi}$ & $170 \%$ & 0.017 \\
\hline Rail & & $604 \mathrm{mi}$ & $-15 \%$ & 0.758 \\
\hline Air & & $2480 \mathrm{mi}$ & $-20 \%$ & 0.008 \\
\hline Car Type Owned & & - & - & 0.023 \\
\hline Hybrid & & $5.8 \%$ & $-0.4 \%$ & - \\
\hline Small or compact car & & $23.8 \%$ & $1.5 \%$ & - \\
\hline Mid sized car & & $62.6 \%$ & $1.4 \%$ & - \\
\hline Large car, van, or minivan & & $3.0 \%$ & $0.0 \%$ & - \\
\hline Pickup truck or SUV & & $4.8 \%$ & $-2.5 \%$ & - \\
\hline Car Share & & $48.6 \%$ & $4.3 \%$ & 0.006 \\
\hline Energy Saving Features & & - & - & - \\
\hline Compact fluorescent bulbs & & $96.8 \%$ & $4.0 \%$ & 0.000 \\
\hline Energy efficient appliances & & $61.7 \%$ & $3.8 \%$ & 0.035 \\
\hline Extra insulation & & $27.3 \%$ & $5.2 \%$ & 0.001 \\
\hline Insulating blinds & & $19.5 \%$ & $4.7 \%$ & 0.001 \\
\hline Solar panels & & $4.3 \%$ & $1.6 \%$ & 0.011 \\
\hline Storm doors and windows & & $14.7 \%$ & $2.5 \%$ & 0.063 \\
\hline Water saving fixtures & & $46.4 \%$ & $12.4 \%$ & 0.000 \\
\hline Energy Saving Habits & & - & - & - \\
\hline Turn off lights when leaving rooms & & $99.6 \%$ & $0.5 \%$ & 0.102 \\
\hline Use power strips to turn off & & $41.8 \%$ & $9.6 \%$ & 0.001 \\
\hline Turn off computers and monitors & & $80.9 \%$ & $5.9 \%$ & 0.000 \\
\hline Dry clothes outside & & $33.5 \%$ & $5.9 \%$ & 0.000 \\
\hline Keep thermostat relatively low in & & $76.0 \%$ & $3.8 \%$ & 0.029 \\
\hline Unplug small appliances & & $64.6 \%$ & $11.7 \%$ & 0.000 \\
\hline Minimize power landscaping & & $57.7 \%$ & $8.2 \%$ & 0.000 \\
\hline Residence Is Located in... & & - & - & 0.183 \\
\hline The inner city & & $32.1 \%$ & $-4.5 \%$ & - \\
\hline The older suburb & & $55.5 \%$ & $5.5 \%$ & - \\
\hline The newer suburb & & $8.4 \%$ & $-1.0 \%$ & - \\
\hline A rural area & & $4.0 \%$ & $0.0 \%$ & - \\
\hline Carbon Offsets & & - & - & - \\
\hline Purchased Carbon Offsets & & $3.4 \%$ & $2.1 \%$ & 0.001 \\
\hline Food Footprint Category & Baseline & Final & Change & P-Value \\
\hline Diet Type & & - & - & 0.000 \\
\hline Vegan & & $2.6 \%$ & $0.8 \%$ & - \\
\hline Vegetarian & & $12.5 \%$ & $2.1 \%$ & - \\
\hline
\end{tabular}


Omnivore

Carnivore

Top of the food chain

Shop at...

Farmers markets, gardens, co-ops,

Natural foods markets

Supermarkets/natural food markets

Supermarkets and restaurants

Restaurants and fast foods

Eat certified organic...

Most of the time

Sometimes

Almost never

Meal eaten per day...

One large meal plus light snacks

Two large meals plus snacks

Three large meals plus snacks

Vegetable Gardens

Have a garden

Garden size $\begin{array}{ccc}79.5 \% & 5.4 \% & - \\ 3.2 \% & -5.2 \% & - \\ 2.2 \% & -3.0 \% & - \\ - & - & 0.000\end{array}$

$8.4 \% \quad 2.3 \%$

$10.3 \% \quad 3.4 \%$

$62.5 \% \quad 11.7 \%$

$17.3 \%-16.9 \%$

$1.5 \% \quad-0.5 \%$

0.000

$28.4 \% \quad 5.6 \%$

$64.8 \% \quad 6.6 \%$

$6.7 \% \quad-12.2 \%$

$-$

$33.0 \%$

$2.7 \%$

$65.5 \% \quad 0.3 \%$

$1.5 \% \quad-3.0 \%$

$-$

$35.6 \%$

$4.0 \%$

$-22 \%$

111.1

Change

Baseline

Final

-

$1.0 \%$

$1.0 \%$

Chen

$31.2 \%$

$-0.7 \%$

$-1.1 \%$

$18.4 \%$

$2.3 \%$

$18.5 \%$

$-0.7 \%$

$0.3 \%$

$-$

\section{$8.2 \%$}

$26.4 \%$

$65.4 \%$

-

.

$9.9 \%$

$20.5 \%$

$38.5 \%$

$31.2 \%$

$83.8 \%$

$84.6 \%$

$2.9 \%$

$-13.0 \%$

$10.2 \%$

$6.7 \%$

$-$

$-5.9 \%$

$-7.1 \%$

$11.4 \%$

$1.6 \%$

$4.4 \%$

$3.3 \%$

$7.8 \%$

$7.1 \%$

$2.1 \%$

$0.0 \%$

$1.2 \%$
0.002

0.002

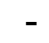

$-$

-

$-$

NA

P-Value

0.404

-

-

-

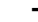

-

0.000
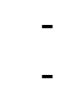

-

0.000
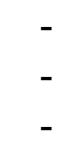

-

0.000

0.000

0.014

0.879

0.039 
Drought tolerant landscape

Water Saving Habits

Compost rather than garbage

Minimize shower time and flushing

Run clothes/dish washers when full

Wash cars rarely

Look for and fix leaks regularly

Avoid hosing down driveway, etc.

Non-toxic Cleaning Materials

Almost never

Sometimes

Most of the time

Spending Habits Are...

Spend all of income and then some

Live within means

Frugal spender and save money

Goods and Services Footprint Category

Replacing things...

Use until I genuinely need to replace

Some before I need to others not

Replace belongings often

Garbage Bins Filled Per Week

Less than one

One or two

More than two

Recycle Paper

Almost all

A fair amount

None

Recycle Aluminum

Almost all

A fair amount

None

Recycle Glass

Almost all

A fair amount

None

Recycle Plastics

Almost all

A fair amount

None

Recycle Electronics
$25.8 \% \quad 4.4 \% \quad 0.007$

$27.3 \% \quad 3.0 \% \quad 0.036$

$69.5 \% \quad 10.4 \% \quad 0.000$

$85.0 \% \quad 3.0 \% \quad 0.044$

$86.4 \% \quad 4.4 \% \quad 0.004$

$60.6 \% \quad 11.4 \% \quad 0$

$75.0 \% \quad 8.1 \% \quad 0$

$\begin{array}{lll}- & - & 0.019\end{array}$

$4.8 \% \quad-6.2 \% \quad-$

$54.8 \% \quad-0.5 \%$

$40.4 \% \quad 6.7 \%$

$\begin{array}{lll}- & - & 0\end{array}$

$3.4 \% \quad-2.9 \%=$

$51.9 \% \quad-3.3 \% \quad-$

$44.6 \% \quad 6.2 \%$

Final Change P-Value

$\begin{array}{lll}- & - & 0.074\end{array}$

$67.2 \% \quad 2.6 \%$

$32.3 \%-1.8 \%$

$0.5 \% \quad-0.8 \%$

$\begin{array}{lll}- & - & 0.071\end{array}$

$62.2 \% \quad 1.0 \%$

$37.1 \% \quad 1.2 \%$

$0.7 \% \quad-2.2 \% \quad-$

0.078

$73.9 \% \quad 2.2 \%$

$23.8 \% \quad 0.5 \%$

$2.3 \% \quad-2.7 \%$

$\begin{array}{ll}- & 0.004\end{array}$

$78.3 \% \quad-0.4 \% \quad-$

$19.4 \% \quad 3.0 \%$

$2.3 \% \quad-2.6 \%$

$\begin{array}{lll}- & - & 0.655\end{array}$

$79.5 \% \quad 1.6 \%$

$17.0 \% \quad-0.4 \%$

$3.4 \% \quad-1.2 \%$

$\begin{array}{lll}- & - & 0.387\end{array}$

$78.3 \% \quad 0.8 \%$

$20.1 \% \quad 0.3 \%$

$1.6 \% \quad-1.1 \%$

0.000 
Almost all

A fair amount

None

Use Natural Clothing/Paper Products

Almost never

$47.8 \% \quad 7.8 \% \quad-$

$41.9 \% \quad 1.6 \% \quad-$

$10.3 \% \quad-9.5 \% \quad-$

Sometimes

$14.8 \% \quad-12.2 \%$

0.000

Almost always

$72.1 \% \quad 9.6 \%$

$13.0 \% \quad 2.6 \%$

Note: For multiple-choice questions each answer was ranked and $p$-values comparing the 2009 to 2010 results were calculated for each question overall. 


\section{APPENDIX F: Change in Ecological Footprint Quiz Answers - Students}

\begin{tabular}{|c|c|c|c|c|}
\hline Carbon Footprint Category & Baseline & Final & Change & P-Value \\
\hline \multicolumn{5}{|l|}{ Miles Travelled By... } \\
\hline Auto & & $6208 \mathrm{mi}$ & $-19.4 \%$ & 0 \\
\hline Bus & & $2663 \mathrm{mi}$ & $215.1 \%$ & 0.008 \\
\hline Rail & & $562 \mathrm{mi}$ & $-21.5 \%$ & 0.202 \\
\hline Air & & $2061 \mathrm{mi}$ & $-18.6 \%$ & 0.087 \\
\hline Car Type Owned & & & & 0.100 \\
\hline Hybrid & & $3.9 \%$ & $-0.5 \%$ & \\
\hline Small or compact car & & $25.8 \%$ & $1.4 \%$ & \\
\hline Mid sized car & & $63.5 \%$ & $0.9 \%$ & \\
\hline Large car, van, or minivan & & $2.7 \%$ & $0.4 \%$ & \\
\hline Pickup truck or SUV & & $4.1 \%$ & $-2.1 \%$ & \\
\hline Car Share & & $51.6 \%$ & $3.2 \%$ & 0.131 \\
\hline \multicolumn{5}{|l|}{ Energy Saving Features } \\
\hline Compact fluorescent bulbs & & $97.0 \%$ & $4.1 \%$ & 0.000 \\
\hline Energy efficient appliances & & $57.1 \%$ & $5.0 \%$ & 0.025 \\
\hline Extra insulation & & $23.0 \%$ & $6.0 \%$ & 0.001 \\
\hline Insulating blinds & & $15.1 \%$ & $3.7 \%$ & 0.024 \\
\hline Solar panels & & $4.8 \%$ & $1.8 \%$ & 0.025 \\
\hline Storm doors and windows & & $11.7 \%$ & $3.0 \%$ & 0.032 \\
\hline Water saving fixtures & & $40.4 \%$ & $12.8 \%$ & 0.000 \\
\hline \multicolumn{5}{|l|}{ Energy Saving Habits } \\
\hline Turn off lights when leaving rooms & & $99.8 \%$ & $0.7 \%$ & 0.046 \\
\hline Use power strips to turn off & & $43.1 \%$ & $10.5 \%$ & 0.006 \\
\hline Turn off computers and monitors & & $81.9 \%$ & $5.5 \%$ & 0.000 \\
\hline Dry clothes outside & & $32.6 \%$ & $6.0 \%$ & 0.000 \\
\hline Keep thermostat relatively low in & & $72.8 \%$ & $3.2 \%$ & 0.120 \\
\hline Unplug small appliances & & $65.1 \%$ & $11.0 \%$ & 0.000 \\
\hline Minimize power landscaping & & $53.2 \%$ & $7.5 \%$ & 0.001 \\
\hline Residence Is Located in... & & & & 0.181 \\
\hline The inner city & & $35.4 \%$ & $-4.8 \%$ & \\
\hline The older suburb & & $52.7 \%$ & $5.7 \%$ & \\
\hline The newer suburb & & $8.5 \%$ & $-1.1 \%$ & \\
\hline A rural area & & $3.4 \%$ & $0.2 \%$ & \\
\hline Carbon Offsets & & & & 0.035 \\
\hline Purchased Carbon Offsets & & $2.3 \%$ & $1.2 \%$ & \\
\hline Food Footprint Category & Baseline & Final & Change & P-Value \\
\hline Diet Type & & & & 0.000 \\
\hline Vegan & & $3.0 \%$ & $1.2 \%$ & \\
\hline Vegetarian & & $12.8 \%$ & $2.0 \%$ & \\
\hline
\end{tabular}


Omnivore

Carnivore

Top of the food chain

Shop at...

Farmers markets, gardens, co-ops,

Natural foods markets

Supermarkets/natural food markets

Supermarkets and restaurants

Restaurants and fast foods

Eat certified organic...

Most of the time

Sometimes

Almost never

Meal eaten per day...

One large meal plus light snacks

Two large meals plus snacks

Three large meals plus snacks

Vegetable Gardens

Have a garden

Garden size

\begin{tabular}{l}
\hline Housing Footprint Category \\
\hline House Type \\
Estate, ranch or farm \\
Free standing single family house \\
House or building with $<4$ units \\
Apartment/dorm $(5-20$ units $)$ \\
Apartment/dorm building $(20+$ \\
Green Design \\
Yes \\
No \\
Not sure \\
Furnishings made of recycled \\
Almost none \\
A few \\
A fair amount \\
Almost all \\
Water Saving Features \\
Low flow toilets \\
Low flow shower heads and faucets \\
Instant water heaters on sinks \\
Rainwater catchment system \\
Grey water recycling system
\end{tabular}

$78.3 \% \quad 4.1 \%$

$3.6 \% \quad-4.6 \%$

$2.3 \% \quad-2.7 \%$

0.000

$\begin{array}{cc}7.8 \% & 2.1 \% \\ 10.3 \% & 4.4 \% \\ 61.0 \% & 12.8 \% \\ 19.2 \% & -18.7 \% \\ 1.6 \% & -0.7 \%\end{array}$

0.000

$27.4 \% \quad 6.2 \%$

$66.0 \% \quad 7.1 \%$

$6.6 \% \quad-13.3 \%$

0.002

$32.7 \% \quad 3.4 \%$

$65.8 \% \quad-0.2 \%$

$1.4 \% \quad-3.2 \%$

$31.9 \% \quad 3.9 \% \quad 0.008$ $120.9 \mathrm{sq} \quad-23.0 \%$

Baseline Final Change P-Value

0.749

$\begin{array}{cc}0.9 \% & -0.7 \% \\ 24.2 \% & -0.4 \% \\ 32.9 \% & 1.8 \% \\ 20.8 \% & -1.2 \% \\ 21.2 \% & 0.5 \%\end{array}$

$7.7 \% \quad 3.2 \%$

$23.5 \% \quad-12.1 \%$

$68.9 \% \quad 8.9 \%$

0.000

$8.7 \% \quad-4.8 \%$

$18.1 \% \quad-8.0 \%$

$37.5 \% \quad 11.0 \%$

$35.6 \% \quad 1.8 \%$

$81.5 \% \quad 7.1 \% \quad 0.000$

$84.7 \% \quad 7.3 \% \quad 0.000$

$7.1 \% \quad 2.5 \% \quad 0.016$

$4.3 \% \quad 0.5 \% \quad 0.602$

$2.8 \% \quad 0.9 \% \quad 0.166$ 
Drought tolerant landscape

Water Saving Habits

Compost rather than garbage

Minimize shower time and flushing

Run clothes/dish washers when full

Wash cars rarely

Look for and fix leaks regularly

Avoid hosing down driveway, etc.

Non-toxic Cleaning Materials

Almost never

Sometimes

Most of the time

Spending Habits Are...

Spend all of income and then some

Live within means

Frugal spender and save money

Goods and Services Footprint Category

Replacing things...

Use until I genuinely need to replace

Some before I need to others not

Replace belongings often

Garbage Bins Filled Per Week

Less than one

One or two

More than two

Recycle Paper

Almost all

A fair amount

None

Recycle Aluminum

Almost all

A fair amount

None

Recycle Glass

Almost all

A fair amount

None

Recycle Plastics

Almost all

A fair amount

None

Recycle Electronics
$20.3 \% \quad 3.6 \% \quad 0.037$

$25.4 \% \quad 3.2 \% \quad 0.063$

$67.3 \% \quad 10.0 \% \quad 0.000$

$82.4 \% \quad 3.4 \% \quad 0.076$

$84.9 \% \quad 4.6 \% \quad 0.011$

$55.7 \% \quad 11.4 \% \quad 0.000$

$72.1 \% \quad 8.5 \% \quad 0.000$

0.013

$4.3 \% \quad-6.8 \%$

$55.9 \% \quad 0.2 \%$

$39.9 \% \quad 6.6 \%$

0.000

$3.6 \% \quad-3.0 \%$

$52.1 \% \quad-3.4 \%$

$42.9 \% \quad 5.0 \%$

Baseline

Final

Change

P-Value

$65.5 \% \quad 2.8 \%$

$34.0 \% \quad-2.0 \%$

$0.5 \% \quad-0.9 \%$

0.082

$59.8 \% \quad 1.2 \%$

$39.5 \% \quad 1.4 \%$

$0.7 \% \quad-2.7 \%$

0.170

$70.3 \% \quad 2.3 \%$

$26.9 \% \quad 0.5 \%$

$2.8 \% \quad-2.8 \%$

0.020

$75.6 \% \quad-0.2 \%$

$21.4 \% \quad 2.8 \%$

$3.0 \% \quad-2.7 \%$

0.435

$75.6 \% \quad 1.1 \%$

$20.3 \% \quad 0.4 \%$

$4.1 \% \quad-1.4 \%$

0.472

$75.8 \% \quad 0.2 \%$

$22.1 \% \quad 0.7 \%$

$2.1 \% \quad-0.9 \%$

0.000 
Almost all

A fair amount

None

Use Natural Clothing/Paper Products

Almost never

Sometimes

Almost always
$42.9 \% \quad 9.3 \%$

$45.2 \% \quad 2.0 \%$

$11.9 \% \quad-11.2 \%$

$14.8 \% \quad-13.2 \%$

$73.3 \% \quad 10.0 \%$

$11.9 \% \quad 3.2 \%$
0.000 


\section{APPENDIX G: Change in Ecological Footprint Quiz Answers - Faculty}

\begin{tabular}{|c|c|c|c|c|}
\hline Carbon Footprint Category & Baseline & Final & Change & P-Value \\
\hline \multicolumn{5}{|l|}{ Miles Travelled By... } \\
\hline Auto & & $8559 \mathrm{mi}$ & $-7.0 \%$ & 0.055 \\
\hline Bus & & $128 \mathrm{mi}$ & $20.0 \%$ & 0.702 \\
\hline Rail & & $1188 \mathrm{mi}$ & $1.6 \%$ & 0.438 \\
\hline Air & & $5544 \mathrm{mi}$ & $-16.6 \%$ & 0.158 \\
\hline Car Type Owned & & & & 0.156 \\
\hline Hybrid & & $21.2 \%$ & $0.0 \%$ & \\
\hline Small or compact car & & $13.5 \%$ & $-1.9 \%$ & \\
\hline Mid sized car & & $59.6 \%$ & $9.6 \%$ & \\
\hline Large car, van, or minivan & & $3.8 \%$ & $0.0 \%$ & \\
\hline Pickup truck or SUV & & $1.9 \%$ & $-7.7 \%$ & \\
\hline Car Share & & $46.2 \%$ & $11.5 \%$ & 0.008 \\
\hline \multicolumn{5}{|l|}{ Energy Saving Features } \\
\hline Compact fluorescent bulbs & & $100.0 \%$ & $1.9 \%$ & 0.317 \\
\hline Energy efficient appliances & & $84.6 \%$ & $-1.9 \%$ & 1.000 \\
\hline Extra insulation & & $51.9 \%$ & $-3.8 \%$ & 0.564 \\
\hline Insulating blinds & & $40.4 \%$ & $11.5 \%$ & 0.052 \\
\hline Solar panels & & $3.8 \%$ & $0.0 \%$ & 1.000 \\
\hline Storm doors and windows & & $25.0 \%$ & $7.7 \%$ & 0.102 \\
\hline Water saving fixtures & & $76.9 \%$ & $7.7 \%$ & 0.405 \\
\hline \multicolumn{5}{|l|}{ Energy Saving Habits } \\
\hline Turn off lights when leaving rooms & & $98.1 \%$ & $-1.9 \%$ & 0.317 \\
\hline Use power strips to turn off & & $44.2 \%$ & $9.6 \%$ & 0.739 \\
\hline Turn off computers and monitors & & $71.2 \%$ & $3.8 \%$ & 0.346 \\
\hline Dry clothes outside & & $46.2 \%$ & $3.8 \%$ & 0.102 \\
\hline Keep thermostat relatively low in & & $84.6 \%$ & $1.9 \%$ & 0.739 \\
\hline Unplug small appliances & & $63.5 \%$ & $17.3 \%$ & 0.059 \\
\hline Minimize power landscaping & & $88.5 \%$ & $15.4 \%$ & 0.046 \\
\hline Residence Is Located in... & & & & 0.107 \\
\hline The inner city & & $15.4 \%$ & $0.0 \%$ & \\
\hline The older suburb & & $76.9 \%$ & $5.8 \%$ & \\
\hline The newer suburb & & $1.9 \%$ & $-1.9 \%$ & \\
\hline A rural area & & $5.8 \%$ & $-3.8 \%$ & \\
\hline \multicolumn{5}{|l|}{ Carbon Offsets } \\
\hline Purchased Carbon Offsets & & $15.4 \%$ & $7.7 \%$ & 0.102 \\
\hline Food Footprint Category & Baseline & Final & Change & P-Value \\
\hline Diet Type & & & & 0.033 \\
\hline Vegan & & $0.0 \%$ & $0.0 \%$ & \\
\hline Vegetarian & & $23.1 \%$ & $3.8 \%$ & \\
\hline
\end{tabular}




\begin{tabular}{|c|c|c|c|c|}
\hline Omnivore & & $75.0 \%$ & $5.8 \%$ & \\
\hline Carnivore & & $1.9 \%$ & $-5.8 \%$ & \\
\hline Top of the food chain & & $0.0 \%$ & $-3.8 \%$ & \\
\hline Shop at... & & & & 0.186 \\
\hline Farmers markets, gardens, co-ops, & & $13.5 \%$ & $1.9 \%$ & \\
\hline Natural foods markets & & $13.5 \%$ & $-3.8 \%$ & \\
\hline Supermarkets/natural food markets & & $67.3 \%$ & $7.7 \%$ & \\
\hline Supermarkets and restaurants & & $5.8 \%$ & $-5.8 \%$ & \\
\hline Restaurants and fast foods & & $0.0 \%$ & $0.0 \%$ & \\
\hline Eat certified organic... & & & & 0.021 \\
\hline Most of the time & & $50.0 \%$ & $5.8 \%$ & \\
\hline Sometimes & & $44.2 \%$ & $-3.8 \%$ & \\
\hline Almost never & & $1.9 \%$ & $-5.8 \%$ & \\
\hline Meal eaten per day... & & & & 0.439 \\
\hline One large meal plus light snacks & & $46.2 \%$ & $3.8 \%$ & \\
\hline Two large meals plus snacks & & $53.8 \%$ & $-1.9 \%$ & \\
\hline Three large meals plus snacks & & $0.0 \%$ & $-1.9 \%$ & \\
\hline \multicolumn{5}{|l|}{ Vegetable Gardens } \\
\hline Have a garden & & $69.2 \%$ & $13.5 \%$ & 0.005 \\
\hline Garden size & & $1721 \mathrm{sq}$ & $32.0 \%$ & NA \\
\hline Housing Footprint Category & Baseline & Final & Change & P-Value \\
\hline House Type & & & & 0.029 \\
\hline Estate, ranch or farm & & $0.0 \%$ & $-1.9 \%$ & \\
\hline Free standing single family house & & $65.4 \%$ & $-7.7 \%$ & \\
\hline House or building with $<4$ units & & $19.2 \%$ & $5.8 \%$ & \\
\hline Apartment/dorm (5-20 units) & & $9.6 \%$ & $3.8 \%$ & \\
\hline Apartment/dorm building ( $20+$ units) & & $5.8 \%$ & $0.0 \%$ & \\
\hline Green Design & & & & 0.042 \\
\hline Yes & & $17.3 \%$ & $1.9 \%$ & \\
\hline No & & $44.2 \%$ & $-19.2 \%$ & \\
\hline Not sure & & $38.5 \%$ & $17.3 \%$ & \\
\hline Furnishings made of recycled & & & & 0.004 \\
\hline Almost none & & $15.4 \%$ & $-9.6 \%$ & \\
\hline A few & & $26.9 \%$ & $-3.8 \%$ & \\
\hline A fair amount & & $40.4 \%$ & $13.5 \%$ & \\
\hline Almost all & & $17.3 \%$ & $0.0 \%$ & \\
\hline \multicolumn{5}{|l|}{ Water Saving Features } \\
\hline Low flow toilets & & $96.2 \%$ & $7.7 \%$ & 0.025 \\
\hline Low flow shower heads and faucets & & $84.6 \%$ & $-1.9 \%$ & 1 \\
\hline Instant water heaters on sinks & & $7.7 \%$ & $-1.9 \%$ & 0.317 \\
\hline Rainwater catchment system & & $9.6 \%$ & $-1.9 \%$ & 0.317 \\
\hline Grey water recycling system & & $9.6 \%$ & $3.8 \%$ & 0.317 \\
\hline
\end{tabular}




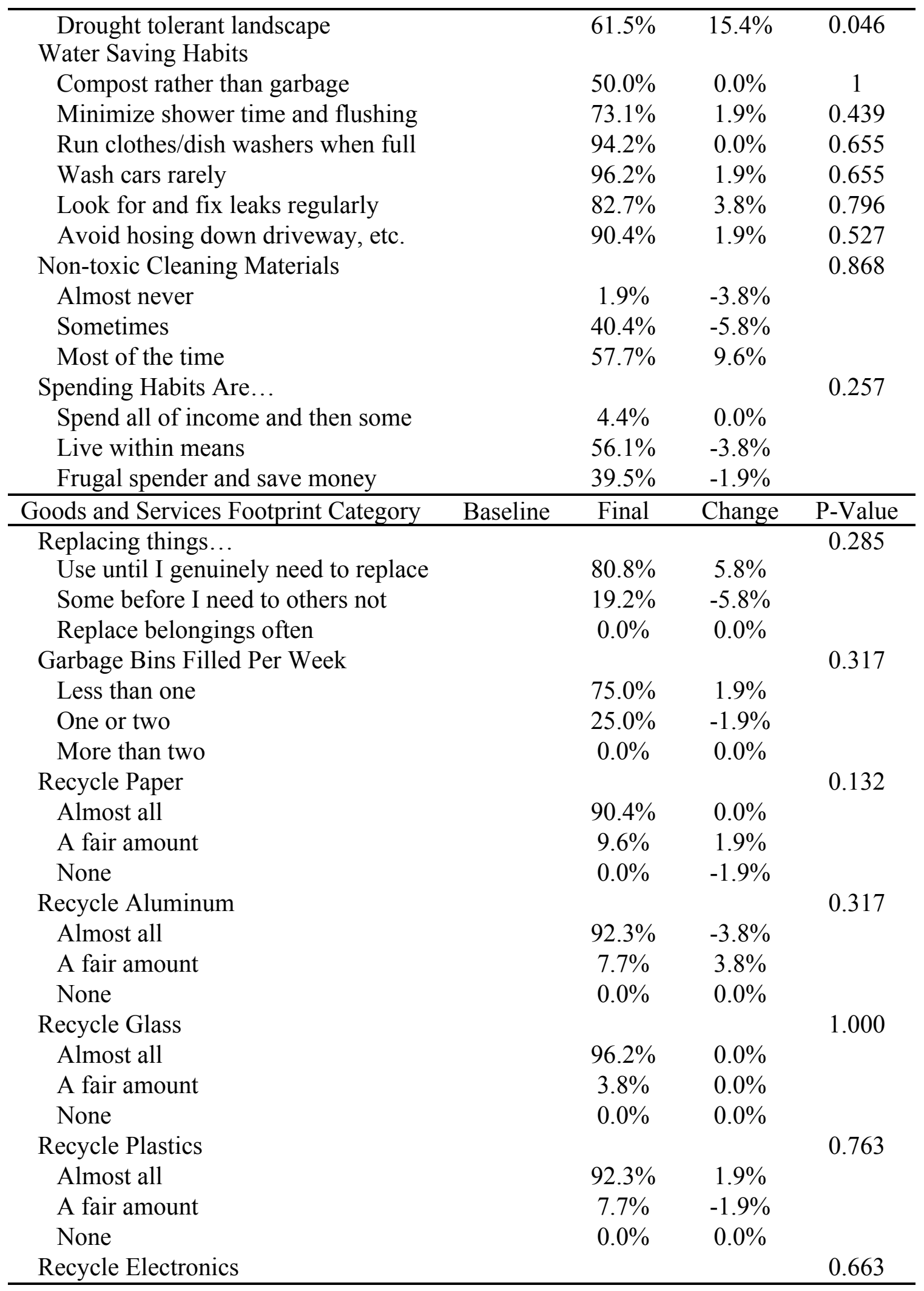




\begin{tabular}{lccc}
\hline Almost all & $73.1 \%$ & $3.8 \%$ & \\
A fair amount & $25.0 \%$ & $-1.9 \%$ & \\
None & $1.9 \%$ & $-1.9 \%$ & \\
Use Natural Clothing/Paper Products & & & 0.095 \\
Almost never & $13.5 \%$ & $-1.9 \%$ & \\
Sometimes & $55.8 \%$ & $-5.8 \%$ & \\
Almost always & $30.8 \%$ & $7.7 \%$ & \\
\hline
\end{tabular}




\section{APPENDIX H: Change in Ecological Footprint Quiz Answers - Staff}

\begin{tabular}{|c|c|c|c|c|}
\hline Carbon Footprint Category & Baseline & Final & Change & P-Value \\
\hline \multicolumn{5}{|l|}{ Miles Travelled By... } \\
\hline Auto & & $8987 \mathrm{mi}$ & $-7.7 \%$ & 0.051 \\
\hline Bus & & $821 \mathrm{mi}$ & $-14.7 \%$ & 0.607 \\
\hline Rail & & $548 \mathrm{mi}$ & $17.6 \%$ & 0.065 \\
\hline Air & & $3147 \mathrm{mi}$ & $-27.5 \%$ & 0.079 \\
\hline Car Type Owned & & & & 0.264 \\
\hline Hybrid & & $7.9 \%$ & $0.0 \%$ & \\
\hline Small or compact car & & $18.4 \%$ & $3.5 \%$ & \\
\hline Mid sized car & & $59.6 \%$ & $0.0 \%$ & \\
\hline Large car, van, or minivan & & $4.4 \%$ & $-1.8 \%$ & \\
\hline Pickup truck or SUV & & $9.6 \%$ & $-1.8 \%$ & \\
\hline Car Share & & $35.1 \%$ & $6.1 \%$ & 0.108 \\
\hline \multicolumn{5}{|l|}{ Energy Saving Features } \\
\hline Compact fluorescent bulbs & & $94.7 \%$ & $4.4 \%$ & 0.166 \\
\hline Energy efficient appliances & & $73.7 \%$ & $0.9 \%$ & 0.835 \\
\hline Extra insulation & & $37.7 \%$ & $5.3 \%$ & 0.257 \\
\hline Insulating blinds & & $31.6 \%$ & $6.1 \%$ & 0.108 \\
\hline Solar panels & & $1.8 \%$ & $1.8 \%$ & 0.157 \\
\hline Storm doors and windows & & $24.6 \%$ & $-2.6 \%$ & 0.549 \\
\hline Water saving fixtures & & $62.3 \%$ & $12.3 \%$ & 0.016 \\
\hline \multicolumn{5}{|l|}{ Energy Saving Habits } \\
\hline Turn off lights when leaving rooms & & $99.1 \%$ & $0.9 \%$ & 0.317 \\
\hline Use power strips to turn off & & $34.2 \%$ & $5.3 \%$ & 0.033 \\
\hline Turn off computers and monitors & & $80.7 \%$ & $8.8 \%$ & 0.239 \\
\hline Dry clothes outside & & $32.5 \%$ & $6.1 \%$ & 0.052 \\
\hline Keep thermostat relatively low in & & $87.7 \%$ & $7.9 \%$ & 0.05 \\
\hline Unplug small appliances & & $62.3 \%$ & $12.3 \%$ & 0.013 \\
\hline Minimize power landscaping & & $65.8 \%$ & $8.8 \%$ & 0.068 \\
\hline Residence Is Located in... & & & & 0.147 \\
\hline The inner city & & $23.7 \%$ & $-5.3 \%$ & \\
\hline The older suburb & & $59.6 \%$ & $4.4 \%$ & \\
\hline The newer suburb & & $10.5 \%$ & $0.0 \%$ & \\
\hline A rural area & & $6.1 \%$ & $0.9 \%$ & \\
\hline \multicolumn{5}{|l|}{ Carbon Offsets } \\
\hline Purchased Carbon Offsets & & $3.5 \%$ & $3.5 \%$ & 0.046 \\
\hline Food Footprint Category & Baseline & Final & Change & P-Value \\
\hline Diet Type & & & & 0.001 \\
\hline Vegan & & $1.8 \%$ & $-0.9 \%$ & \\
\hline
\end{tabular}




\begin{tabular}{|c|c|c|c|c|}
\hline Omnivore & & $87.7 \%$ & $11.4 \%$ & \\
\hline Carnivore & & $1.8 \%$ & $-7.9 \%$ & \\
\hline Top of the food chain & & $2.6 \%$ & $-4.4 \%$ & \\
\hline Shop at... & & & & 0.002 \\
\hline Farmers markets, gardens, co-ops, & & $8.8 \%$ & $3.5 \%$ & \\
\hline Natural foods markets & & $8.8 \%$ & $1.8 \%$ & \\
\hline Supermarkets/natural food markets & & $67.5 \%$ & $7.9 \%$ & \\
\hline Supermarkets and restaurants & & $13.2 \%$ & $-13.2 \%$ & \\
\hline Restaurants and fast foods & & $1.8 \%$ & $0.0 \%$ & \\
\hline Eat certified organic... & & & & 0.006 \\
\hline Most of the time & & $23.7 \%$ & $2.6 \%$ & \\
\hline Sometimes & & $64.9 \%$ & $5.3 \%$ & \\
\hline Almost never & & $9.6 \%$ & $-9.6 \%$ & \\
\hline Meal eaten per day... & & & & 0.683 \\
\hline One large meal plus light snacks & & $28.1 \%$ & $-0.9 \%$ & \\
\hline Two large meals plus snacks & & $69.3 \%$ & $3.5 \%$ & \\
\hline Three large meals plus snacks & & $2.6 \%$ & $-2.6 \%$ & \\
\hline \multicolumn{5}{|l|}{ Vegetable Gardens } \\
\hline Have a garden & & $38.6 \%$ & $0.0 \%$ & 1.000 \\
\hline Garden size & & $35.1 \mathrm{sq}$ & $34.1 \%$ & NA \\
\hline Housing Footprint Category & Baseline & Final & Change & P-Value \\
\hline House Type & & & & 0.885 \\
\hline Estate, ranch or farm & & $1.8 \%$ & $0.0 \%$ & \\
\hline Free standing single family house & & $48.2 \%$ & $-2.6 \%$ & \\
\hline House or building with $<4$ units & & $28.1 \%$ & $3.5 \%$ & \\
\hline Apartment/dorm (5-20 units) & & $10.5 \%$ & $0.0 \%$ & \\
\hline Apartment/dorm building (20+ units) & & $11.4 \%$ & $-0.9 \%$ & \\
\hline Green Design & & & & 0.008 \\
\hline Yes & & $7.0 \%$ & $1.8 \%$ & \\
\hline No & & $32.5 \%$ & $-14.9 \%$ & \\
\hline Not sure & & $60.5 \%$ & $13.2 \%$ & \\
\hline Furnishings made of recycled materials & & & & 0.002 \\
\hline Almost none & & $13.2 \%$ & $-9.6 \%$ & \\
\hline A few & & $28.9 \%$ & $-4.4 \%$ & \\
\hline A fair amount & & $42.1 \%$ & $12.3 \%$ & \\
\hline Almost all & & $15.8 \%$ & $0.0 \%$ & \\
\hline \multicolumn{5}{|l|}{ Water Saving Features } \\
\hline Low flow toilets & & $89.5 \%$ & $11.4 \%$ & 0.007 \\
\hline Low flow shower heads and faucets & & $84.2 \%$ & $10.5 \%$ & 0.014 \\
\hline Instant water heaters on sinks & & $4.4 \%$ & $1.8 \%$ & 0.157 \\
\hline Rainwater catchment system & & $2.6 \%$ & $-1.8 \%$ & 0.414 \\
\hline
\end{tabular}




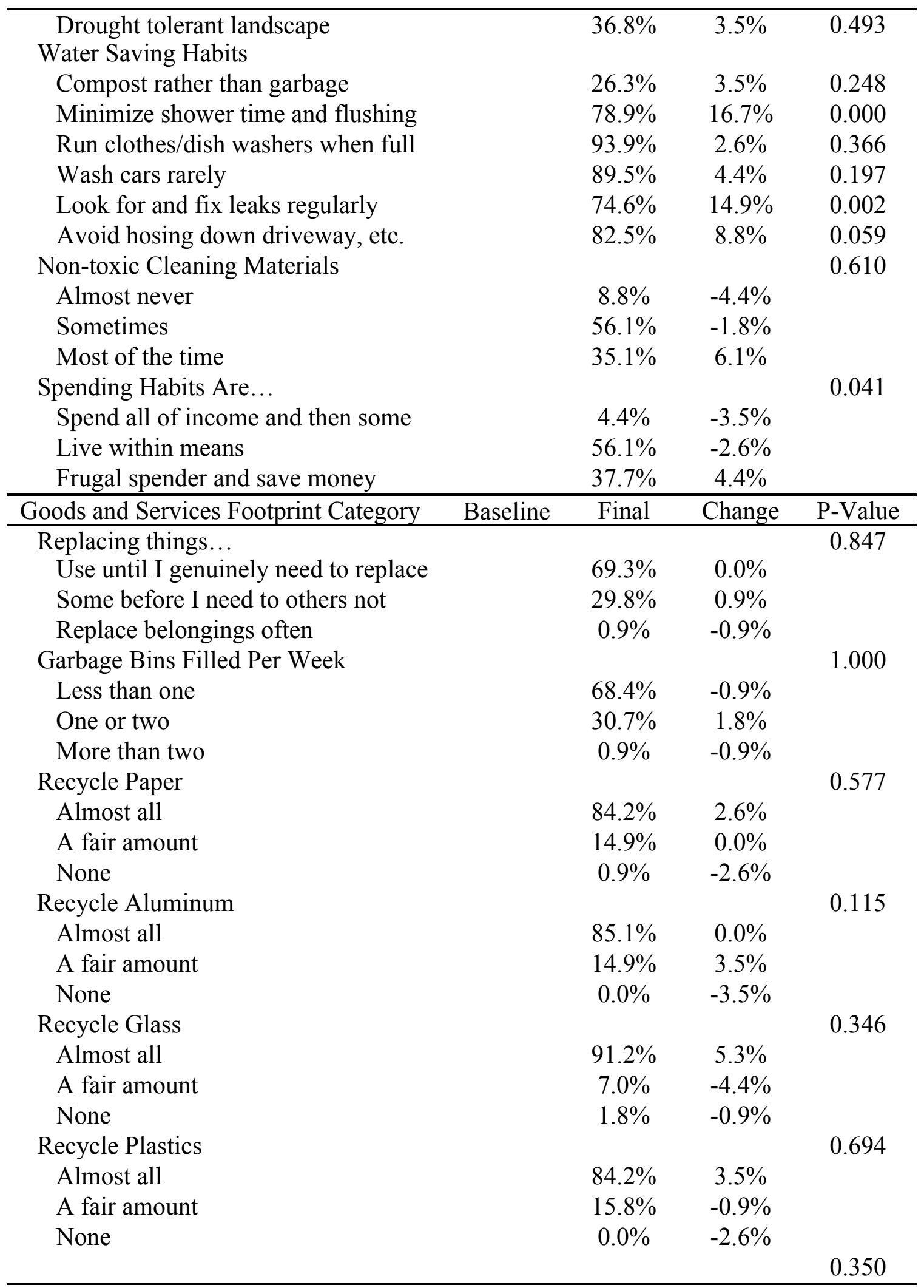




\begin{tabular}{lccc}
\hline Almost all & $60.5 \%$ & $2.6 \%$ & \\
A fair amount & $33.3 \%$ & $1.8 \%$ & \\
None & $6.1 \%$ & $-4.4 \%$ & \\
Use Natural Clothing/Paper Products & & & 0.145 \\
Almost never & $15.8 \%$ & $-12.3 \%$ & \\
Sometimes & $73.7 \%$ & $14.9 \%$ & \\
Almost always & $10.5 \%$ & $-2.6 \%$ & \\
\hline
\end{tabular}

